\title{
ANÁLISE NUMÉRICA POR ELEMENTOS FINITOS DE TENSÕES RESIDUAIS GERADAS POR MUDANÇA DE FASE EM AÇOS TRATADOS TERMICAMENTE
}

Tese de doutorado apresentada ao Departamento de Engenharia Civil da PUCRio como parte dos requisitos para obtenção do título de Doutor em Ciências de Engenharia Civil: Estruturas.

Orientadores:

Luis Eloy Vaz

Carlos Sergio da Costa Viana (IME)

Departamento de Engenharia Civil

Pontifícia Universidade Católica do Rio de Janeiro

Rio de Janeiro, fevereiro de 2002 
Para Francisco, meu filho. 


\section{AGRADECIMENTOS}

Ao professor Luiz Eloy Vaz, por ter aceito a orientação de um trabalho já em andamento, e ao professor Carlos Sérgio da Costa Viana por aceitar a co-orientação.

Aos professores Eurípedes do Amaral Vargas, Luis Fernando Martha, Nadja Vasconcellos de Avila e Mauro Antonio Rincon por comporem a banca.

A Ana Roxo, secretária do DEC.

Aos amigos Andrea Borges e Aellington Freire por, muitas vezes, terem sido orientadores informais.

Ao CNPq pela concessão de bolsa de doutorado. 


\section{RESUMO}

O objetivo deste trabalho é fazer uma modelagem numérica por elementos finitos de tensões residuais em peças de liga ferro-níquel e aço carbono submetidas a tratamentos térmicos, considerando mudanças de fase.

Com este objetivo, foram desenvolvidos códigos computacionais orientados a objetos para análise térmica não-linear acoplado à análise da micro-estrutura. Códigos implementados em POO também foram criados para análise elasto-plástica, onde a distribuição de temperatura e as frações parciais dos constituintes são dados de entrada. As propriedades termo-mecânicas do material são consideradas dependentes tanto da temperatura quanto da fração parcial de cada constituinte.

No tratamento térmico está sendo considerado a formação de martensita segundo o esquema de Koistinen \& Marburger (1959). É abordado também a formação difusional de perlita e bainita, segundo o esquema proposto por Avrami (1939).

Por fim, é apresentado um novo modelo para calcular os parâmetros cinéticos das transformações difusionais austenita-perlita e austenita-bainita. 


\begin{abstract}
The objective of this thesis is to perform a finite element analysis of residual stress in $\mathrm{Fe}-\mathrm{Ni}$ alloys and carbon steel heat-treated pieces, considering phase changes.

To achieve this goal, a object oriented computer code for the non-linear thermal analysis coupled with a code for a micro-structural analysis were developed. OPP codes were also created for an elasto-plastic analysis, with temperature distribution and constituents partial fraction as input data. The material properties are considered dependent on both the temperature and the partial fraction for all analyses.

In the thermal treatment, the martensite transformation according to Koistinen \& Marburger (1959) scheme and the diffusional formation of pearlite and bainite according to Avrami (1939) are considered.
\end{abstract}

Finally, a new model to calculate the kinetics parameters of the diffusional austenitepearlite and austenite-bainite transformations is presented. 


\section{SUMÁRIO}

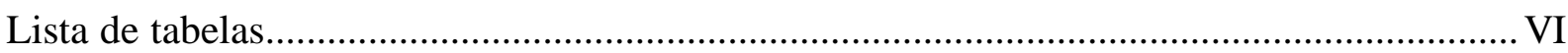

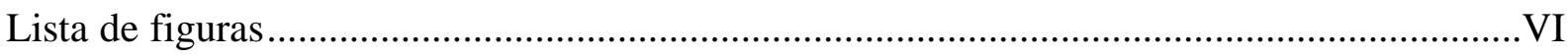

Lista de símbolos ............................................................................................................

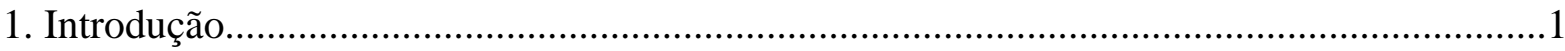

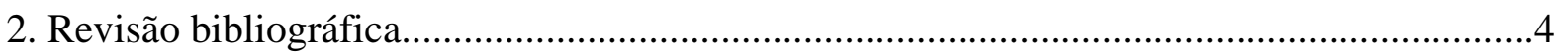

2.1. Transformações em ligas ferro-níquel...................................................... 4

2.1.1 Nucleação martensítica.........................................................................

2.1.2 A estrutura cristalina da martensita..........................................................6

2.2. Transformações em aços ao carbono.............................................................. 7

2.2.1 Transformação perlítica em aços ao carbono...............................................

2.2.2 Transformação bainítica em aços ao carbono.............................................11

2.2.3 Transformação martensítica em aços ao carbono........................................13

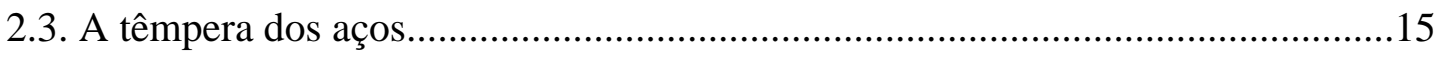

3. Resolução numérica das equações.....................................................................................17

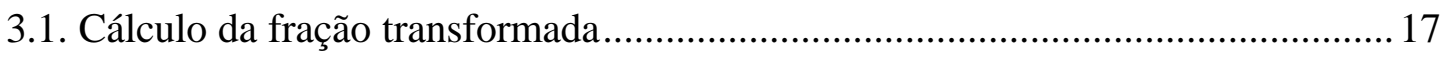

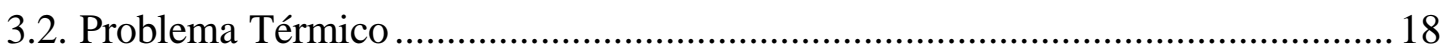

3.2.1 Equação termodinâmica.................................................................... 18

3.2.2 Formulações forte e fraca para o problema térmico....................................21

3.2.3 Formulação de Galerkin..........................................................................23

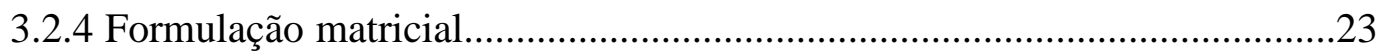

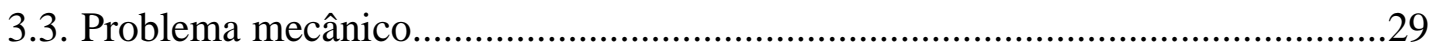


3.3.1 Plasticidade induzida por transformação 30

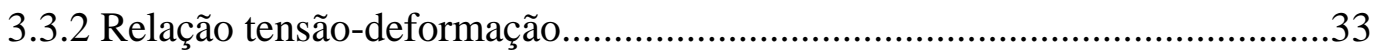

3.3.3 Implementação computacional...............................................................36

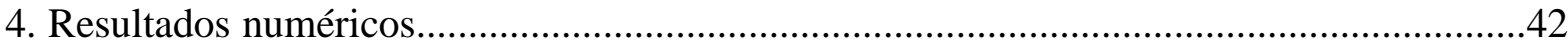

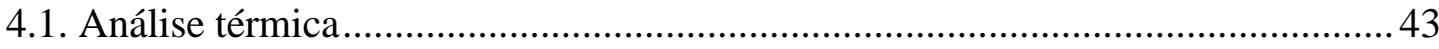

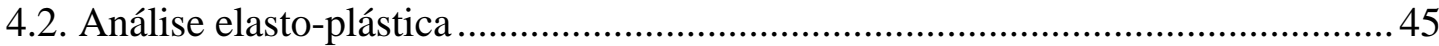

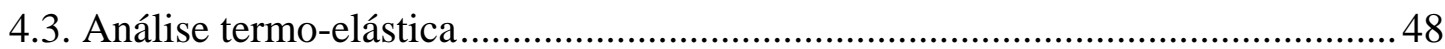

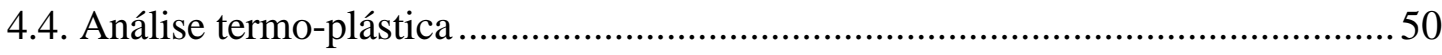

4.5. Análise térmica e de micro-estrutura..................................................................51

4.6. Análise termo-elasto-plástica com mudança de fase............................................55

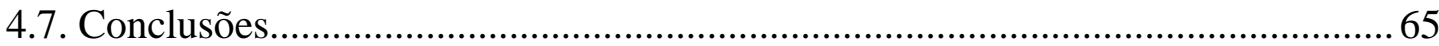

5.Cálculo das frações transformadas por processos de difusão 66

5.1. Cálculo das frações transformadas em aços ao carbono ....................................67

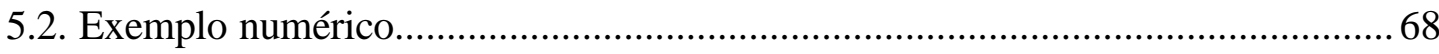

5.3. Cálculo dos parâmetros cinéticos em função da taxa de temperatura ...................71

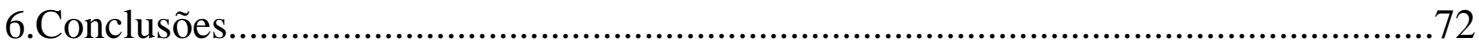

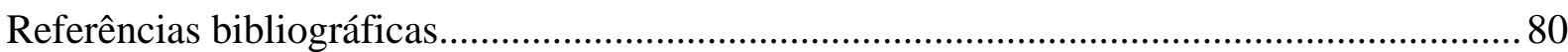




\section{Lista de tabelas}

Título

página

Tabela 1: dados do material para o exemplo 4.5.2 .54

\section{Lista de figuras}

Título

página

Figura 1.1 : diagrama das relações entre os problemas. .1

Figura 2.1: plaquetas de martensita numa liga ferro-níquel [REED-HILL,1982]. 6

Figura 2.2: (a) célula tatragonal de corpo centrado na estrutura cúbica de face centrada,

(b) tatragonal de corpo centrado e (c) cúbica de corpo centrado após distorção

de Bain, liga ferro-níquel. [REED-HILL, 1982]....

Figura 2.3: diagrama de equilíbrio de um aço ao carbono [LESLIE] .......................................

Figura 2.4: aço eutetóide parcialmente transformado em perlita [SMITH, 1993]....................9

Figura 2.5: Nucleação e crescimento de perlita [Reed-Hill,1982] .........................................10

Figura 2.6: trajetória de difusão de carbono durante o crescimento de perlita..........................11

Figura 2.7: (a) bainita superior e (b) bainita inferior [REED-HILL, 1982] ...............................11

Figura 2.8: curva de transformação isotérmica: (a) aço eutetóide,

(b) aço 4340 [CHIAVERINI,1965]... .13

Figura 2.9: (a) representação tetragonal da austenita e (b) martensita tetragonal......................14

Figura 2.10: (a) micro estrutura martensítica formada em aço com baixo (em ripa) e

(b) alto carbono (lenticular) [SMITH,1993]. .15

Figura 2.11: curva CTT de um aço eutetóide [CHIAVERINI,1965] ] ....................................16

Figura 3.1 : fluxograma para análise térmica transiente não-linear.......................................28

Figura 3.2: plasticidade induzida por transformação $\mathrm{x}$ fração parcial de martensita transformada, para diferentes tensões aplicadas. Aço $\mathrm{Fe}-0,5 \mathrm{C}-20 \mathrm{Ni}$

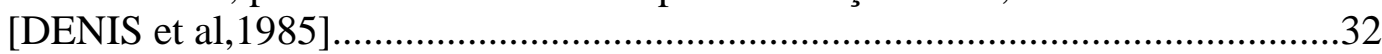

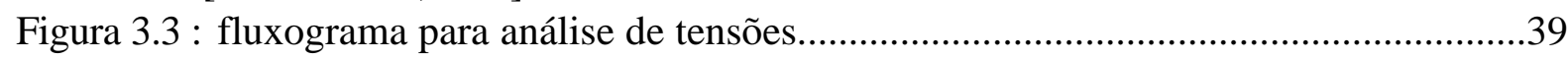

Figura 3.4 : algoritmo para análise de tensões...................................................................40

Figura 3.5 : algoritmo para cálculo do estado de tensões no ponto de Gauss............................41

Figura 4.1: malha de elementos finitos para o exemplo 4.4.1 ...............................................44

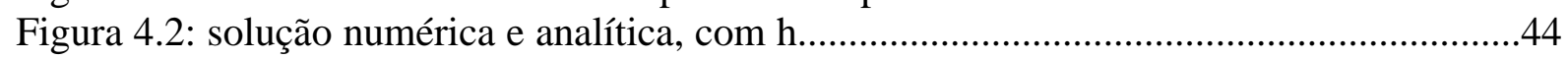

Figura 4.3: solução numérica e analítica, com $h$ finito..............................................................45

Figura 4.4: esquema representativo e malha de elementos finitos para o Exemplo 4.2.1.......46

Figura 4.5: deslocamento da face interna com o aumento da pressão para o Exemplo 1.........46

Figura 4.6: tensão $\sigma_{1}$ quando a pressão é igual a $14 \mathrm{dN} / \mathrm{mm}^{2}$ para o Exemplo 1 .......................47

Figura 4.7: (a) malha utilizada e (b) tensões de von Mises do Exemplo 4.2.2 .........................47

Figura 4.8: (a) malha utilizada e (b) do Exemplo 4.2.3 ….................................................48

Figura 4.9: malha de elementos finitos do exemplo 4.3.2 ................................................49 
Figura 4.10: configuração deformada e tensões $\sigma_{\mathrm{x}}$ do Exemplo 4.3.3 .....................................50

Figura 4.11: tensões de von Mises para o exemplo 4.4.1....................................................51

Figura 4.12: condutividade térmica e capacidade térmica do material do exemplo 4.5.1.......52

Figura 4.13: malha e distribuição de temperatura no instante $\mathrm{t}=12 \mathrm{~s}$ para o exemplo 4.5.1......53

Figura 4.14: evolução da temperatura na superfície para o exemplo 4.5.1 ..............................53

Figura 4.15: distribuição de temperatura em 3 pontos do cilindro do exemplo 4.5.2..............54

Figura 4.16: frações parciais de martensita e perlita do exemplo 4.5.2 .................................55

Figura 4.17: malha de elementos finitos para o exemplo 4.6.1 .............................................58

Figura 4.18: distribuição de temperaturas após 30s de têmpera do cilindro de aço

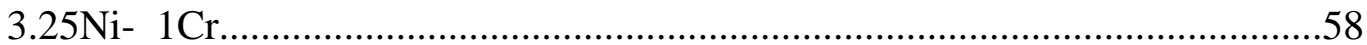

Figura 4.19: região transformada em martensita após 30s de têmpera do cilindro

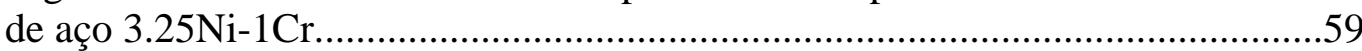

Figura 4.20: tensões $\sigma_{z}$ no centro da peça do cilindro de aço $3.25 \mathrm{Ni}-1 \mathrm{Cr}$, após $13 \mathrm{~s}$.............59

Figura 4.21: configuração deformada e não-deformada e fração martensítica

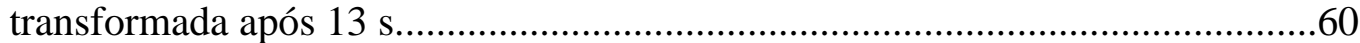

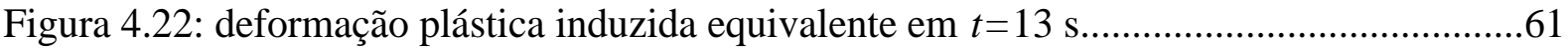

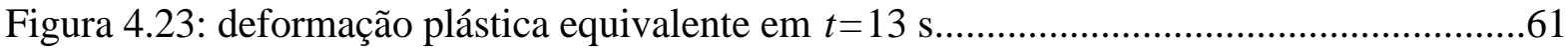

Figura 4.24: têmpera progressiva de uma chapa de aço.......................................................62

Figura 4.25: malha de elementos finitos e restrições ao deslocamento para o

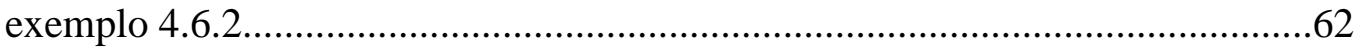

Figura 4.26: distribuição de temperatura nos instantes $1 \mathrm{~s}, 2 \mathrm{~s}$ e $5 \mathrm{~s}$ para a têmpera progressiva... .....................................................................................63

Figura 4.27: fração transformada de martensita nos instantes 1s, 2 s e 5 s para a têmpera progressiva.

Figura 4.28: tensão $\sigma_{\mathrm{x}}$ e configuração deformada nos instantes $1 \mathrm{~s}, 2 \mathrm{~s}$ e $5 \mathrm{~s}$ para a

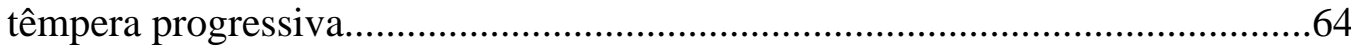

Figura 5.1: distribuição de concentração de bainita após 100s de têmpera..............................69

Figura 5.2: concentração de bainita e martensita no ponto ${ }^{a}$...................................................69

Figura 5.3: evolução da temperatura no ponto A ao longo do tempo e curvas de

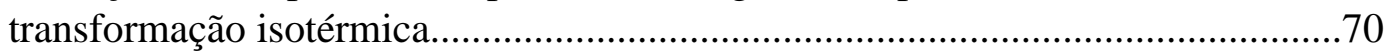

Figura 5.4: evolução da temperatura no ponto A e curvas de nível da superfície de resfriamento contínuo referentes à transformação bainítica...

Figura 5.5: representação da superfície de fração de bainita transformada baseada na curva de transformação isotérmica do aço AISI 4340 ....................................................71

Figura 5.6: comparação entre os valores de $t_{s}$ e $t_{f}$ calculados pelos diferentes esquemas.........72

Figura 5.7: fração parcial de bainita : comparação entre os métodos.......................................73

Figura 5.8: evolução da temperatura no ponto central da peça, para diversos valores de $h \ldots . . .74$

Figura 5.9: comparação entre o esquema proposto e o clássico, para o cálculo das

frações transformadas (módulo do vetor de fração parcial de bainita ao

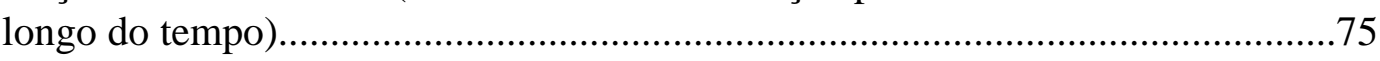

Figura 5.10: evolução da temperatura no ponto central da peça durante a têmpera, para dois valores de . .76

Figura 5.11: comparação entre o esquema proposto e o clássico, para o cálculo das frações transformadas na têmpera de um cilindro (módulo do vetor de fração parcial de bainita ao longo do tempo) 


\section{Lista de símbolos}

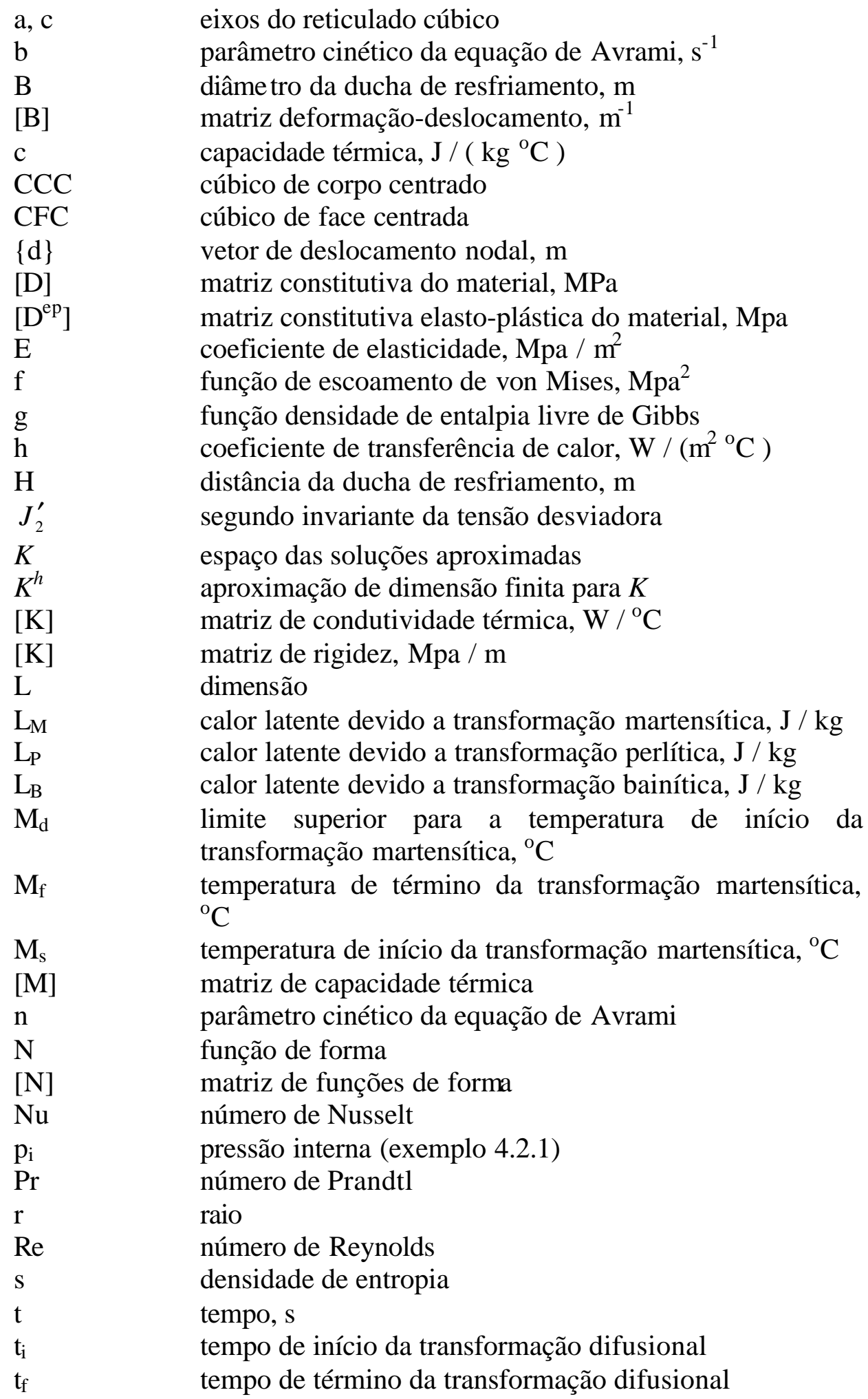


temperatura

u

u',

V

$V^{h}$

$\mathrm{V}$

$\mathrm{V}_{\mathrm{A}}$

$\mathrm{V}_{\mathrm{M}}$

$\Delta \mathrm{t}$

$\alpha$

$\alpha$

$\beta$

$\chi$

$\varepsilon$

$\varepsilon^{\mathrm{e}}$

$\varepsilon^{\mathrm{p}}$

$\varepsilon^{\text {th }}$

$\varepsilon^{\text {tr }}$

$\eta_{s}$

$\eta_{f}$

$\kappa$

$\mathrm{d} \lambda$

$v$

$\theta$

$\dot{\theta}$

$\rho$

$\sigma$

$\sigma^{\prime}$

$\sigma_{\mathrm{e}}$

$\sigma_{\mathrm{E}}$

$\sigma_{\mathrm{y}}$

$\xi_{\mathrm{A}}$

$\xi_{\mathrm{M}}$

$\xi_{\mathrm{P}}$

$\xi_{\mathrm{B}}$

$\Gamma$

$\Omega$

$a(),,($, )

densidade de energia interna

energia interna (exemplo 4.1.1), $\mathrm{W} / \mathrm{m}^{3}$

espaço das variações

aproximação de dimensão finita para $V$

volume

volume da célula unitária da austenita

volume da célula unitária da martensita

passo de tempo. S

parâmetro de colocação do método trapezoidal generalizado

coeficiente de dilatação térmica linear, $\mathrm{m} /\left(\mathrm{m}{ }^{\circ} \mathrm{C}\right)$

coeficiente de expansão por transformação, $\mathrm{m} \mathrm{m}^{-1}$

parâmetro de encruamento

deformação total

deformação elástica

deformação plástica

deformação térmica

deformação por transformação de fase

valor da fração parcial que define o início da transformação

valor da fração parcial que define o término da transformação

condutividade térmica, $\mathrm{W} /(\mathrm{m} \mathrm{K})$

multiplicador plástica

módulo de poisson

temperatura, ${ }^{\circ} \mathrm{C}$

derivada da temperatura em relação a $t,{ }^{\circ} \mathrm{C} / \mathrm{s}$

densidade de massa, $\mathrm{kg} / \mathrm{m}^{3}$

tensão uniaxial

tensor desviador

tensão equivalente

tensão de escoamento da fase mais fraca

tensão de escoamento

fração parcial de austenita

fração parcial de martensita

fração parcial de perlita

fração parcial de bainita

fronteira de um elemento finito ou de uma região $\Omega$ qualquer, $\mathrm{m}$

volume de um elemento finito ou de uma região

qualquer, $\mathrm{m}^{3}$

operadores lineares 


\section{1 - INTRODUÇÃO}

Materiais metálicos apresentam um complexo comportamento durante processos de engenharia envolvendo mudança de fase, em particular a transformação austenita-martensita durante a têmpera de peças de aço, devido ao acoplamento entre efeitos de distribuição de temperatura, das mudanças de fase da estrutura metálica e das transformações elásticas e inelásticas.

A partir de determinados valores, a diminuição da temperatura ocasiona uma transformação da estrutura metálica que, por sua vez, altera as propriedades termo-físicas do material e, assim, influencia no campo de temperaturas. Além disso, mudanças locais de temperatura e de estrutura ocasionam dilatação volumétrica não uniforme da peça, resultando em tensões térmicas e de transformação, respectivamente. Além disso, o trabalho mecânico gera calor, influenciando na distribuição de temperatura, e o estado de tensões induz a transformação de fase alterando a temperatura inicial da transformação martensítica, denominada efeito cinético. No diagrama abaixo vê-se a interseção entre os três fenômenos.

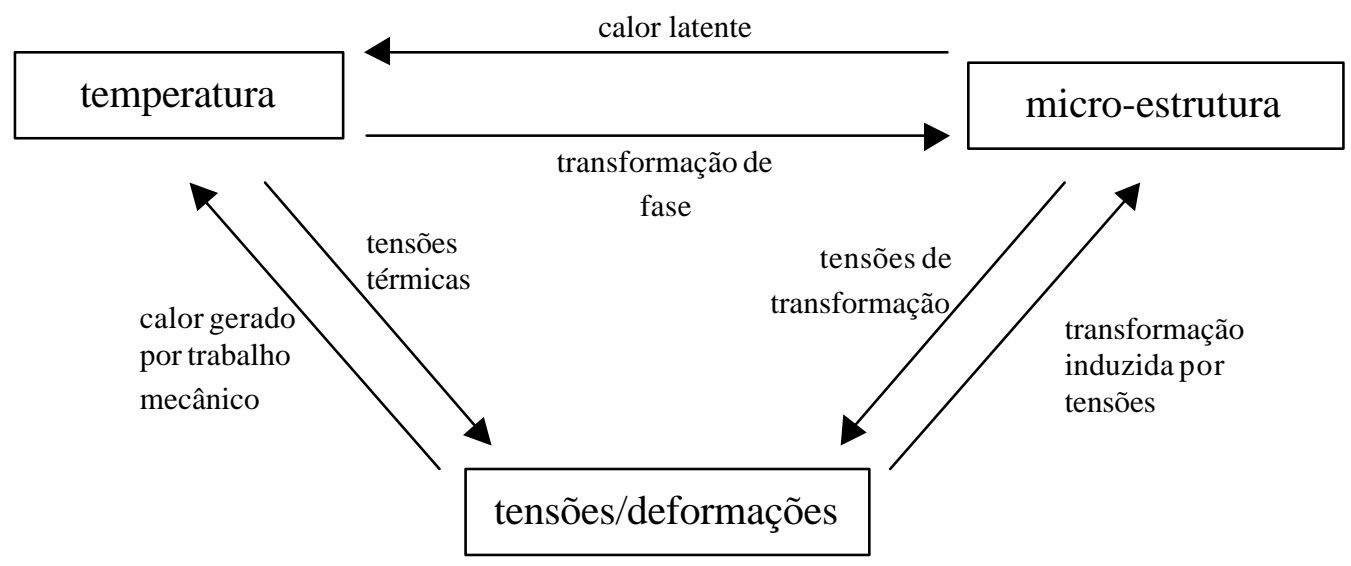

Figura 1.1 : diagrama das relações entre os problemas

Um modelo incorporando o acoplamento mútuo entre fluxo de calor, geração de tensões e transformação de fase foi apresentado por vários autores como [DENIS, GAUTIER,SIMON \& 
BECK 1985], [SLÖSTROM, 1985] e [ABBASI \& FLETCHER, 1985]. Porém, foi constatado que o calor gerado por trabalho mecânico representa menos de $1 \%$ dos termos de geração de calor e da taxa de variação de temperatura da equação de energia [SJÖSTRÖM, 1985], correspondendo, em um problema de têmpera, a uma alteração de cerca de $2^{\circ} \mathrm{C}$ na temperatura e, por isso, pode ser desprezado quando comparado as variações de temperatura devido a condução e aquelas induzidas pelo calor latente [LEBLOND, MOTTET,DEVAUX \& DEVAUX, 1985]. Por sua vez, a influência do estado de tensões na estrutura metálica, o efeito cinético, não influencia na magnitude e perfil das tensões residuais [DENIS, GAUTIER, SIMON \& BECK, 1985] e [LEBLOND, MOTTET, DEVAUX \& DEVAUX, 1985] e também não será considerado neste trabalho.

No trabalho de [ARGYRIS, SZIMMAT \& WILLAM,1985], a deformação plástica devida a transformação é simulada através da diminuição do valor da tensão de escoamento, técnica esta substituída em trabalhos mais recentes pela inclusão, durante a transformação, de uma deformação plástica, chamada de deformação plástica induzida pela deformação (PIT), mesmo para estados de tensão abaixo da tensão de escoamento. [CAMARÃO, 1998], ao estudar a têmpera em cilindros de aço, não considera a plasticidade induzida por transformação e a influência das frações parciais no cálculo das constantes do material. [BOKOTA \& ISKIERKA, 1998], apesar de considerar as transformações austenita-martensita, austenita-perlita e austenitabainita, também não considera a plasticidade induzida por transformação.

Este trabalho é uma tentativa de unificar essas abordagens, considerando tanto a transformação martensítica quanto a influência da plasticidade induzida pela transformação nos estado final de tensões. Além disso, pretende-se apresentar uma nova proposta para o cálculo das frações transformadas em fenômenos difusionais. 
No Capítulo 2 é apresentada uma revisão bibliográfica com os principais conceitos envolvendo a transformação austenita-martensita em ligas de ferro-níquel e as transformações de fase em aços ao carbono.

No Capítulo 3 são abordados os problemas térmico, de cálculo da micro-estrutura e de tensões, bem como a abordagem computacional utilizada no cálculo dos resultados. Na Seção 3.1 são apresentadas a dedução da equação termo-mecânica, as formulações forte, fraca, de Galerkin e matricial para o problema térmico, bem como os métodos utilizados para sua resolução. Na Seção 3.2 é discutida a plasticidade induzida pela transformação, além de apresentar a relação tensão-deformação, considerando os efeitos térmico e de mudança de fase, bem como a resolução numérica do cálculo das tensões geradas. Na Seção 3.3 são abordadas as equações que modelam a quantidade de fração martensítica transformada.

No Capítulo 4 são apresentados diversos resultados numéricos que validam as formulações apresentadas. Esses resultados são divididos em quatro seções: análise térmica, análise mecânica, análise térmica com mudança de fase e análise termo-mecânica com mudança de fase. Na última seção é feita uma discussão dos resultados obtidos.

No Capítulo 5 é apresentada uma breve introdução teórica das transformações de fase que ocorrem em peças de aço carbono, bem como um novo modelo para o cálculo dos parâmetros cinéticos das transformações difusionais austenita-perlita, austenita-bainita e austenita-ferrita. É apresentado também um exemplo numérico para o cálculo das frações parciais dos constituintes de um aço ao carbono e um estudo comparativo entre os métodos.

No Capítulo 6 encontram-se as conclusões alcançadas neste trabalho e sugestões para etapas subseqüentes. 


\section{2 - REVISÃO BIBLIOGRÁFICA}

Quando uma peça de aço é aquecida por tempo suficiente até atingir uma determinada temperatura, sua micro-estrutura é alterada para uma forma estável, denominada austenita ou ferro- $\gamma$, fornecendo à peça maleabilidade e ductilidade necessárias a processos de fabricação.

Um desses processos, a têmpera, consiste na redução, muitas vezes brusca, da temperatura da peça, tendo como objetivo principal ocasionar a reação martensítica, ou seja, a transformação de austenita em martensita, esta última mais dura, resistente e não-ductil.

Neste capítulo serão abordados os principais conceitos e análises sobre as transformações estruturais que ocorrem durante o resfriamento no processo de têmpera de ligas de ferro-níquel e de aços carbono.

\section{1) Transformações em ligas ferro-níquel}

As ligas de ferro-níquel são de alta temperabilidade, ou seja, a transformação austenitamartensita ocorre mesmo para taxas de resfriamento pequenas. Por isso, neste trabalho será considerado que este metal, ao ser tratado termicamente por têmpera, gera idealmente martensita.

\subsection{1) Nucleação martensítica}

Dados experimentais indicam que os núcleos de martensita em ligas de ferro-níquel, que vem a ser os pontos onde se iniciam a transformação, se originam heterogeneamente e se localizam em defeitos tais como contorno dos grãos, discordâncias e em vazios gerados durante o resfriamento. Além disso, embora a formação isotérmica da martensita seja observada em algumas ligas, a nucleação martensítica - início da transformação de fase pela formação de partículas martensíticas muito pequenas (núcleos) - tende a ocorrer atermicamente, ou seja, a formação de martensita depende principalmente de temperatura e independe da taxa de resfriamento, tendo o tempo um efeito secundário ou mesmo negativo 
nesta transformação, uma vez que uma manutenção isotérmica da amostra durante a transformação tende a estabilizar a interface.

Outra comprovação do fato da transformação ser atérmica é que a nucleação pode ocorrer, em algumas ligas, em temperaturas tão baixas como $4^{\circ} \mathrm{K}$, onde a energia das vibrações térmicas é extremamente pequena.

Uma vez iniciada a nucleação, a velocidade de crescimento dos núcleos, independentemente da temperatura de início da transformação, é da ordem de um terço da velocidade do som na matriz, evidenciando assim a independência do crescimento em relação a ativação térmica. Desse modo, na ligas de ferro-níquel, as placas de martensita se formam e crescem muito rapidamente até seu tamanho final, e a transformação continua através da nucleação de plaquetas adicionais, causada pela diminuição da temperatura. Por sua vez, tensões associadas ao crescimento das plaquetas nesta liga são suficientemente grandes para provocar deformação plástica na matriz austenítica que envolve a plaqueta de martensita, provocando uma perda de coerência na interface entre as plaquetas e a matriz e, consequentemente, o crescimento é interrompido.

O plano de hábito, plano sobre o qual as plaquetas de martensita se formam, é geralmente admitido como um plano não-distorcido, ou seja, todas as direções nesse plano permanecem inalteradas pela transformação. A deformação macroscópica, causada pelos realinhamentos atômicos associados às reações martensíticas, que ocorre na formação de uma plaqueta de martensita, é constituída de um cisalhamento paralelo ao plano de hábito, associada a uma deformação por tração ou compressão uniaxial, perpendicular ao plano de hábito, sendo esta última de uma magnitude maior que a primeira. Desse modo, como a mudança de formato é principalmente um cisalhamento, as plaquetas de martensita deformam o reticulado da matriz, fazendo com que plaquetas individuais de martensita, formadas no 
interior de um cristal, sejam de forma lenticular e, caso algumas delas corte um cristal, seus contornos sejam planos e paralelos ao plano de hábito (Figura 2.1).

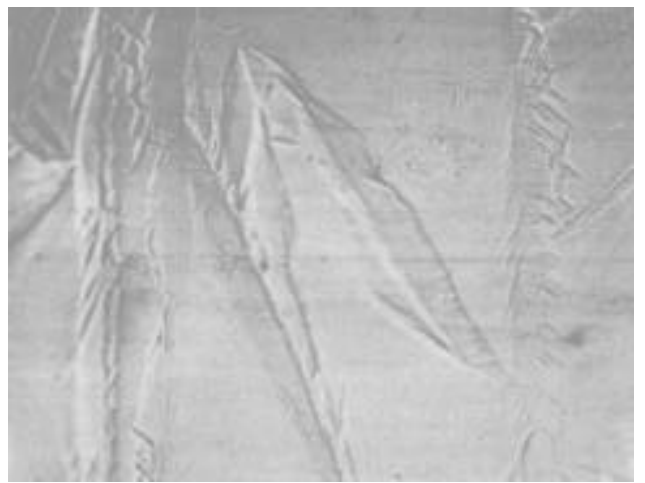

Figura 2.1: plaquetas de martensita numa liga ferro-níquel [REED-HILL,1982]

Como a formação das plaquetas de martensita envolve uma mudança de forma de um volume finito de matéria, uma tensão aplicada pode influenciar a reação, aumentando ou diminuindo a temperatura de início da transformação martensítica, dado por $M_{s}$. A temperatura $M_{f}$, por sua vez, corresponde àquela abaixo da qual a continuação do resfriamento não aumenta a quantidade de martensita, podendo ficar ainda alguma austenita retida.

No caso de deformações plásticas, estas aumentam as deformações internas, ajudando na geração de discordâncias e, consequentemente, aumentando o número de locais onde ocorrem a nucleação e favorecendo a transformação martensítica, elevando a temperatura $M_{s}$. Porém, há um limite superior para o valor de $M_{s}$, dado por $M_{d}$, uma vez que deformações muito grandes podem induzir restrições ao crescimento do núcleo.

\subsection{2) A estrutura cristalina da martensita}

Em ligas de ferro-níquel, o reticulado martensítico é cúbico de corpo centrado (CCC), ao contrário da austenita, que é cúbica de face centrada (CFC). Esta transformação de CFC em CCC foi explicada em 1924 por E. C. Bain que sugeriu que um reticulado CCC poderia ser obtido de uma estrutura CFC por meio de uma compressão paralela ao eixo $c$, vertical, e de uma expansão nos dois eixos $a$, no plano $x y$, da estrutura cristalina. Na Figura 2.2 está 
representada uma estrutura $\mathrm{CFC}$, que pode ser considerada uma estrutura tetragonal de corpo centrado, que sofreria a distorção de Bain, convertendo-se em CCC.

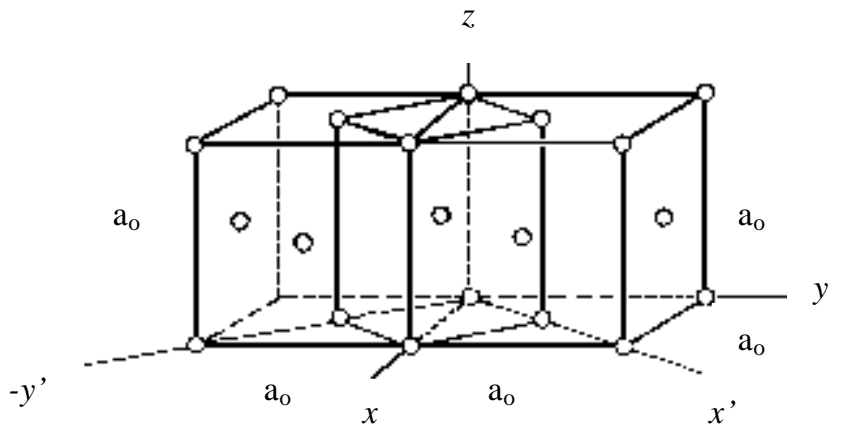

(a)

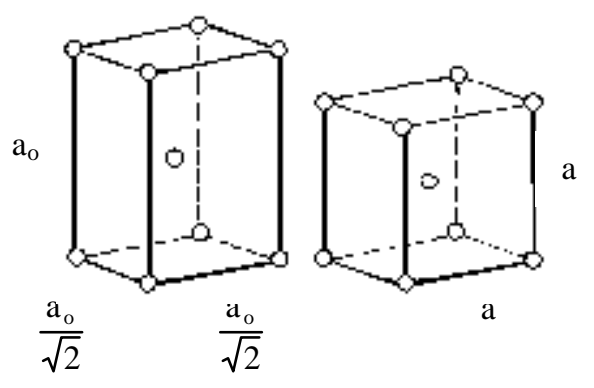

(b)

(c)

Figura 2.2: (a) célula tetragonal de corpo centrado na estrutura cúbica de face centrada, (b) tetragonal de corpo centrado e (c) cúbica de corpo centrado após distorção de Bain, liga ferro-níquel. [REED-HILL,1982]

Porém, a natureza dos mecanismos atômicos que convertem uma estrutura cristalina em outra não é conhecida. Wechsler, Lieberman e Read mostraram que as características cristalográficas das transformações martensíticas podem ser explicadas em termos de 3 deformações básicas: uma distorção de Bain, uma deformação por cisalhamento e uma rotação do reticulado transformado [REED-HILL,1982].

\section{2) Transformações em aços ao carbono}

A forma estável do ferro puro entre $910^{\circ} \mathrm{C}$ e $1400^{\circ} \mathrm{C}$, de estrutura cúbica de faces centradas (CFC), é denominada austenita, ou ferro- $\gamma$. Por ser mole e dúctil, presta-se bem a processos de fabricação, razão pela qual muitos metais são laminados ou forjados na faixa de temperatura austenítica.

Esta estrutura possui espaços interatômicos ligeiramente maiores que os átomos de carbono, de forma que a dissolução deste componente na austenita introduz deformações na estrutura. Desse modo, nem todos os vazios são preenchidos simultaneamente e a solubilidade máxima é de 2,06\% de carbono. Este valor máximo caracteriza os sistemas $\mathrm{Fe}-\mathrm{C}$ chamados 
genericamente de aços, nos quais todo o carbono encontra-se dissolvido na austenita em elevadas temperaturas.

Admitindo resfriamento lento a partir de uma temperatura austenítica, as mudanças de fase dos aços podem ser previstas pelo uso do diagrama de equilíbrio apresentado na Figura 2.3. Por outro lado, quando as transformações não ocorrem sob condições de equilíbrio, como quando o metal é resfriado rapidamente em tratamentos térmicos de têmpera, outras fases metaestáveis são formadas.

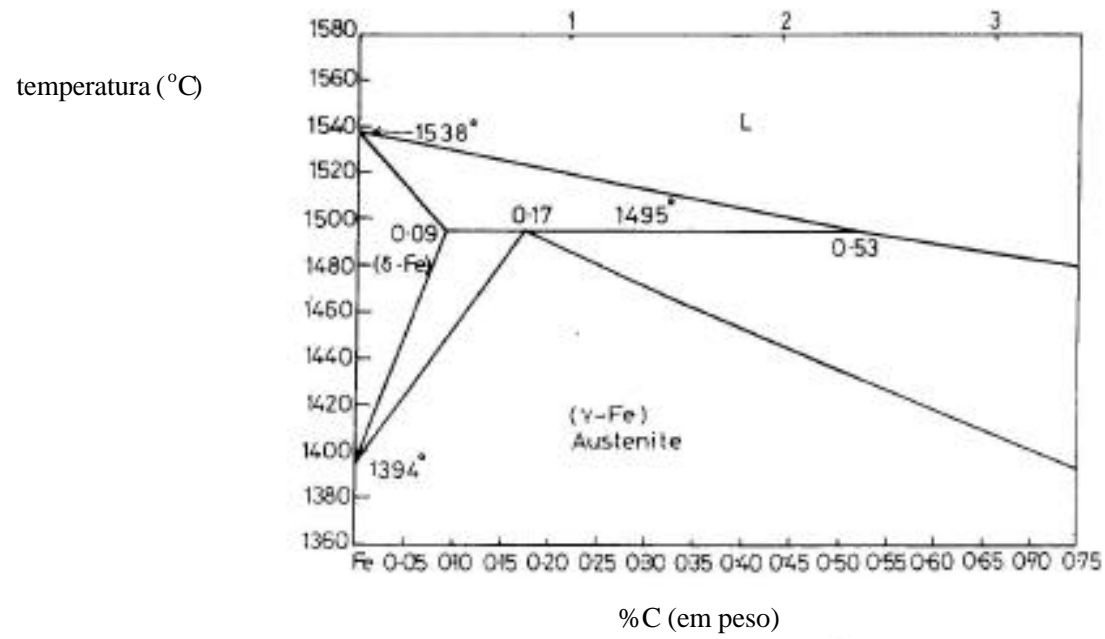

Figura 2.3: diagrama de equilíbrio de um aço ao carbono [LESLIE]

Nas seções seguintes serão abordadas, então, as diversas transformações sofridas pelos aços durante o resfriamento em tratamentos térmicos de têmpera.

\subsection{1) Transformação perlítica em aços ao carbono}

A perlita é um constituinte formado pela mistura de duas fases, ferrita e cementita $\left(\mathrm{Fe}_{3} \mathrm{C}\right)$ em proporções definidas, sendo aproximadamente $87,5 \%$ de ferrita e $12,5 \%$ de cementita. Ao microscópio a perlita pode ser identificada como uma série de plaquetas alternadas dos dois constituintes, sendo a ferrita a fase contínua (Figura 2.4). 


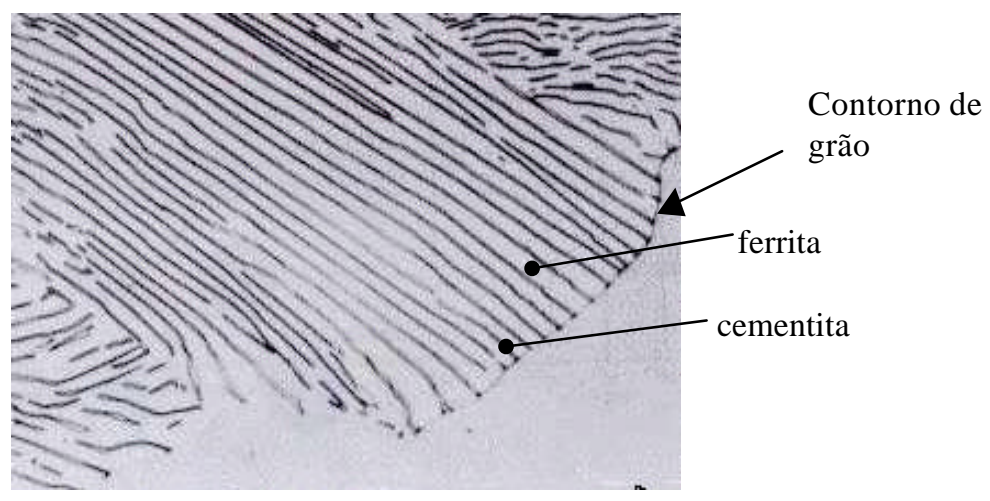

Figura 2.4: aço eutetóide parcialmente transformado em perlita [SMITH, 1993]

A decomposição de austenita em perlita ocorre por nucleação, ou seja, formação de partículas perlíticas muito pequenas (núcleos), e crescimento, sendo esta nucleação heterogênea e ocorrendo quase que exclusivamente nos contornos de grão caso a austenita seja de composição uniforme. Quando a austenita apresenta gradientes de concentração e partículas de carboneto de ferro não dissolvidas, a nucleação pode ocorrer também no interior dos grãos.

Não há comprovação de como o mecanismo de formação de perlita ocorre, nem qual constituinte se forma primeiro. Segundo as propostas iniciais de R. F. Mehl, a nucleação se inicia no contorno de grão austenítico com uma pequena lamela de cementita. Crescendo em comprimento e largura, esta lamela remove átomos de carbono da austenita que a envolve, até atingir uma concentração que permite a nucleação e o crescimento de ferrita na superfície da plaqueta de cementita. Como a lamela de ferrita contém uma concentração muito baixa de carbono, seu crescimento é acompanhado de um acúmulo de carbono na interface ferritaaustenita, até a nucleação de uma nova camada de cementita. Com a continuação desse processo, formam-se as camadas alternadas dos constituintes da perlita. Desse modo, o crescimento das colônias de perlita ocorre pela nucleação de lamelas adicionais e também 
pelo avanço frontal das lamelas, além da nucleação de novas colônias nas interfaces entre as colônias antigas e a austenita matriz. A Figura 2.5 abaixo ilustra este mecanismo:

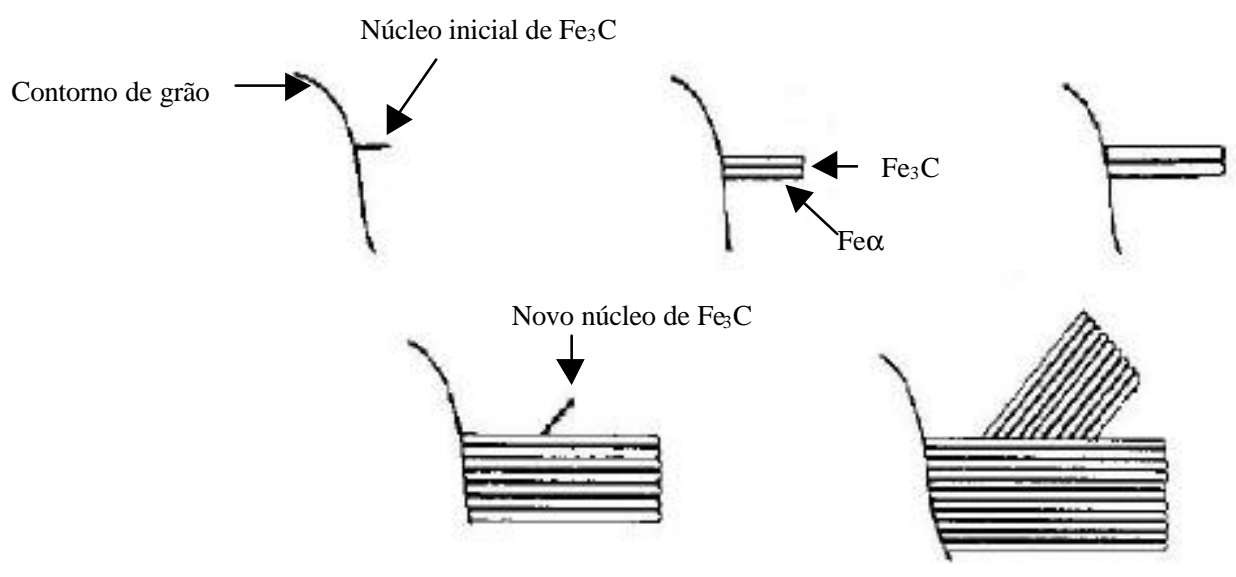

Figura 2.5: Nucleação e crescimento de perlita [Reed-Hill,1982]

Dados experimentais indicam que o espaçamento interlamelar da perlita independe da estrutura, ou seja, independe do tamanho do grão e de qualquer heterogeneidade de composição austenítica, mas é afetado pela temperatura de transformação - quanto menor a temperatura de reação, menor o espaçamento e mais duro o material obtido - e pela velocidade de resfriamento.

A maioria das teorias que explicam a grande movimentação de átomos de carbono para a formação de cementita admite que a difusão ocorre quase que inteiramente na austenita, decorrente dos gradientes de concentração que se desenvolvem no lado austenítico da interface (Figura 2.6). Essa transferência de átomos de carbono pela interface ferrita-austenita é uma reação química irreversível, e determinante na velocidade de crescimento da perlita, que atingiria um valor máximo em temperaturas próximas a $600^{\circ} \mathrm{C}$.

A velocidade de nucleação, número de núcleos que se formam em uma unidade de volume, por segundo, ao contrário da velocidade de crescimento, é uma função do tempo. No Capítulo 3, seção 3.3, serão apresentadas expressões para o cálculo da fração transformada. 


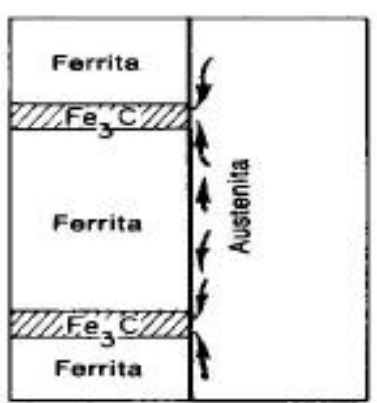

Figura 2.6: trajetória de difusão de carbono durante o crescimento de perlita

\subsection{2) Transformação bainítica em aços ao carbono}

Como a perlita, a bainita é uma mistura de duas fases, constituída de partículas de carboneto, com alta concentração de carbono, numa matriz ferrítica. Por envolver mudança de composição a reação bainítica implica na difusão de carbono, dependendo, assim, do tempo, ou seja, é uma reação difusional.

Ao contrário da perlita, a bainita cresce em plaquetas semelhantes às plaquetas de martensita, e sua formação também é acompanhada de distorções superficiais. Porém, as plaquetas de bainita crescem lenta e continuamente, ao contrário da martensita.

Cada plaqueta de bainita é composta por um volume de ferrita, no qual estão imersas partículas de carboneto. Em temperaturas relativamente altas (cerca de $460^{\circ} \mathrm{C}$ ) forma-se a chamada bainita superior (figura 2.7a), e em temperaturas mais baixas (cerca de $250^{\circ} \mathrm{C}$ ) forma-se a bainita inferior (figura 2.7b). Neste último caso, outros carbonetos que não a cementita podem se formar, como o caso do carboneto $\varepsilon$, que possui uma estrutura cristalográfica hexagonal, ao invés da estrutura otorrômbica da cementita.
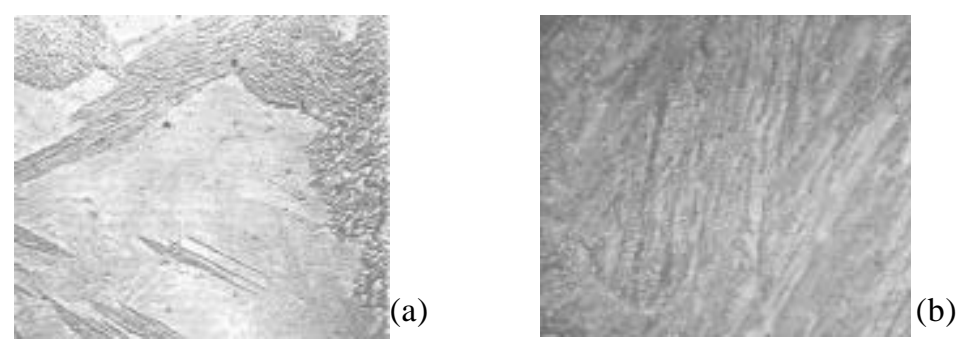

Figura 2.7: (a) bainita superior e (b) bainita inferior [REED-HILL, 1982] 
Outra característica da transformação bainítica, que a difere da perlítica, é o fato de que sua nucleação ocorre pela formação de ferrita, através de um deslocamento por cisalhamento dos átomos de ferro CFC para um arranjo CCC, combinado com a precipitação de cementita ao longo de planos cristalinos específicos do grão austenítico. Além disso, ela só se forma isotermicamente em um intervalo de temperatura entre $B_{S}$ e $B_{F}$, que são, respectivamente, a temperatura de início e de término da transformação bainítica. Porém, esta transformação não se completa no intervalo de temperatura entre $B_{S}$ e $B_{F}$, indicando que, neste intervalo, tanto a nucleação quanto o crescimento se paralisam antes que toda a austenita seja consumida. As razões da paralisação da nucleação não estão determinadas, mas considera-se que uma plaqueta da bainita cresce até interceptar outra plaqueta ou um contorno de grão da austenita, além de poder ter seu crescimento impedido pela falta de coerência entre a ferrita da plaqueta e a austenita matriz.

Em um aço eutetóide, acima de $530^{\circ} \mathrm{C}$ a perlita forma-se mais rapidamente que a bainita, pois a velocidade de difusão é suficientemente elevada para permitir o movimento dos átomos de carbono ao longo de distâncias relativamente longas. Abaixo de $530^{\circ} \mathrm{C}$, quando a transformação por cisalhamento produz muitos pontos de nucleação ao longo dos vários planos de cisalhamento, o carbono não consegue percorrer por difusão distâncias muito grandes e a bainita forma-se mais rapidamente. Na região de superposição perlita-bainita, considera-se que, numa transformação isotérmica, a austenita não transformada em bainita origina a perlita. No caso dos aços-liga, como o aço 4340 abaixo, as reações bainítica e perlítica não se superpõem, e considera-se que a fração de austenita não transformada transforma-se em martensita quando resfriado até a temperatura ambiente. Na figura 2.8 vê-se as curvas de transformação isotérmica de um aço eutetóide e do aço 4340, em perlita e bainita. 


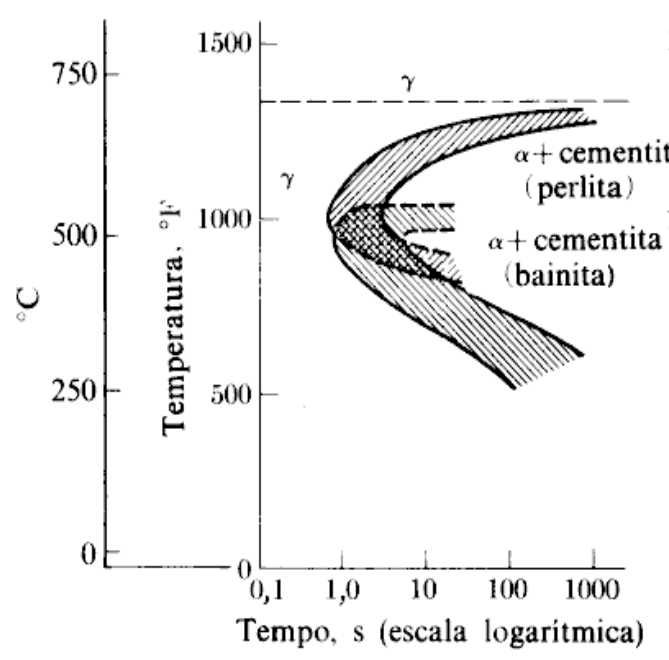

(a)

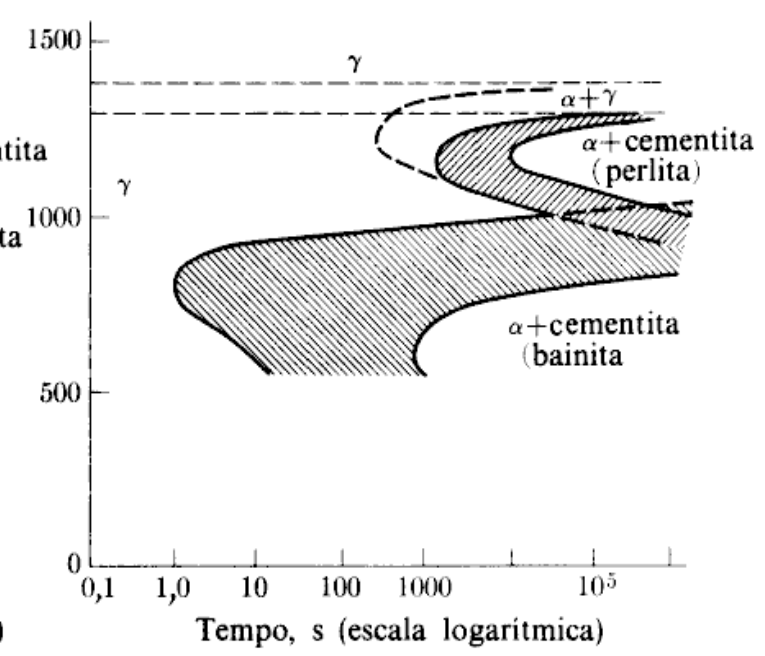

(b)

Figura 2.8: curva de transformação isotérmica: (a) aço eutetóide, (b) aço 4340 [CHIAVERINI,1965]

\subsection{3) Transformação martensítica em aços ao carbono}

Como visto na Seção 2.1.2, a estrutura cristalina da martensita é tetragonal de corpo centrado mas, nos aços, que são essencialmente ligas de ferro-carbono, os pontos médios das arestas do cubo são ocupadas por átomos de carbono, sendo estes considerados os elementos deformadores do reticulado, produzindo uma configuração tetragonal com elevada deformação interna. A extensão da tetragonalidade que ocorre na austenita e na martensita é dada, em função da concentração $x$ de carbono, por $c=2,861+0,11 x, a=2,861-0,013 x$ e $a_{0}=3,548+0,044 x$ (Figura 2.9). Desse modo, a variação relativa do volume durante a transformação martensítica, variação esta considerada isotrópica devido às diversas orientações que as plaquetas de martensita podem assumir num cristal de austenita, pode ser calculada por $\left(V_{M}-V_{A}\right) / V_{A}$, onde $V_{M}$ é o volume da célula unitária da martensita e $V_{A}$ o volume da célula unitária da austenita. O valor da variação relativa, para a maioria dos aços é considerado aproximadamente igual a 4,3\%, calculado para uma concentração de carbono igual a $1 \%$. 


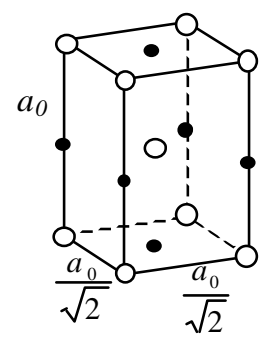

(a)

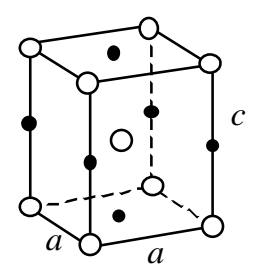

(b)

Figura 2.9: (a) representação tetragonal da austenita e (b) martensita tetragonal

As plaquetas de martensita que se formam na região de médio carbono têm aparência semelhante às que ocorrem nas ligas de ferro-níquel, ou seja, de pequeno tamanho e forma lenticular. Esta transformação também é essencialmente atérmica, podendo uma pequena quantidade de austenita se transformar isotermicamente. Mas, ao contrário das ligas ferroníquel, a reação martensítica dos aços não é reversível.

A transformação dos últimos resíduos de austenita se torna cada vez mais difícil, quanto menor a quantidade de austenita remanescente. Desse modo, a reação martensítica teoricamente nunca se completa, mesmo na temperatura zero absoluto, fazendo com que a temperatura final da transformação, $M_{F}$, não seja claramente definida. Por sua vez, a temperatura de início da transformação, $M_{S}$, é função do teor de carbono, bem como de elementos de liga substitucionais, estes últimos também influenciando os índices do plano de hábito e as relações de orientação entre a martensita e a austenita matriz. A temperatura de início da transformação martensítica pode, então, ser diminuída pelo acréscimo de carbono ou de elementos de liga, de acordo com a equação abaixo:

$$
\mathrm{M}_{\mathrm{s}}\left({ }^{\circ} \mathrm{C}\right)=561-474(\% \mathrm{C})-33(\% \mathrm{Mn})-17(\% \mathrm{Ni})-17(\% \mathrm{Cr})-21(\% \mathrm{Mo})
$$

O teor de carbono também influencia nos tipos de reações martensíticas possíveis. Com o aumento do teor de carbono, a temperatura $M_{S}$ diminui, fazendo com que a martensita transformada seja do tipo lenticular, ao contrário de aços com baixo teor de carbono (e conseqüente aumento de $M_{S}$ ), que geram o tipo em ripa (Figura 2.10). 
A martensita em forma de ripa caracteriza-se, ao contrário da forma lenticular, por uma alta densidade interna de discordâncias, arranjadas em células em forma de plaquetas. Neste caso, durante a transformação os átomos de carbono tendem a difundir-se e segregar-se em torno dessas discordâncias, mesmo em resfriamentos muito bruscos. No caso da martensita em ripa, os átomos de carbono tendem a ocupar os interstícios normais.
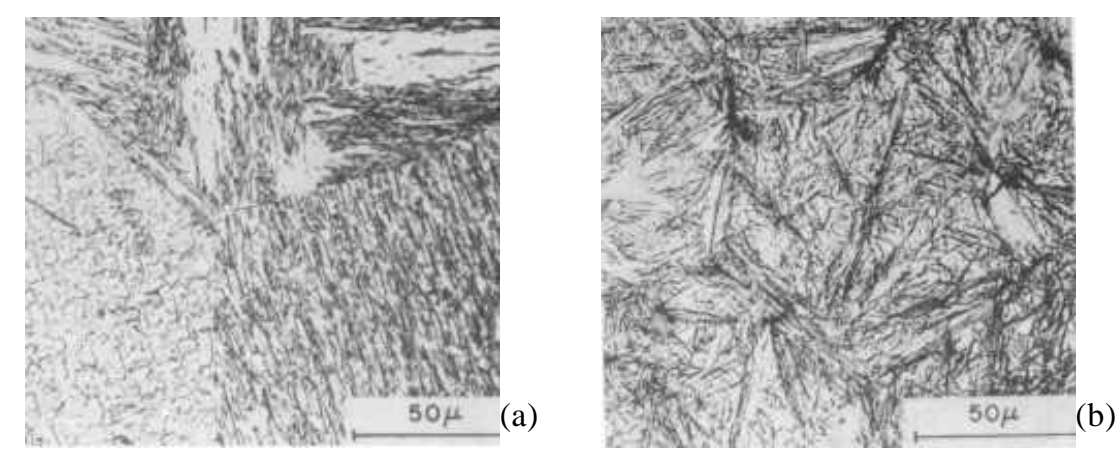

Figura 2.10 : (a) micro estrutura martensítica formada em aço com baixo (em ripa) e (b) alto carbono (lenticular) [SMITH,1993]

\section{3) A têmpera dos aços}

No tratamento térmico para formação da martensita, a têmpera, o metal é aquecido no campo austenítico e, a seguir, resfriado até a temperatura ambiente numa taxa alta o suficiente para evitar a formação de ferrita e cementita em altas temperaturas, taxa esta que depende do tipo de tratamento, tamanho e forma da amostra. Na figura 2.11 vê-se um diagrama de resfriamento contínuo de um aço eutetóide, mostrando a taxa de resfriamento mínima $\left(\mathrm{CR}_{\mathrm{M}}\right)$ para a formação de $100 \%$ de martensita, com temperatura inicial de $740^{\circ} \mathrm{C}$.

Em peças de aço muito grandes o calor no centro pode não ser retirado com rapidez suficiente para a formação de martensita. Porém, a adição de elementos de liga retarda a transformação em ferrita e cementita, aumentando o período de resfriamento da têmpera e, consequentemente, diminuindo a taxa de resfriamento. Desse modo, é possível obter-se uma têmpera mais profunda e uma diminuição das tensões térmicas, a partir das quais podem se originar fissuras. 
Além disso, a temperabilidade dos aços aumenta com o teor de carbono e é inversamente proporcional ao tamanho do grão austenítico. Este último efeito ocorre uma vez que, em aços de grão fino, a área de contato entre os grãos é maior que em aços de grão grosseiro, favorecendo uma maior difusão de átomos de carbono e uma conseqüente maior rapidez na nucleação de perlita. Desse modo, aços de grão fino têm uma menor temperabilidade. Porém, o uso de tamanho de grão grosseiro para promover o aumento da temperabilidade não é uma prática utilizada, devido ao aumento de fragilidade e perda de ductilidade decorrente desta técnica, além da maior ocorrência de trincas de têmpera, causadas devido ao choque térmico e às tensões decorrentes do processo.

Desse modo, uma estimativa qualitativa e quantitativa das tensões geradas em processos de têmpera de ligas de ferro-níquel e de aços carbono é de extrema importância para prever o comportamento e as propriedades mecânicas obtidas em peças metálicas submetidas a este tipo de tratamento térmico.

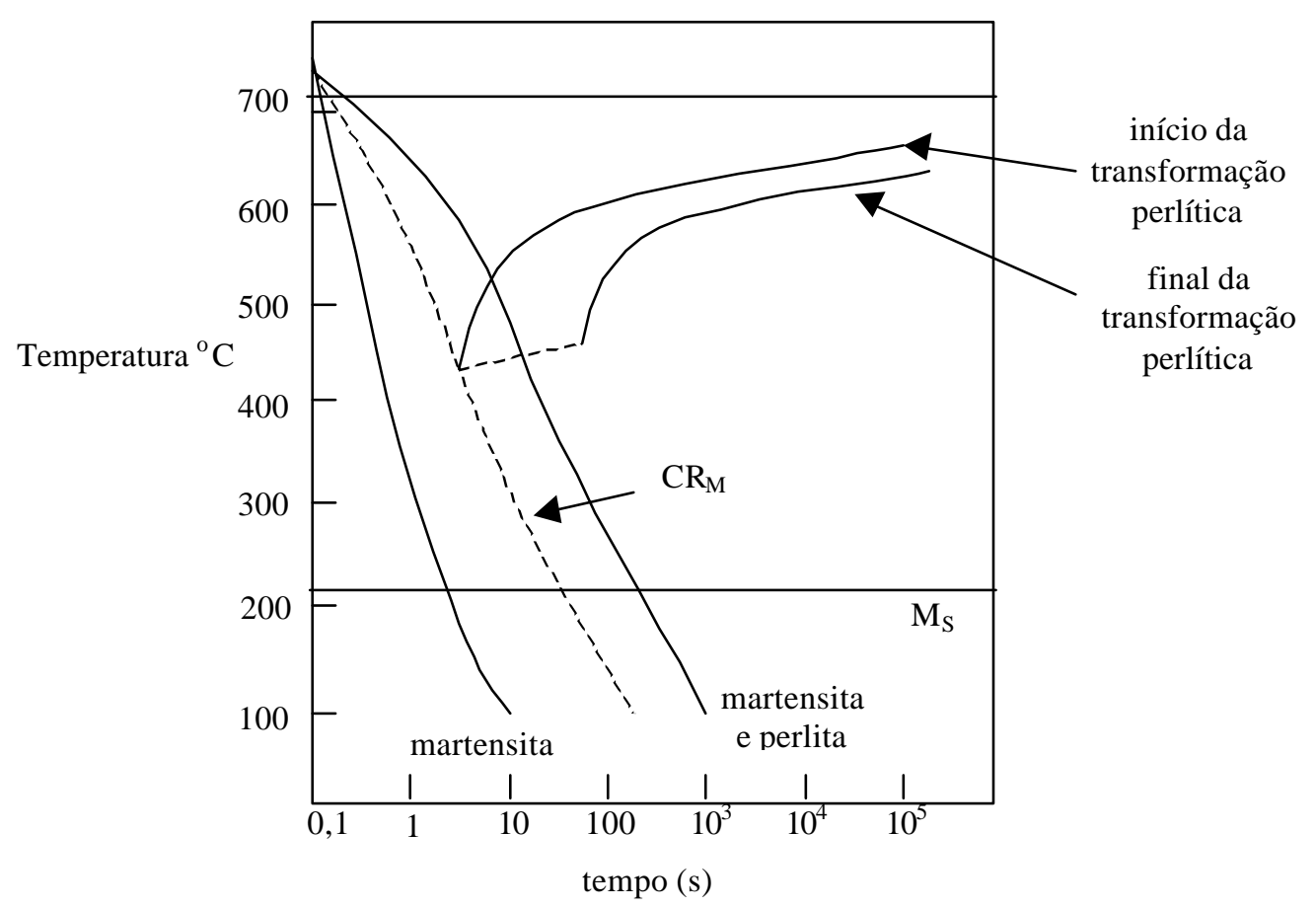

Figura 2.11: curva CTT de um aço eutetóide [CHIAVERINI,1965] 


\section{3 - RESOLUÇÃO NUMÉRICA DAS EQUAÇÕES}

Neste capítulo são abordados os problemas térmico, de cálculo de micro-estrutura e de tensões, bem como os métodos numéricos utilizados no cálculo dos resultados. Na Seção 3.1 é abordada a equação que modela a quantidade de fração martensítica transformada. Na Seção 3.2 são apresentadas a dedução da equação termo-mecânica, as formulações forte, fraca, de Galerkin e matricial para o problema térmico, bem como os métodos utilizados para sua resolução. Na Seção 3.3 é discutida a plasticidade induzida pela transformação, além de apresentar a relação tensão-deformação considerando os efeitos térmico e de mudança de fase, bem como a resolução numérica do cálculo das tensões geradas.

\subsection{Cálculo da fração transformada}

Como visto no Capítulo 2, no decorrer da têmpera de uma peça de ferro-níquel uma estrutura de fase simples, a austenita, transforma-se idealmente em martensita. No caso de peças de aço ao carbono, a austenita transforma-se idealmente em perlita, bainita e martensita, dependendo do tempo de transformação, da temperatura e da taxa de resfriamento.

As frações volumétricas das fases transformadas são determinadas pela expressão de Avrami [AVRAMI,1939], assumindo-se válido o princípio da aditividade, dada genericamente por,

$$
\xi=1-e^{-b t^{n}}
$$

A fração volumétrica da martensita, cuja formação é adifusional, é dada pela equação empírica de Koistiner e Marburger [KOISTINER,1959]

$$
\xi_{M}(\theta)=1-e^{-0,011\left(M_{S}-\theta\right)} \quad, \quad \theta<M_{S}
$$

onde $M_{S}$ é a temperatura de início da transformação martensítica. Além disso, o princípio da aditividade fornece a fração volumétrica da austenita retida 
Como citado anteriormente, no Capítulo 5 será abordado o cálculo das frações parciais transformadas em processos difusionais que ocorrem em aços ao carbono e apresentada uma nova formulação, onde será estudada a influência da taxa de resfriamento sobre o cálculo das frações parciais em transformações difusionais.

\subsection{Problema Térmico}

\subsubsection{Equação Termodinâmica}

Considera-se uma liga de ferro-níquel sob processo de têmpera como uma mistura de dois tipos de constituintes, de modo que

$$
\xi_{A}+\xi_{M}=1
$$

onde $\xi_{\mathrm{A}}$ é a fração volumétrica de austenita e $\xi_{\mathrm{M}}$ a fração volumétrica de martensita, e assume-se que seu estado termodinâmico seja definido pelo estado de tensões $\boldsymbol{\sigma}$, temperatura $\theta$, gradiente de temperatura $\overline{\mathbf{g}}$, pelas frações volumétricas $\xi_{i}$ dos dois constituinte, deformação plástica $\boldsymbol{\varepsilon}^{p}$ e pelo parâmetro de encruamento $\chi$, estes dois últimos considerados como variáveis internas.

Desse modo, a relação constitutiva da função densidade de entalpia livre de Gibbs é dada por

$$
\Phi=\Phi\left(\sigma, \theta, \overrightarrow{\mathbf{g}}, \xi_{i}, \varepsilon^{p}, \chi\right)
$$

com $\Phi$ sendo definida por

$$
\Phi=u-\theta s-\frac{1}{\rho} \sigma: \varepsilon^{e}
$$

onde $u$ é a densidade de energia interna, $s$ é a densidade de entropia e $\varepsilon^{e}$ é o tensor de deformação elástica. 
Considerando-se a função $\Phi$ suficientemente suave, tem-se que

$$
\dot{\Phi}=\frac{\partial \Phi}{\partial \sigma}: \dot{\sigma}+\frac{\partial \Phi}{\partial \theta} \dot{\theta}+\frac{\partial \Phi}{\partial \overrightarrow{\mathbf{g}}} \dot{\mathbf{g}}+\frac{\partial \Phi}{\partial \xi_{i}}+\frac{\partial \Phi}{\partial \chi}: \dot{\chi}+\frac{\partial \Phi}{\partial \varepsilon^{p}}: \dot{\varepsilon}^{p}
$$

Substituindo-se a expressão acima na desigualdade de Clausius-Duhen, dada por

$$
\sigma: \dot{\varepsilon}^{e}-\rho(\dot{\Phi}+s \dot{\theta})-\dot{\mathbf{q}} \frac{\overrightarrow{\mathbf{g}}}{\boldsymbol{\theta}}-\frac{d}{d t}\left(\sigma: \varepsilon^{e}\right) \geq 0
$$

onde $\overrightarrow{\mathbf{q}}$ é o fluxo de calor e $\rho$ a densidade de massa, chega-se a

$$
\rho \dot{\theta}\left(\frac{\partial \Phi}{\partial \theta}+s\right)+\left(\rho \frac{\partial \Phi}{\partial \sigma}+\varepsilon^{e}\right): \dot{\sigma}+\overrightarrow{\mathbf{q}} \frac{\overrightarrow{\mathbf{g}}}{\theta}+\frac{\partial \Phi}{\partial \varepsilon^{p}}: \dot{\varepsilon}^{p}+\rho \frac{\partial \Phi}{\partial \chi}: \dot{\chi}+\rho \frac{\partial \Phi}{\partial \xi_{i}} \xi_{i}+\rho \frac{\partial \Phi}{\partial \overrightarrow{\mathbf{g}}} \dot{\overrightarrow{\mathbf{g}}} \leq 0
$$

O princípio da entropia requer que a desigualdade acima seja válida para todo processo termodinâmico $\left\{\sigma, \theta, \overrightarrow{\mathbf{g}}, \xi_{i}, \varepsilon^{p}, \chi\right\}$. Hipóteses clássicas permitem calcular alguns termos desta desigualdade independentemente [I SHII LIU]. Deve-se imaginar, em primeiro lugar, uma deformação elástica com temperatura constante $(\dot{\theta}=0)$ e uniforme $(\overrightarrow{\mathbf{g}}=0)$, sem transformação de fase. Como a desigualdade é válida para todo estado de tensões $\sigma$, tem-se que

$$
\varepsilon^{e}=-\rho \frac{\partial \Phi}{\partial \sigma}\left(\sigma, \theta, \overrightarrow{\mathbf{g}}, \xi_{i}, \chi, \varepsilon^{p}\right)
$$

De modo análogo, chega-se às expressões

$$
\begin{aligned}
s & =-\frac{\partial \Phi}{\partial \theta}\left(\sigma, \theta, \overrightarrow{\mathbf{g}}, \xi_{i}, \chi, \varepsilon^{p}\right) \\
\frac{\partial \Phi}{\partial \varepsilon^{p}} & =0 \\
\frac{\partial \Phi}{\partial \chi} & =0
\end{aligned}
$$




$$
\begin{aligned}
& \frac{\partial \Phi}{\partial \xi_{i}}=0 \\
& \frac{\partial \Phi}{\partial \overrightarrow{\mathbf{g}}}=0
\end{aligned}
$$

e também a

$$
\overrightarrow{\mathbf{q}} \overrightarrow{\mathbf{g}} \leq 0
$$

esta última conhecida como desigualdade de Fourier.

Desse modo, de (3.4), (3.5), (3.6) e (3.7) tem-se que $\Phi=\Phi(\sigma, \theta)$ e sendo

$$
\Psi=\Phi+\theta s
$$

a entalpia específica, tem-se que

$$
\frac{\partial \Psi}{\partial \sigma}=\frac{\partial \Phi}{\partial \sigma}+\theta \frac{\partial s}{\partial \sigma}
$$

e, utilizando-se (3.3), que

$$
\frac{\partial \Psi}{\partial \theta}=\frac{\partial \Phi}{\partial \theta}+s+\theta \frac{\partial s}{\partial \theta}=\theta \frac{\partial s}{\partial \theta}
$$

Utilizando-se as expressões (3.8), (3.9) e (3.10) na expressão de $\dot{u}$ obtida de (3.1), chega-se a

$$
\dot{u}=\frac{\partial \Phi}{\partial \sigma}: \dot{\sigma}+\theta \frac{\partial s}{\partial \sigma}: \dot{\sigma}+\theta \frac{\partial s}{\partial \theta} \dot{\theta}+\frac{\partial \Psi}{\partial \varepsilon^{p}}: \dot{\varepsilon}^{p}+\frac{\partial \Psi}{\partial \chi}: \dot{\chi}+\frac{\partial \Psi}{\partial \xi_{i}} \dot{\xi}_{i}+\frac{\dot{\sigma}: \varepsilon^{e}}{\rho}+\frac{\sigma: \dot{\varepsilon}^{e}}{\rho}
$$

Por (3.2) e (3.3), tem-se que

$$
\frac{\partial s}{\partial \sigma}=\frac{1}{\rho} \frac{\partial \varepsilon^{e}}{\partial \theta}
$$

e por (3.2)

$$
\frac{\partial \Phi}{\partial \sigma}=-\frac{\varepsilon^{e}}{\rho}
$$

Utilizando-se a Lei de Fourier, dada por 


$$
\overrightarrow{\mathbf{q}}=-\kappa \overrightarrow{\mathbf{g}}
$$

onde אé a condutividade térmica, e substituindo-se as expressões (3.12) e (3.13) em (3.11) e esta última na equação de balanço de energia, dada por

$$
\rho \dot{u}+\operatorname{div} \vec{q}=\sigma: \dot{\varepsilon}+\rho r
$$

chega-se a equação termodinânica, dada por

$$
\rho c \dot{\theta}+\theta\left(\frac{\partial \varepsilon^{e}}{\partial \theta}: \dot{\sigma}\right)+\rho\left(\frac{\partial \Psi}{\partial \varepsilon^{p}}: \dot{\varepsilon}^{p}\right)+\rho\left(\frac{\partial \Psi}{\partial \chi}: \dot{\chi}\right)+\rho L_{M} \dot{\xi}_{M}-\sigma: \dot{\varepsilon}^{p}=\operatorname{div}(\kappa \dot{g})+\rho r
$$

onde onde $c=\theta \frac{\partial s}{\partial \theta}$ é a capacidade térmica, $L_{M}=\frac{\partial \Psi}{\partial \xi_{M}}$ o calor latente devido a transformação da matriz austenítica em martensita e $r$ o termo que representa o calor gerado internamente por outros fenômenos como radiação, por exemplo.

Como citado anteriormente, desconsidera-se a geração de calor devido ao trabalho mecânico e obtém-se a equação do calor considerando-se a influência da transformação de fase, dada por

$$
\rho c \dot{\theta}+L_{M} \xi_{M}+\operatorname{div} \dot{q}=\rho r
$$

com as propriedades térmicas satisfazendo à regra da mistura dos gases, ou seja,

$$
\begin{aligned}
& c=\xi_{A} c_{A}+\xi_{M} c_{M} \\
& k=\xi_{A} k_{A}+\xi_{M} k_{M}
\end{aligned}
$$

\subsubsection{Formulações forte e fraca para o problema térmico}

Considerando o problema sem acoplamento mecânico, temos o seguinte problema de valor inicial e de contorno, em sua formulação forte: encontrar o campo de temperaturas $\theta(\boldsymbol{x}, t)$, tal que 


$$
\begin{aligned}
& \left.q_{i, i}+\rho c \theta_{, t}=f \quad \text { em } \quad \Omega \times\right] 0, T[ \\
& \left.\theta=g \quad \text { em } \quad \Gamma_{g} \times\right] 0, T[ \\
& \left.-q_{i} \eta_{i}=h \quad \text { em } \quad \Gamma_{h} \times\right] 0, T[ \\
& \boldsymbol{\theta}(\mathbf{x}, 0)=\theta_{0}(\mathbf{x}), \quad \mathbf{x} \in \Omega
\end{aligned}
$$

onde $f, g$ e $h$ são, respectivamente, funções de $\Omega x] 0, t\left[, \Gamma_{g} x\right] 0, t\left[\right.$ e $\left.\Gamma_{h} x\right] 0, t[$ em $I R$, com $q$ dado pela lei de Fourier de acordo com $q_{i}=-K_{i j} \theta_{, j}$, onde $K_{i j}=K_{i j}(\boldsymbol{x})$ é o tensor de condutividade térmica do material.

Sejam $K=\left\{\theta(., t): \theta(x, t)=g(x, t)\right.$ em $\left.\Gamma_{g}, \quad \theta(., t) \in H^{l}(\Omega)\right\}$ como o espaço das soluções aproximadas e $V=\left\{w(\boldsymbol{x}): w \in H^{l}, w=0\right.$ em $\left.\Gamma_{g}\right\}$ como o espaço das variações. A formulação fraca do problema é descrita da seguinte forma: encontrar o campo de temperaturas $\theta(x, t) \in K$ tal que

$$
-\int_{\Omega} w_{i} q_{i} d \Omega+\int_{\Omega} w \rho c \dot{\theta} d \Omega=\int_{\Omega} w f d \Omega+\int_{\Gamma_{h}} w h d \Gamma \quad \forall w \in V
$$

ou, em sua forma reduzida,

$$
a(w, \boldsymbol{\theta})-(w, \rho c \dot{\boldsymbol{\theta}})=(w, f)+(w, h)_{\Gamma_{h}}
$$

com a ajuda dos operadores lineares

$$
\begin{aligned}
& a(w, v)=\int_{\Omega} w_{, i} K_{i j} v_{, j} d \Omega \\
& (w, v)=\int_{\Omega} w v d \Omega \\
& (w, v)_{\Gamma}=\int_{\Gamma} w v d \Gamma
\end{aligned}
$$

onde f, g e h são dadas como em (3.15).

Em [TEIXEIRA,1996] encontram-se as demonstrações de equivalência entre as formulações forte e fraca, bem como as demonstrações de existência, unicidade e regularidade da solução do problema térmico. 


\subsubsection{Formulação de Galerkin}

Sejam agora $K^{h}$ e $V^{h}$ aproximações para $K$ e $V$, com dimensão finita, de tal modo que se $v^{h} \in V^{h}$, então $v^{h} \approx 0$ em $\Gamma_{g}$ e, se $\theta^{h} \in K^{h}$ então $\theta^{h}$ admite a seguinte representação

$$
\theta^{h}=v^{h}+g^{h}
$$

onde $v^{h} \in V^{h}$ e $\mathrm{g}^{h} \approx g$ em $\Gamma_{g}$.

Escrevendo a formulação fraca em termos de $\theta^{h}$ e $v^{h}$, tem-se: encontrar o campo de temperaturas $\theta^{h}(x, t) \in K^{h}$ tal que

$$
\begin{aligned}
& a\left(w^{h}, \boldsymbol{\theta}^{h}\right)-\left(w^{h}, \rho c \dot{\theta}^{h}\right)=\left(w^{h}, f\right)+\left(w^{h}, h\right)_{\Gamma_{h}} \\
& \left(w^{h}, \rho c \boldsymbol{\theta}(x, 0)\right)=\left(w^{h}, \rho c \boldsymbol{\theta}_{0}\right)
\end{aligned}
$$

Como $\theta^{h}=v^{h}+g^{h}$, a formulação de Galerkin para o problema é dada por: encontrar $\theta^{h}$ $=v^{h}+g^{h}, \theta^{h}(x, t) \in K^{h}$, tal que

$$
a\left(w^{h}, v^{h}\right)+\left(w^{h}, \rho c \dot{v}^{h}\right)=\left(w^{h}, f\right)+\left(w^{h}, h\right)_{\Gamma_{h}}-\left(w^{h}, \rho c \dot{g}^{h}\right)-a\left(w^{h}, g^{h}\right) \quad \forall w^{h} \in V^{h}
$$

\subsubsection{Formulação matricial}

Discretizando o domínio pelo método dos elementos finitos, tem-se

$$
w^{h}=\sum_{A \in \eta \backslash \eta_{g}} N_{A}(\mathbf{x}) c_{A}=\sum_{A \in \eta_{e}} N_{A}(\mathbf{x}) c_{A}
$$

onde $w^{h}$ se anula se e só se $c_{A}=0 \forall A \in \eta \backslash \eta_{g}$,

$$
v^{h}=\sum_{A \in \eta \eta_{g}} N_{A}(\mathbf{x}) d_{A}(t)
$$

onde $d_{A}$ é a temperatura a calcular no nó $A$ e

$$
g^{h}=\sum_{A \in \eta_{g}} N_{A}(\mathbf{x}) g\left(\mathbf{x}_{A}, t\right)=\sum_{A \in \eta_{g}} N_{A}(\mathbf{x}) g_{A}(t)
$$

onde $\mathrm{N}_{\mathrm{A}}$ são as funções de forma ou de interpolação. 
Substituindo as expressões acima nas equações da formulação de Garlekin (3.16), temse

$$
\begin{aligned}
& a\left(\sum_{A \in \eta_{e}} N_{A} c_{A}, \sum_{B \in \eta_{e}} N_{B} d_{B}\right)+\left(\sum_{A \in \eta_{e}} N_{A} c_{A}, \rho c \sum_{B \in \eta_{e}} N_{B} \dot{d}_{B}\right)= \\
& \left(\sum_{A \in \eta_{e}} N_{A} c_{A}, f\right)+\left(\sum_{A \in \eta_{e}} N_{A} c_{A}, h\right)-a\left(\sum_{A \in \eta_{e}} N_{A} c_{A}, \sum_{B \in \eta_{e}} N_{B} g_{B}\right)-\left(\sum_{A \in \eta_{e}} N_{A} c_{A}, \rho c \sum_{B \in \eta_{e}} N_{B} \dot{g}_{B}\right) \Rightarrow \\
& \sum_{B \in \eta_{e}}\left[\left(N_{A}, \rho c N_{B}\right) \dot{d}_{B}+a\left(N_{A}, N_{B}\right) d_{B}\right]=\left(N_{A}, f\right)+\left(N_{A}, h\right)_{\Gamma}-\sum_{B \in \eta_{e}}\left[a\left(N_{A}, N_{B} g_{B}\right)+\left(N_{A}, \rho c N_{B} \dot{g}_{B}\right)\right]
\end{aligned}
$$

e de modo análogo

$$
\sum_{B \in \eta_{e}}\left(N_{A}, N_{B}\right) d_{B}(0)=\left(N_{A}, \rho c \theta_{0}\right)-\sum_{B \in \eta_{g}}\left(N_{A}, N_{B} g_{B}(0)\right)
$$

Assim, chega-se a seguinte formulação matricial do problema térmico [HUGHES,87]: dado $\mathbf{F}:] 0, T\left[\rightarrow I R^{n_{e q}}\right.$, encontrar o vetor das temperaturas nodais è $:[0, T] \rightarrow I R^{n_{e q}}$ tal que

$$
\begin{aligned}
& \mathbf{M} \dot{\theta}+\mathbf{K} \boldsymbol{\theta}=\mathbf{F}, \quad t \in] 0, T[ \\
& \boldsymbol{\theta}(\mathbf{0})=\theta_{\mathbf{0}}
\end{aligned}
$$

onde

$$
\begin{aligned}
& \mathbf{M}=\stackrel{\mathrm{nel}}{e=1}_{e} \mathbf{M}^{e}, \quad M_{A B}{ }^{e}=\left(N_{A}, \rho c N_{B}\right)_{\Omega^{e}} \\
& \mathbf{K}={\underset{e}{e=1}}_{\mathrm{nel}} \mathbf{K}^{e}, \quad K_{A B}{ }^{e}=a\left(N_{A}, N_{B}\right)_{\Omega^{e}} \\
& \mathbf{F}=\AA_{e=1}^{\mathrm{nel}} \mathbf{F}^{e}, \quad F_{A}{ }^{e}=\left(N_{A}, f\right)_{\Omega^{e}}+\left(N_{A}, h\right)_{\Gamma_{h}{ }^{e}}-\sum_{B \in \eta_{g}}\left(M_{A B}{ }^{e} \dot{g}_{B}{ }^{e}+K_{A B}^{e} g_{B}{ }^{e}\right)
\end{aligned}
$$

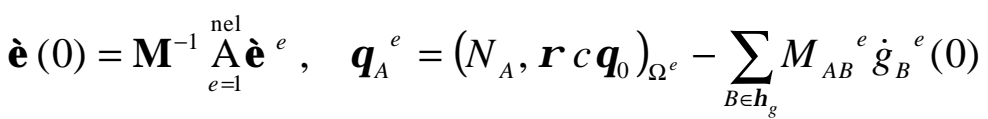

onde [B] é a matriz das derivadas das funções de forma.

Para resolver o problema matricial acima descrito, utilizou-se primeiramente o método trapezoidal generalizado para problemas lineares [HUGHES,87]. Porém, a estabilidade do método não é alcançada para valores do parâmetro $\alpha$ diferentes de um e, para este valor, a convergência é linear. 
Com o objetivo de alcançar estabilidade com uma convergência quadrática foi implementado o algoritmo proposto por [HUGHES,77], devidamente adaptado para o problema térmico com mudança de fase, que consiste em encontrar $\theta_{n}$ tal que

$$
\begin{aligned}
& \mathbf{M}_{n+\alpha} \dot{\boldsymbol{\theta}}_{n+\alpha}+\mathbf{K}_{n+\alpha} \boldsymbol{\theta}_{n+\alpha}=\mathbf{F}_{n+\alpha} \\
& \boldsymbol{\theta}_{n+\alpha}=\boldsymbol{\theta}_{n}+\int_{t_{n}}^{t_{n+1}} \dot{\boldsymbol{\theta}}(t) d t=\theta_{n}+\dot{\theta}_{n+\alpha} \Delta t
\end{aligned}
$$

onde $\Delta$ t é o passo de tempo, $\alpha \in[0,1], \theta_{n}$ aproximação de $\theta\left(t_{n}\right)$ e

$$
\begin{aligned}
& \mathbf{M}_{n+\alpha}=\mathbf{M}\left(\boldsymbol{\theta}_{n+\alpha}, \xi^{i}{ }_{n+\alpha}, t_{n+\alpha}\right) \\
& \mathbf{K}_{n+\alpha}=\mathbf{K}\left(\boldsymbol{\theta}_{n+\alpha}, \xi^{i}{ }_{n+\alpha}, t_{n+\alpha}\right) \\
& \boldsymbol{\theta}_{n+\alpha}=(1-\alpha) \boldsymbol{\theta}_{n}+\alpha \boldsymbol{\theta}_{n+1} \\
& \mathbf{F}_{n+\alpha}=(1-\alpha) \mathbf{F}_{n}+\alpha \mathbf{F}_{n+1} \\
& \dot{\theta}_{n+\alpha}=(1-\alpha) \dot{\theta}_{n}+\alpha \dot{\theta}_{n+1} \\
& t_{n+\alpha}=(n+\alpha) \Delta t
\end{aligned}
$$

cujos métodos incondicionalmente estáveis para o problema linear mantém esta propriedade no regime não linear, em particular para o método definido por $\alpha=0,5$, cuja convergência é quadrática [HUGHES,87]. As demonstrações detalhadas da estabilidade e da convergência deste método podem ser encontradas na referência citada.

No passo inicial $n=0, \boldsymbol{\theta}_{n}$ é conhecido e determina-se $\dot{\boldsymbol{\theta}_{n}}$ a partir de $\mathbf{M} \dot{\boldsymbol{\theta}}_{0}=\mathbf{F}_{0}-\mathbf{K} \boldsymbol{\theta}_{0}$. Considerando-se o passo genérico $n$, é necessário determinar uma primeira aproximação para $\theta_{n+1}$. A partir desse resultado calcula-se $\theta_{n+\alpha}$ e $\dot{\theta}_{n+\alpha}$, através de 3.21 c e 3.21 e, e $\theta_{n+1}$ e $\dot{\theta}_{n+1}$ até que a convergência seja alcançada, ou seja, $\frac{\left\|\theta_{n+1}^{k+1}-\theta_{n+1}^{k}\right\|}{\left\|\theta_{n+1}^{k}\right\|}<\varepsilon$, para algum $\varepsilon$ dado.

Para a determinação da primeira aproximação de $\theta_{n+1}$ utiliza-se o método trapezoidal generalizado para problemas lineares, dado por 


$$
\begin{aligned}
& \mathbf{M} \dot{\theta}_{n+1}+\mathbf{K} \boldsymbol{\theta}_{n+1}=\mathbf{F}_{n+1} \\
& \boldsymbol{\theta}_{n+1}=\theta_{n}+\int_{t_{n}}^{t_{n+1}} \dot{\theta}(t) d t=\theta_{n}+\dot{\theta}_{\alpha} \Delta t \\
& \dot{\theta}_{\alpha}=(1-\alpha) \dot{\theta}_{n}+\alpha \dot{\theta}_{n+1}
\end{aligned}
$$

onde $\boldsymbol{\theta}_{n}$ e $\dot{\theta}_{n}$ são aproximações de $\boldsymbol{\theta}\left(t_{n}\right)$ e $\dot{\boldsymbol{\theta}}\left(t_{n}\right), \mathbf{F}_{\mathbf{n}+\mathbf{1}}=\mathbf{F}\left(\mathrm{t}_{\mathrm{n}+1}\right), \Delta \mathrm{t}$ é o passo de tempo e $\alpha \in[0,1]$.

Em sua implementação na forma-V [HUGHES,87] define-se o preditor de $\theta_{n+1}$ por meio de $\tilde{\theta}_{n+1}=\theta_{n}+(1-\alpha) \Delta t \dot{\theta}_{n}$. Então

$$
\theta_{n+1}=\theta_{n}+(1-\alpha) \Delta t \dot{\theta}_{n}+\alpha \Delta t \dot{\theta}_{n+1} \Rightarrow \theta_{n+1}=\tilde{\theta}_{n+1}+\alpha \Delta t \dot{\theta}_{n+1}
$$

Substituindo em (3.22) obtêm-se

$$
[\tilde{\mathbf{M}}+\alpha \Delta t \tilde{\mathbf{K}}] \dot{\theta}_{n+1}=\mathbf{F}_{n+1}-\tilde{\mathbf{K}} \tilde{\boldsymbol{\theta}}_{n+1}
$$

onde $\tilde{\mathbf{M}}=\mathbf{M}\left(\tilde{\boldsymbol{\theta}}_{n+1}, \xi_{n+1}^{i}, t_{n}\right)$ e $\tilde{\mathbf{K}}=\mathbf{K}\left(\tilde{\boldsymbol{\theta}}_{n+1}, \xi_{n+1}^{i}, t_{n}\right)$, que vem a ser um sistema de equações algébricas lineares, cuja solução fornece $\dot{\theta}_{n+1}$. Substituindo a solução em (3.23) chega-se a $\theta_{n+1}$ e, consequentemente, a $\theta_{n+\alpha}$ e $\dot{\theta}_{n+\alpha}$ através de (3.21c) e (3.21e), respectivamente.

No caso particular $\alpha=0$, tem-se o método explícito de Euler e o cálculo da primeira aproximação para $\theta_{n+1}$ resume-se a

$$
\theta_{n+1}=\theta_{n}+\Delta t \dot{\theta}_{n}
$$

e $\dot{\boldsymbol{\theta}}_{n+1}$ é calculado resolvendo-se o sistema linear dado por $\mathbf{M}_{n} \dot{\theta}_{n+1}=\mathbf{F}_{n+1}-\mathbf{K}_{n} \boldsymbol{\theta}_{n+1}$.

Em cada iteração para o cálculo de $\theta_{n+1}$, calcula-se $\theta_{n+\alpha}$ e $\dot{\theta}_{n+\alpha}$ através de (3.21c) e (3.21e) respectivamente, e também $\mathbf{M}_{n+\alpha}, \mathbf{K}_{n+\alpha}$ e $\mathbf{F}_{n+\alpha}$ através de (3.21a), (3.21b) e (3.21d).

Desse modo, a equação (3.20) pode ser escrita utilizando-se (3.21c), (3.21d) e $\dot{\theta}_{n+\alpha}=\frac{\theta_{n+1}-\theta_{n}}{\Delta t}$, ou seja, 


$$
\mathbf{M}_{n+\alpha}\left(\frac{\boldsymbol{\theta}_{n+1}-\boldsymbol{\theta}_{n}}{\Delta t}\right)+\mathbf{K}_{n+\alpha}\left[(1-\alpha) \boldsymbol{\theta}_{n}+\alpha \boldsymbol{\theta}_{n+1}\right]=(1-\alpha) \mathbf{F}_{n}+\alpha \mathbf{F}_{n+1}
$$

e assim chega-se a

$$
\left[\mathbf{M}_{n+\alpha}+\alpha \Delta t \mathbf{K}_{n+\alpha}\right] \theta_{n+1}=\left[\mathbf{M}_{n+\alpha}-\Delta t(1-\alpha) \mathbf{K}_{n+\alpha}\right] \theta_{n+1}+\Delta t(1-\alpha) \mathbf{F}_{n}+\Delta t \alpha \mathbf{F}_{n+1}
$$

cuja solução fornece um novo valor para $\theta_{n+1}$ e $\dot{\theta}_{n+1}$ é calculado através de

$$
\mathbf{M}_{n} \dot{\theta}_{n+1}=\mathbf{F}_{n+1}-\mathbf{K}_{n} \boldsymbol{\theta}_{n+1}
$$

O fluxograma do algoritmo de análise térmica acoplada à mudança de fase é apresentado na página seguinte. 


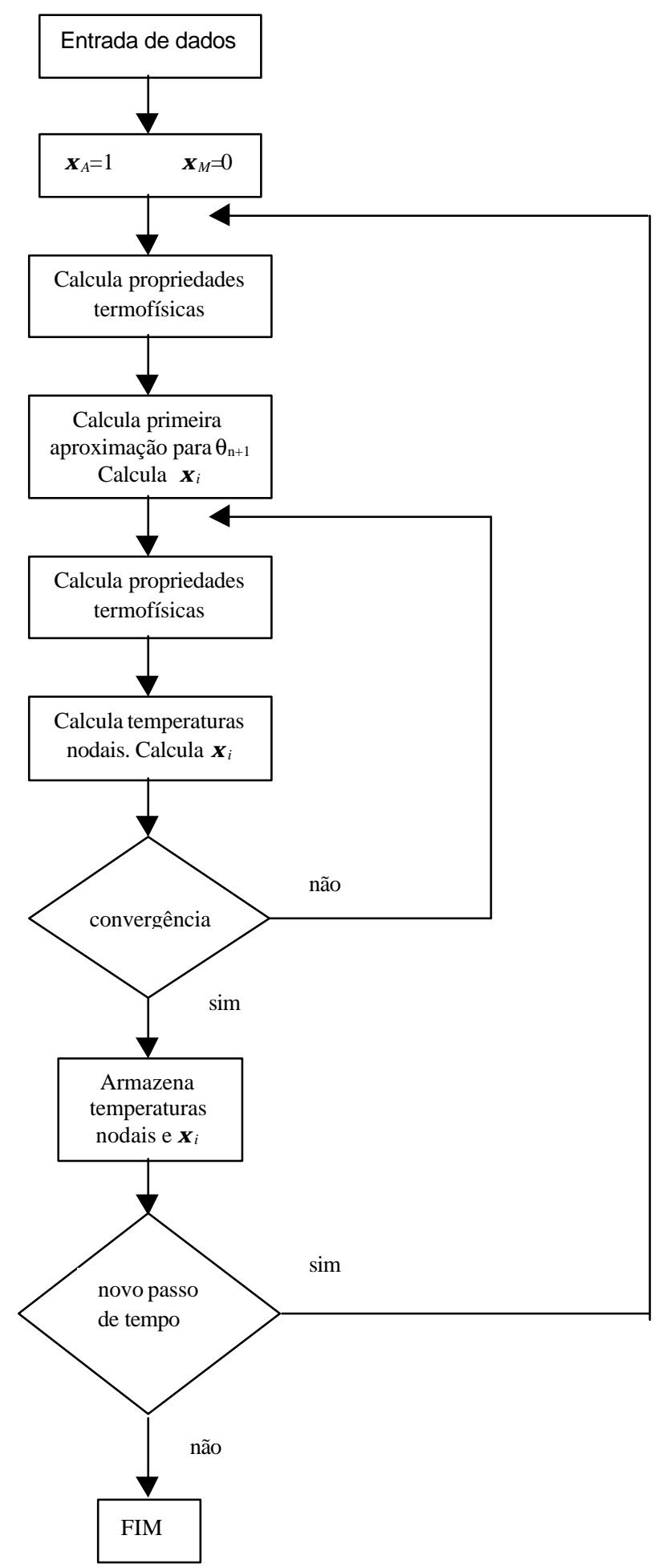

Figura 3.1 : fluxograma para análise térmica transiente não-linear 
A título de comparação, implementou-se a resolução do problema matricial (3.19) utilizando-se o método trapezoidal generalizado para problemas lineares. Desse modo, devido a forte natureza não linear do problema e ao acentuado choque térmico sofrido pela peça, fazse necessário a utilização de um passo de tempo bastante pequeno. Porém, foi notado que esta necessidade diminui com o passar do tempo, geralmente após $2 s$ de análise, uma vez que a temperatura da borda e do centro da peça estão mais próximas e o gradiente de temperatura apresenta-se menor. Desse modo, a partir desse momento não é mais necessário um passo de tempo tão pequeno. Para tornar o programa mais rápido sem deixar de ser convergente nos instantes iniciais da análise, é realizado um refinamento do passo de tempo, verificando-se a cada segundo de análise da variação relativa do vetor de temperaturas em relação ao passo anterior. Caso esta variação seja menor ou maior que uma certa tolerância então o passo de tempo é dividido ou multiplicado, respectivamente, por um fator. Desse modo, a análise numérica não fica prejudicada nos instantes iniciais, onde a não linearidade é maior, e o programa gera resultados mais rápidos, sem perder em convergência.

Notou-se que, devido a estabilidade do método proposto por [HUGHES,1977] para o problema térmico não-linear e a convergência quadrática utilizando $\alpha=0,5$, este foi cerca de duas vezes mais rápido do que o algoritmo para o problema térmico linear, aplicado a um mesmo exemplo de análise numérica da distribuição de temperatura e de fração parcial, durante $13 \mathrm{~s}$ de têmpera de um cilindro de ferro-níquel.

\subsection{Problema mecânico}

A influência que o campo de temperaturas e as transformações de fase exercem sobre as propriedades mecânicas de materiais metálicos, como a taxa de encruamento, é fundamental para as aplicações comerciais de tratamento de calor. Por isso, propriedades como módulo de 
Young E, módulo de Poisson $v$, tensão de escoamento $\sigma_{\mathrm{y}}$ e a função de escoamento passam a ser funções da temperatura, da concentração de cada componente e, em caso de problemas elasto-visco-plásticos, do tempo.

Além de influir nas propriedades mecânicas, a transformação de fase também influi no comportamento mecânico, neste caso denominado plasticidade induzida por transformação (PIT).

\subsubsection{Plasticidade induzida por transformação}

Quando uma transformação de fase ocorre na presença de tensões internas ou tensões aplicadas, as mudanças de dimensão do material são afetadas pela magnitude das tensões, como se o material tivesse sido sujeito a uma deformação plástica, mesmo para estados de tensão abaixo da tensão de escoamento do material.

A primeira tentativa de reproduzir numericamente este fenômeno foi feita, como em [ARGIRYS, 1985], através da diminuição artificial do limite elástico durante o intervalo de tempo em que ocorre a transformação de fase.

Posteriormente, a maioria das expressões para calcular a plasticidade por transformação em modelos matemáticos foram desenvolvidas baseadas no modelo e nas interpretações para este fenômeno desenvolvidas por Greenwood e Johnson (1965), que consideraram que a plasticidade induzida por transformação ocorre como conseqüência de fluxo microscópico em pontos onde uma concentração de tensão excede localmente a tensão de escoamento da fase mais fraca do material. Esta tensão seria o resultado combinado da tensão interna gerada pela variação de volume durante a transformação com tensões externas aplicadas, mesmo que estas tensões externas estivessem abaixo do limite de escoamento. Neste caso, a deformação plástica induzida pela transformação, que ocorreria na direção das tensões aplicadas, seria dada por 


$$
\varepsilon^{p t}=\frac{5}{6} \frac{\sigma}{\sigma_{E}} \frac{\Delta V}{V}
$$

onde $\sigma$ é a tensão uniaxial aplicada, $\sigma_{\mathrm{E}}$ a tensão de escoamento da fase mais fraca, e $\Delta V / V$ é a variação de volume sofrida pela peça.

Abrassart modificou este modelo e introduziu a quantidade de martensita formada, resultando em [DENIS et al, 1985]

$$
\varepsilon^{p t}=\frac{3}{4} \frac{\sigma}{\sigma_{E}} \frac{\Delta V}{V}\left(\xi_{M}-\frac{2}{3}\left(\xi_{M}\right)^{3 / 2}\right)
$$

porém conseguiu resultados menos satisfatórios que os encontrados por Greenwood e Johnson.

O modelo proposto por Scheil considera que, quando a transformação martensítica ocorre sob tensões aplicadas, o produto resultante escolhe uma orientação que minimiza a energia total, incluindo a energia resultante das tensões aplicadas. Os diversos parâmetros necessários para quantificar a deformação plástica induzida deste modelo são, na prática, difíceis de se obter. Porém, este modelo considera o caso de transformação de fase para materiais onde $\Delta V / V$ é muito pequeno e orientações preferenciais são observadas [DENIS et al, 1985].

Outros modelos, como os de Clinard \& Sherby [Clinard\&Shelby,1964] e Poirier [Poirier,1982] foram propostos mas, devido a ausência de dados, não foram confirmados ou comparados com dados experimentais

No caso de transformação martensítica, a orientação preferencial e a acomodação das tensões internas podem contribuir para a plasticidade por transformação, mesmo sendo difícil quantificar a contribuição de cada um desses fenômenos. Notou-se, porém, que a relação entre a acomodação das tensões internas e a quantidade de produto transformado obedece a uma 
relação mais próxima da linear do que, por exemplo, aquela proposta pelo modelo de Abrassart.

A figura 3.2 mostra curvas experimentais e calculadas pelo método de Abrassart da PIT x percentual de martensita transformada para uma liga de Fe Ni C [Denis et al, 1985]. Nota-se que, apesar das curvas serem similares, os valores calculados pelo método citado estão bem abaixo dos valores medidos. Na mesma referência vê-se que a aplicação do modelo de Greenwood-Johnson resulta em valores super dimensionados para a deformação plástica induzida.

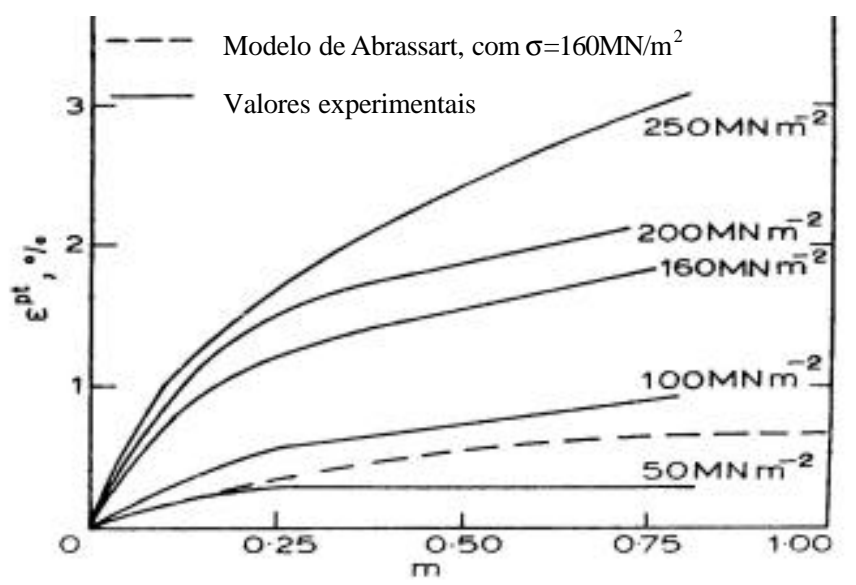

Figura 3.2: plasticidade induzida por transformação $\mathrm{x}$ fração parcial de martensita transformada, para diferentes tensões aplicadas. Aço Fe - 0,5C - 20Ni [DENIS et al,1985]

O rápido aumento de $\varepsilon^{\mathrm{pt}}$ no início da reação sugere ser uma conseqüência de orientação preferencial, com a parte linear correspondendo a contribuição das acomodações das tensões internas.

Um modelo matemático mais preciso e sofisticado para este fenômeno foi proposto por Giusti e utilizado em [NAGASAKA,1993] e neste trabalho. Neste modelo, a deformação plástica induzida por transformação para estados triaxiais de tensão é dada, em sua forma incremental, por

$$
d \varepsilon_{i j}^{p t}=\frac{3}{2}\left(\frac{\left(d \varepsilon_{e}^{p t}\right)_{M}}{\sigma_{e}}\right) \sigma_{i j}^{\prime}
$$


onde $\left(d \varepsilon_{e}^{p t}\right)_{m}$ é definida como uma deformação plástica equivalente de transformação martensítica, dada por

$$
\left(d \varepsilon_{e}^{p t}\right)_{M}=2 K_{M} \sigma_{e}\left(1-\xi_{M}\right) d \xi_{M}
$$

$\operatorname{com} \xi_{M}$ sendo a fração parcial de martensita transformada, $\sigma_{e}$ a tensão equivalente, $\sigma$ ' o tensor desviador e $K_{m}$ uma constante do material para a fase transformada. Nota-se que, neste modelo, as deformações resultantes da transformação martensítica são anisotrópicas, como desejado. Em [LEBLOND et al, 1985] encontram-se argumentos heurísticos que justificam a utilização da equação acima.

\subsubsection{Relação tensão-deformação}

A lei incremental que governa o comportamento elastoplástico sob condições nãoisotérmicas e considerando o efeito da transformação de fase é dada por

$$
d \varepsilon_{i j}=d \varepsilon_{i j}^{e}+d \varepsilon_{i j}^{p}+d \varepsilon_{i j}^{t h}+d \varepsilon_{i j}^{t r}+d \varepsilon_{i j}^{P I T}
$$

com $d \varepsilon_{i j}^{e}$ e $d \varepsilon_{i j}^{p}$ sendo o incremento de deformação elástica e plástica, respectivamente,

decorrentes da aplicação de carregamento mecânico, $d \varepsilon_{i j}^{\text {th }}$ a parcela relativa aos efeitos de dilatação térmica, $d \varepsilon_{i j}^{t r}$ a parcela relativa aos efeitos de expansão de volume devido à transformação da austenita em martensita, e $d \varepsilon_{i j}^{P I T}$ a plasticidade induzida pela transformação martensítica.

Desse modo, a tensão resultante é dada por

$$
\sigma_{i j}=D\left[\varepsilon_{i j}-\varepsilon_{i j}^{p}-\varepsilon_{i j}^{t h}-\varepsilon_{i j}^{t r}-\varepsilon_{i j}^{P I T}\right]
$$

e em sua forma diferencial,

$$
d \sigma_{i j}=D\left[d \varepsilon_{i j}-d \varepsilon_{i j}^{p}-d \varepsilon_{i j}^{t h}-d \varepsilon_{i j}^{t r}-d \varepsilon_{i j}^{P I T}\right]+d D\left[\varepsilon_{i j}-\varepsilon_{i j}^{p}-\varepsilon_{i j}^{t h}-\varepsilon_{i j}^{t r}-\varepsilon_{i j}^{P I T}\right]
$$


uma vez que os parâmetros elásticos dependem da temperatura e da fração parcial dos constituintes, ou seja, $D=D\left(\theta, \xi_{i}\right)$, e assim $d D=\frac{\partial D}{\partial \theta} d \theta+\frac{\partial D}{\partial \xi_{i}} d \xi_{i}$. Desse modo, pode-se escrever $d D\left[\varepsilon_{i j}-\varepsilon_{i j}^{p}-\varepsilon^{t h}{ }_{i j}-\varepsilon_{i j}^{t r}-\varepsilon^{P I T}\right]=\left(\frac{\partial D}{\partial \theta} d \theta+\frac{\partial D}{\partial \xi_{i}} d \xi_{i}\right) D^{-1} \sigma_{i j}$

Além disso, o incremento de deformação térmica é dado por

$$
d \varepsilon^{\text {th }}{ }_{i j}=\alpha d \theta \boldsymbol{e}
$$

e o incremento de deformação devido a transformação de fase

$$
d \varepsilon^{t r}{ }_{i j}=K_{i} d \xi_{i} e
$$

onde $\boldsymbol{e}$ é o vetor $\left(\begin{array}{lll}1 & 1 & 1\end{array}\right)$.

Substituindo as expressões acima na forma diferencial (3.25) obtêm-se

$$
\begin{aligned}
d \sigma & =\left(\frac{\partial D}{\partial \theta} d \theta+\frac{\partial D}{\partial \xi_{i}} d \xi_{i}\right) D^{-1} \sigma_{i j}+D\left[d \varepsilon_{i j}-d \varepsilon_{i j}^{p}-\alpha d \theta \mathbf{e}-K_{i} d \xi_{i}-d \varepsilon_{i j}^{P I T}\right]= \\
& =D\left[d \varepsilon_{i j}-d \varepsilon_{i j}^{p}-d \theta\left(\alpha \mathbf{e}-D^{-1} \frac{\partial D}{\partial \theta} D^{-1} \sigma_{i j}\right)-d \xi_{i}\left(K_{i} \mathbf{e}-D^{-1} \frac{\partial D}{\partial \xi_{i}} D^{-1} \sigma_{i j}\right)-d \varepsilon_{i j}^{P I T}\right]= \\
& =D\left[d \varepsilon_{i j}-d \varepsilon_{i j}^{p}-d \varepsilon_{i j}^{t h^{*}}-d \varepsilon_{i j}^{t^{*}}-d \varepsilon_{i j}^{P I T}\right]
\end{aligned}
$$

onde

$$
d \varepsilon_{i j}^{t{ }^{*}}=\left(\alpha \mathbf{e}-D^{-1} \frac{\partial D}{\partial \theta} D^{-1} \sigma_{i j}\right) d \theta=\alpha^{*} d \theta
$$

é a contribuição da variação de temperatura no incremento de deformação e

$$
d \varepsilon_{i j}^{t r^{*}}=\left(K_{i} \mathbf{e}-D^{-1} \frac{\partial D}{\partial \xi_{i}} D^{-1} \sigma_{i j}\right) d \xi_{i}=K^{*} d \xi_{i}
$$

é o incremento de deformação gerado pela transformação de fase

Utilizando-se a teoria associada da plasticidade, tem-se que o componente plástico da deformação é dado por 


$$
d \varepsilon_{i j}^{p}=d \lambda \frac{\partial f}{\partial \sigma_{i j}}
$$

onde $d \lambda$ é o multiplicador plástico e $f=f\left(\sigma, \bar{\varepsilon}^{p}, \theta, \xi_{i}\right)$ é a função de escoamento, que depende do estado de tensão, da deformação plástica equivalente, da temperatura e das frações parciais dos componentes.

A condição de consistência da plasticidade estabelece $d f=0$. Diferenciando-se a função de escoamento, tem-se

$$
\frac{\partial f}{\partial \sigma} d \sigma+\frac{\partial f}{\partial \bar{\varepsilon}^{p}} d \bar{\varepsilon}^{p}+\frac{\partial f}{\partial \theta} d \theta+\frac{\partial f}{\partial \xi_{i}} d \xi_{i}=0
$$

Como $d \bar{\varepsilon}^{p}=d \lambda$, e substituindo-se a expressão de $d \sigma$ na equação acima, chega-se a uma expressão para o multiplicador plástico $d \lambda$, dada por

$$
d \lambda=\frac{1}{\left[\frac{\partial f}{\partial \sigma} D \frac{\partial f}{\partial \sigma}-\frac{\partial f}{\partial \bar{\varepsilon}^{p}}\right]}\left[\frac{\partial f}{\partial \sigma} D\left(d \varepsilon-d \varepsilon^{t h^{*}}-d \varepsilon^{t r^{*}}-d \varepsilon^{P I T}\right)+\frac{\partial f}{\partial \theta} d \theta+\frac{\partial f}{\partial \xi_{i}} d \xi_{i}\right]
$$

Substituindo-se a expressão acima na expressão de $d \varepsilon_{i j}^{p}$ e esta em (3.26), obtém-se a relação tensão-deformação incremental para materiais termo-elasto-plásticos, considerando-se a mudança de fase, dada por

$$
d \sigma=D^{e p}\left[d \varepsilon-d \varepsilon^{t h^{*}}-d \varepsilon^{t r^{*}}-d \varepsilon^{P I T}\right]-\frac{D \frac{\partial f}{\partial \sigma}}{\bar{H}}\left[\frac{\partial f}{\partial \theta} d \theta+\frac{\partial f}{\partial \xi_{i}} d \xi_{i}\right]
$$

$\operatorname{com} D^{e p}$ sendo a matriz constitutiva elasto-plástica dada por

$$
D^{e p}=D-\frac{D \frac{\partial f}{\partial \sigma} \frac{\partial f}{\partial \sigma} D}{\bar{H}}
$$

e

$$
\bar{H}=\frac{\partial f}{\partial \sigma} D \frac{\partial f}{\partial \sigma}-\frac{\partial f}{\partial \bar{\varepsilon}^{p}}
$$




\subsubsection{Implementação computacional}

Como critério de plastificação é utilizado neste trabalho o critério de von Mises, ou seja,

$$
\begin{aligned}
f\left(\sigma, \bar{\varepsilon}^{p}, \theta, \xi_{i}\right) & =\bar{\sigma}-\sigma_{y}\left(\bar{\varepsilon}^{p}, \theta, \xi_{i}\right)=\bar{\sigma}-\xi_{A} \sigma_{y}^{A}\left(\bar{\varepsilon}^{p}, \theta\right)-\xi_{M} \sigma_{y}^{M}\left(\bar{\varepsilon}^{p}, \theta\right) \\
& =\bar{\sigma}-\left(1-\xi_{M}\right) \sigma_{y}^{A}\left(\bar{\varepsilon}^{p}, \theta\right)-\xi_{M} \sigma_{y}^{M}\left(\bar{\varepsilon}^{p}, \theta\right)
\end{aligned}
$$

Desse modo, tem-se que

$$
\frac{\partial f}{\partial \bar{\varepsilon}^{p}}=-\frac{\partial \sigma_{y}}{\partial \bar{\varepsilon}^{p}}=-H^{\prime}=-\xi_{A} H_{A}^{\prime}-\xi_{M} H_{M}^{\prime}
$$

onde $H^{\prime}$ é a inclinação local da curva tensão/deformação plástica uniaxial, e pode ser determinada para cada componente $i$ experimentalmente por $H_{i}^{\prime}=E_{T i} /\left(1-\frac{E_{T i}}{E_{i}}\right)$, onde $E_{i} \mathrm{e}$ $E_{T i}$ são, respectivamente, o módulo elástico e o módulo tangente elasto-plástico do i-ésimo componente.

Além disso, tem-se que a direção do fluxo plástico é dada em sua forma vetorial por [OWEN,1980]

$$
\frac{\partial f}{\partial \sigma}=\sqrt{3} \frac{\partial\left(J_{2}^{\prime}\right)^{1 / 2}}{\partial \sigma}=\frac{\sqrt{3}}{2\left(J_{2}^{\prime}\right)^{1 / 2}}\left\{\sigma_{x}^{\prime}, \sigma_{y}^{\prime}, \sigma_{z}^{\prime}, 2 \tau_{y z}, 2 \tau_{z x}, 2 \tau_{x y}\right\}
$$

onde $\sigma^{\prime}$ representa as tensões desviadoras, $J_{2}^{\prime}$ o segundo invariante da tensão desviadora e $f_{\xi_{i}}=-\sigma^{i}$

Os dados dos materiais obtidos na bibliografia, e utilizados no Capítulo 4, são aproximados por funções splines. Desse modo, obtêm-se facilmente os valores dos parâmetros elásto-plásticos e de $\frac{\partial f}{\partial \theta}$ para cada temperatura e quantidade de fração transformada.

Para a obtenção do problema matricial utiliza-se o princípio do trabalho virtual, que requer que

$$
\int_{\Omega}\left(\delta \varepsilon^{{ }^{* T}} \sigma-\delta u^{{ }^{*} T}\right) d \Omega-\delta d^{{ }^{* T}} f=0
$$


onde $\sigma$ são as tensões internas, $b$ a carga distribuída por unidade de volume, $f$ as forças aplicadas e $\delta d^{*}$ um deslocamento virtual arbitrário que resulta em deformações $\delta \varepsilon^{*}$ e deslocamentos internos $\delta u^{*}$.

Discretizando a geometria por elementos finitos como feito para o problema térmico na Seção 3.1.4, os deslocamentos e deformações dentro de cada elemento são descritos como

$$
\begin{aligned}
& \delta u^{*}=\mathbf{N} \delta d^{*} \\
& \delta \varepsilon^{*}=\mathbf{B} \delta d^{*}
\end{aligned}
$$

onde $\mathbf{N}$ é a matriz de funções de forma e $\mathbf{B}$ a matriz de derivadas dos funções de forma.

Desse modo, a expressão (3.29) pode ser escrita como

$$
\int_{\Omega} \delta d^{*}\left(\mathbf{B}^{T} \sigma-\mathbf{N}^{T} b\right) d \Omega-\delta d^{* T} f=0 \quad \forall \delta d^{*}
$$

onde a integral acima é a soma das contribuições individuais dos elementos.

Para problemas não-lineares, da expressão chega-se à expressão incremental do vetor de força desequilibrada, dado por

$$
\Delta \Psi=\int_{\Omega} \mathbf{B}^{T} \Delta \sigma d \Omega-\left(\Delta f+\int_{\Omega} \mathbf{N}^{T} \Delta b d \Omega\right)=0
$$

Substituindo a expressão de $d \sigma$ dada em (3.28) na equação (3.30), obtém-se

$$
\begin{array}{r}
\Delta \Psi=\int_{\Omega} \mathbf{B}^{T} D^{e p} \Delta \varepsilon d \Omega-\left[\Delta f+\int_{\Omega} \mathbf{N}^{T} \Delta b d \Omega+\int_{\Omega} \mathbf{B}^{T} \mathbf{D}^{e p}\left(d \varepsilon^{t h^{*}}+d \varepsilon^{t r^{*}}+d \varepsilon^{P I T}\right) d \Omega\right. \\
\left.+\int_{\Omega} \mathbf{B}^{T} \mathbf{D} \frac{\partial f}{\partial \sigma} \frac{1}{\bar{H}}\left(\frac{\partial f}{\partial \theta} d \theta+\frac{\partial f}{\partial \xi_{i}} d \xi_{i}\right) d \Omega\right]=0
\end{array}
$$

que em sua forma matricial pode ser escrita como

$$
[K]\{\Delta d\}-\{\Delta F\}=0
$$


onde $[K]$ é a matriz de rigidez tangente do material, dada por $[K]=\int_{\Omega} \mathbf{B}^{T} D^{e p} \mathbf{B} \Delta \mathbf{d} d \Omega$ e $\{\Delta F\}=\{\Delta f\}+\{\Delta b\}+\left\{\Delta F^{t h}\right\}+\left\{\Delta F^{t r}\right\}+\left\{\Delta F^{P I T}\right\}$ é o vetor de incremento de forças, onde $\{\Delta f\}$ é o vetor de forças externas aplicadas,

$\{\Delta b\}$ o vetor de forças de corpo,

$$
\left\{\Delta F^{t h}\right\}=\int_{\Omega}\left(\mathbf{B}^{T} \mathbf{D}^{e p} d \varepsilon^{t h^{*}}+\mathbf{B}^{T} \mathbf{D} \frac{\partial f}{\partial \sigma} \frac{1}{\bar{H}} \frac{\partial f}{\partial \theta} d \theta\right) d \Omega \text { é o vetor de forças }
$$

geradas por efeito térmico,

$$
\left\{\Delta F^{t r}\right\}=\int_{\Omega}\left(\mathbf{B}^{T} \mathbf{D}^{e p} d \varepsilon^{t r^{*}}+\mathbf{B}^{T} \mathbf{D} \frac{\partial f}{\partial \sigma} \frac{1}{\bar{H}} \frac{\partial f}{\partial \xi_{i}} d \xi_{i}\right) d \Omega \text { o vetor de forças }
$$

gerado pelas transformações de fase e

$$
\left\{\Delta F^{P I T}\right\}=\int_{\Omega} \mathbf{B}^{T} \mathbf{D}^{e p} d \varepsilon^{P I T} d \Omega \text { o vetor de forças geradas pela deformação }
$$

plástica induzida por transformação.

Para a resolução do problema matricial não-linear acima optou-se pelo método de Newton-Raphson padrão, dado por

$$
\Delta d^{n}=-\left[K\left(d^{n}\right)\right]^{-1} \Delta F
$$

O fluxograma do método implementado neste trabalho e o respectivo algoritmo podem ser vistos nas figuras 3.3 e 3.4. Para o cálculo das tensões em cada ponto de Gauss, realizado quando da montagem do vetor de forças internas e da matriz de rigidez como apresentado no algoritmo da figura 3.4, utiliza-se o método de retorno radial à superfície de escoamento, dado pelo algoritmo apresentado na figura 3.5. 


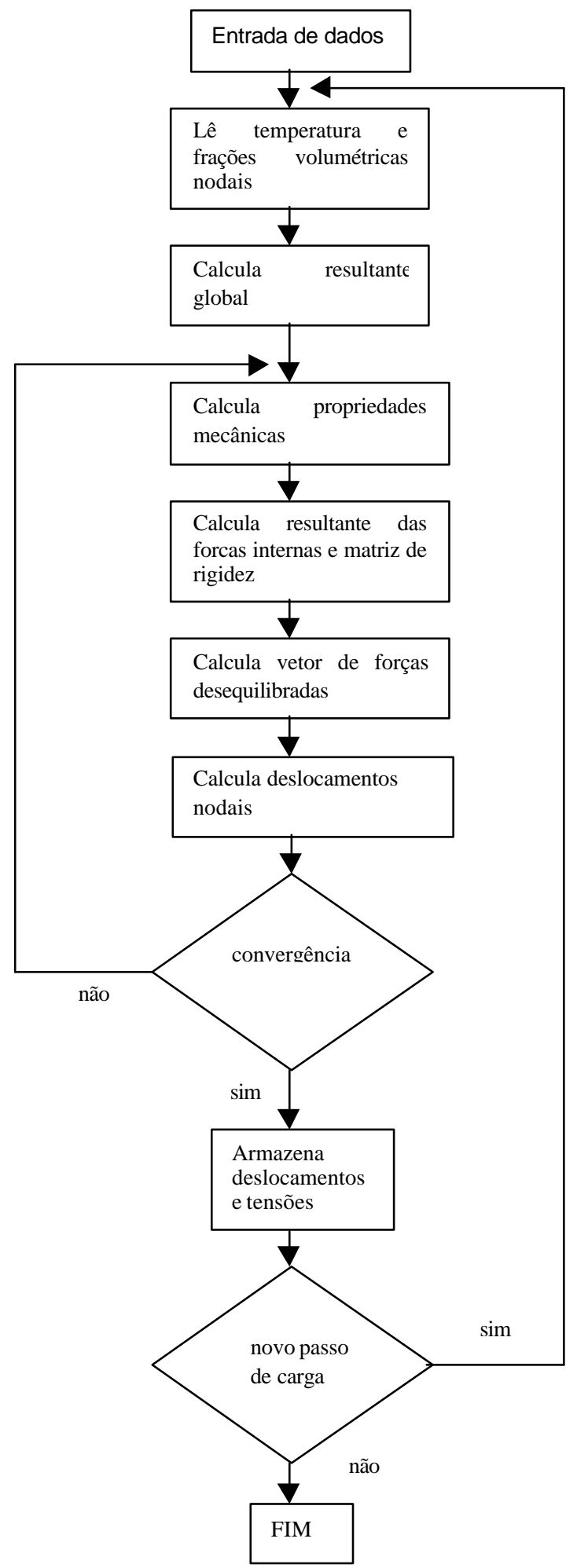

Figura 3.3 : fluxograma para análise de tensões 
para cada incremento de carga faça

lê distribuição de temperatura e frações parciais

enquanto não convergir faça

monta matriz de rigidez e vetor de carga

percorre elementos

percorre ponto de Gauss

calcula tensão

monta matriz de rigidez do elemento

monta vetor de carga do elemento

monta matriz de rigidez

monta vetor de carga

resolve sistema linear

atualiza deslocamentos nodais

verifica convergência

salva resultados

Figura 3.4 : algoritmo para análise de tensões 
calcula deformação térmica:

calcula preditor: $\left\{\begin{array}{l}d \sigma_{n+1}^{*}=D_{n+1}\left[d \varepsilon_{n+1}-d \varepsilon_{n+1}^{t h}-d \varepsilon_{n+1}^{t r}-d \varepsilon_{n+1}^{P I T}-d \varepsilon_{n}^{P}\right] \\ \sigma_{n+1}^{*}=\sigma_{n+1}+d \sigma_{n+1}^{*}\end{array}\right.$

se $F\left(\sigma_{n}, \bar{\varepsilon}_{n}^{P}, \theta_{n}, \xi_{n}\right)<0$ então $\sigma_{n+1} \leftarrow \sigma^{*}{ }_{n+1}$

senão

se $F\left(\sigma_{n}, \bar{\varepsilon}_{n}^{P}, \theta_{n}, \xi_{n}\right)>0$ então $r=1$

senão $r=\frac{\overline{\boldsymbol{\sigma}}_{n+1}^{*}-\sigma_{y}\left(\theta_{n+1}, \bar{\varepsilon}_{n}^{P}, \xi_{n+1}\right)}{\overline{\boldsymbol{\sigma}}_{n+1}^{*}-\overline{\boldsymbol{\sigma}}_{n}}$

calcula estado de tensões na superfície de F: $\sigma_{\text {sup }} \leftarrow \sigma_{n}+(1-r) \Delta \sigma_{n+1}^{*}$

calcula direção do fluxo plástico $a^{t}=\frac{\partial F}{\partial \sigma}\left(\sigma_{\text {sup }}, \bar{\varepsilon}_{n}^{P}, \theta_{n+1}, \xi_{n+1}\right)$

calcula módulo plástico $d \lambda$ como em (4.3)

calcula novo estado de tensões $\sigma_{n+1}=\sigma_{n}+\Delta \sigma^{*}{ }_{n+1}-d \lambda a^{t} D$

calcula deformação plástica equivalente $\bar{\varepsilon}_{n+1}^{P}=\bar{\varepsilon}_{n}^{P}+\frac{d \lambda a^{t} \sigma_{\text {sup }}}{\bar{\sigma}_{\text {sup }}}$

calcula tensão equivalente $\bar{\sigma}_{n+1}$

calcula tensão de escoamento $\sigma_{y}\left(\theta_{n+1}, \bar{\varepsilon}_{+1 n}^{P}, \xi_{n+1}\right)$

recalcula $\sigma_{n+1}=\sigma_{n+1} \frac{\sigma_{y}\left(\theta_{n+1}, \bar{\varepsilon}_{n}^{P}, \xi_{n+1}\right)}{\bar{\sigma}_{n+1}}$

Figura 3.5 : algoritmo para cálculo do estado de tensões no ponto de Gauss 


\section{4 - RESULTADOS NUMÉRICOS}

Para a geração dos resultados numéricos foram desenvolvidos dois programas que interagem entre si: um para análise térmica e cálculo das frações parciais transformadas e outro para análise de tensões, visando o estudo de tensões geradas em tratamentos térmicos, em particular da têmpera de peças de aços.

O programa para análise térmica e de micro-estrutura resolve problemas estacionários e transientes, tanto lineares quanto não lineares. Além disso é possível considerar a têmpera progressiva, em que o jato de água incide sobre uma parte da peça a ser temperada a cada instante de tempo. Como citado no Capítulo 3, foi implementado um algoritmo para adaptação do passo de tempo, visando uma maior velocidade nos cálculos sem comprometer os resultados obtidos.

Neste Capítulo os resultados referem-se a transformações de fase adifusionais (austenita-martensita) que ocorrem em ligas ferro-níquel, utilizando-se o modelo de Koistiner e Marburger. Todos os parâmetros térmico do material dependem da temperatura e das frações parciais de cada componente.

O programa para análise mecânica considera deformações mecânicas bem como deformações térmicas, volumétricas de transformação e deformações plásticas induzidas pela transformações. Para o cálculo desta última é utilizado o modelo proposto por Giusti [GIUSTI,1981].

Para a geração das malhas e posterior visualização dos resultados foi utilizado o programa MTOOL, desenvolvido no TecGraf da Pontifícia Universidade Católica do Rio de Janeiro. 


\subsection{Análise térmica}

Neste item são apresentados alguns exemplos de análise por elementos finitos do problema térmico, com o objetivo de validar resultados posteriores.

Exemplo 4.1.1: Este exemplo trata do problema da transmissão de calor por condução em regime transiente, com geração interna de calor. Considera-se um reator submerso cujo núcleo é constituído de um número de placas verticais de espessura $2 L$. Inicialmente o sistema possui temperatura uniforme $T_{\infty}$. Assume-se que a energia interna constante $u^{\text {',' }}$ é gerada uniformemente nestas placas. O coeficiente de transferência de calor entre as placas e o fluido é dado por $h$. A temperatura do fluido permanece constante e a espessura das placas é pequena quando comparada coma as outras dimensões.

Assim, se os efeitos de borda são desprezados, a transferência de calor pode ser assumida como unidimensional.

A solução deste problema, assumindo-se um coeficiente de transferência de calor elevado $(\mathrm{h} \mapsto \infty)$, resulta na seguinte distribuição de calor [ARPACI,1966]:

$$
\frac{\theta(x, t))}{u^{\prime \prime \prime} L^{2} / \kappa}=\frac{1}{2}\left[1-\left(\frac{x}{L}\right)^{2}\right]-2 \sum_{n=0}^{\infty} \frac{(-1)^{n}}{\left(\lambda_{n} L\right)^{2}} e^{-a \lambda_{n}^{2} t} \cos \left(\lambda_{n} x\right)
$$

onde $\theta=T-T_{\infty}, a=\frac{\kappa}{\rho c}$, com $\kappa, \rho$ e c representando, respectivamente, a condutividade térmica, a densidade e a capacidade térmica do meio e $\lambda_{n} L=(2 n+1) \pi / 2, n=0,1,2, \ldots$

Utilizando-se $T_{\infty}=293,15^{\circ} \mathrm{K}, L=25,0 \mathrm{~mm}, u^{\prime,}{ }^{\prime}=8122,0 \mathrm{~W} / \mathrm{m}^{3}, \mathrm{c}=460,0 \mathrm{~J} / \mathrm{Kg}{ }^{o} \mathrm{~K}, \rho=$ $8618,0 \mathrm{Kg} / \mathrm{m}^{3}$ e $\kappa=35,0 \mathrm{~W} / \mathrm{m}^{\circ} \mathrm{K}$ como dados de entrada e uma malha de elementos finitos com 28 nós, 5 elementos isoparamétricos Q8 e 4 pontos de Gauss por elemento (figura 4.1), obtêm-se as distribuições de temperatura mostradas na figura 4.2, juntamente com a solução analítica correspondente para diferentes instantes. 


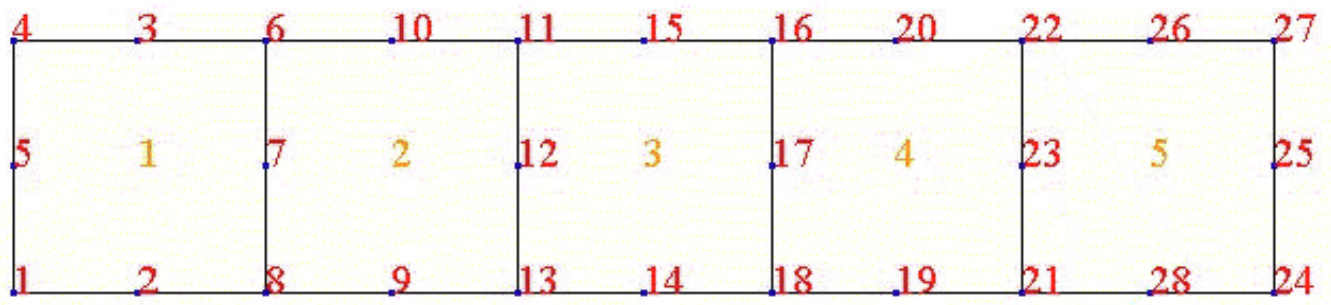

Figura 4.1: malha de elementos finitos para o exemplo 4.4.1

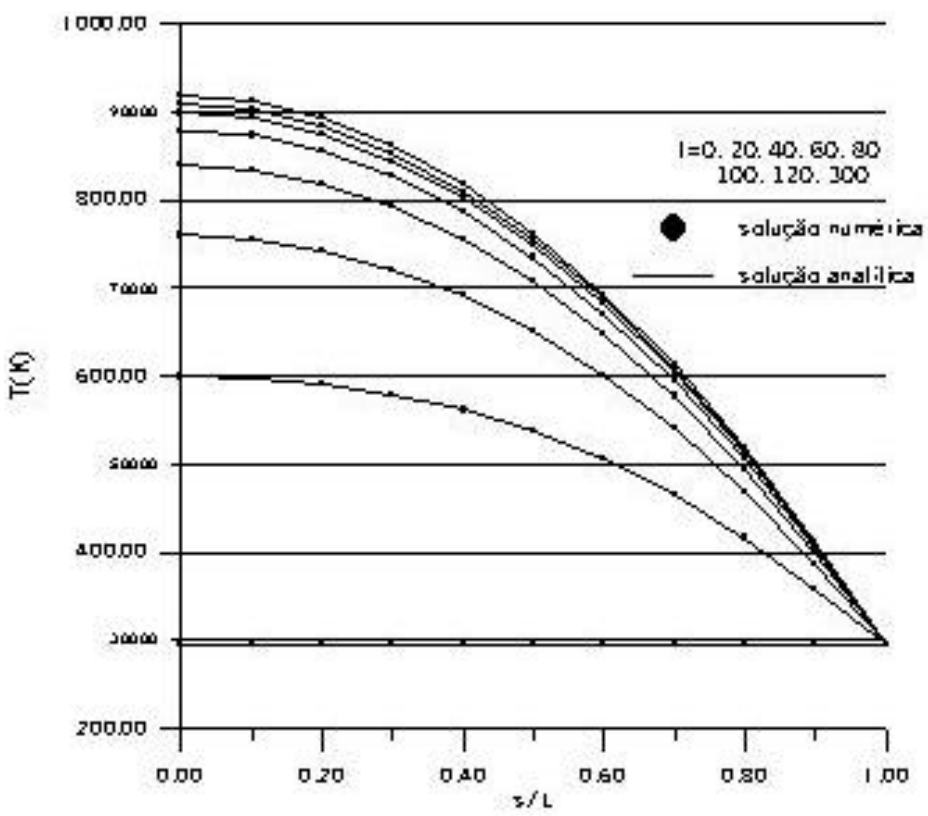

Figura 4.2: solução numérica e analítica, com $h \rightarrow \infty$

Para esta análise utilizou-se a implementação da forma-V [HUGHES,87] do método trapezoidal generalizado, com parâmetro de colocação $\alpha=0,5$ como forma de garantir a estabilidade do algoritmo de integração no tempo. O incremento de tempo $\Delta t=10 \mathrm{~s}$ foi escolhido de modo a atender aos requisitos de convergência do método.

Efetuou-se também uma análise com $h=0.25 \times 10^{5} \mathrm{~W} / \mathrm{m}^{2}{ }^{\circ} \mathrm{K}$ e dados de entrada e malha d elementos finitos como no exemplo acima. As distribuições de temperatura obtidas, para alguns instantes de tempo, podem ser visualizadas na figura 4.3. Utilizou-se novamente a implementação da forma- $\mathrm{V}$ do método trapezoidal generalizado, com $\alpha=0,5$ e $\Delta t=10 \mathrm{~s}$. 


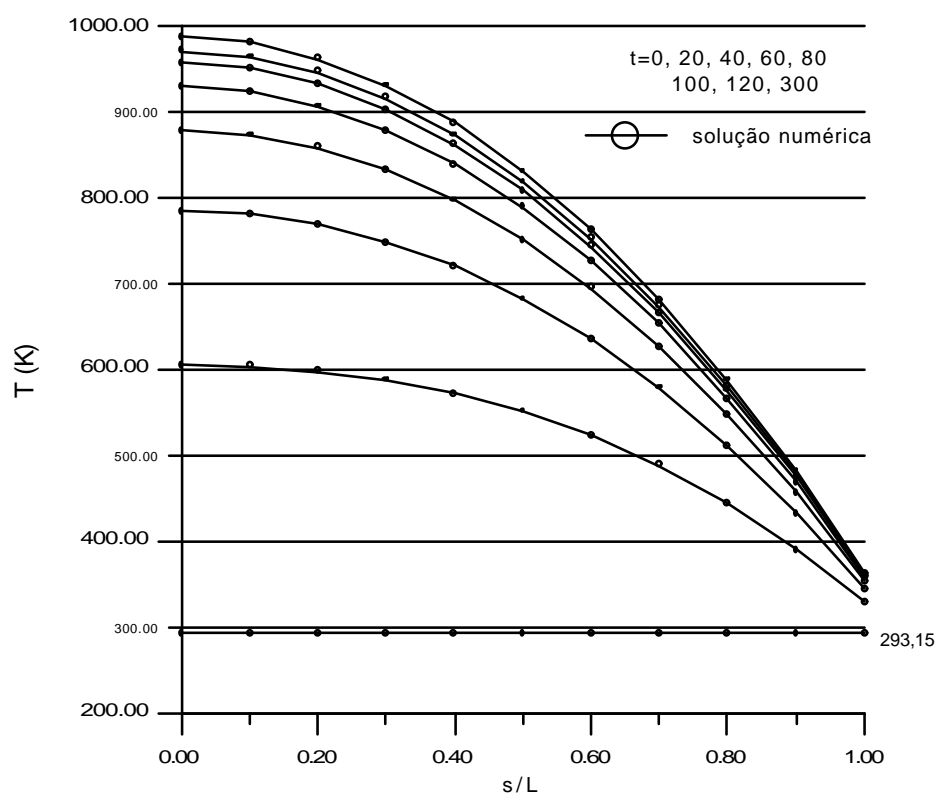

Figura 4.3: solução numérica e analítica, $\operatorname{com} h$ finito

\subsection{Análise elasto-plástica}

Neste item são apresentados alguns exemplos de análise por elementos finitos do problema elasto-plástico, com o objetivo de validar os resultados posteriores.

No exemplo 4.2.1 os resultados obtidos são praticamente coincidentes com os resultados apresentados pela referência. Os resultados obtidos nos exemplos 4.2.2 e 4.2.3 são coerentes com o problema proposto e apresentados na referência.

Exemplo 4.2.1: Neste exemplo é considerado o caso de um vaso de pressão cilíndrico de parede espessa submetido a pressão interna, com condições de deformação plana sendo assumidas na direção axial, como apresentado em [OWEN, 1980]. As constantes do material são dadas por $\mathrm{E}=2.1 \times 10^{4} \mathrm{dN} / \mathrm{mm}^{2}, v=0,3, \sigma_{\mathrm{y}}=24 \mathrm{dN} / \mathrm{mm}^{2}$ e $\mathrm{H}^{\prime}=0$. Devido a simetria do modelo, a análise deste problema de estado plano de deformação foi realizada em um quarto da seção transversal do vaso de pressão utilizando-se 72 elementos isoparamétricos Q8, 
quatro pontos de Gauss por elemento e 480 graus de liberdade. Na figura 4.4 é apresentado um esquema do problema bem como a malha de elementos finitos utilizada.

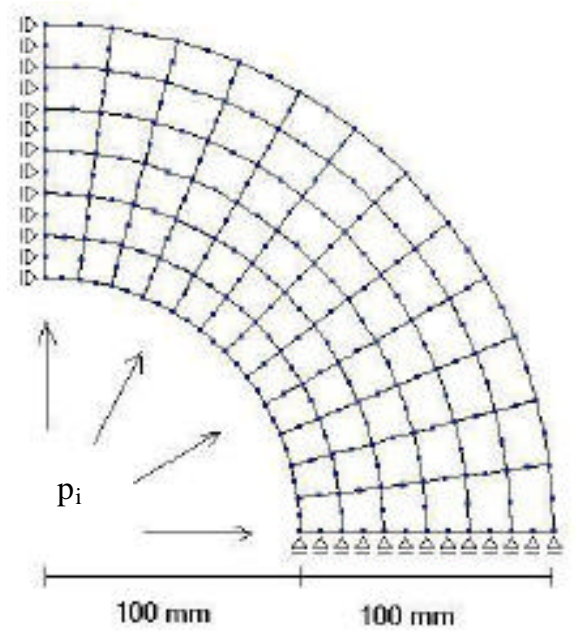

Figura 4.4: esquema representativo e malha de elementos finitos para o Exemplo 4.2.1

Na figura 4.5 vê-se a relação entre o deslocamento da parede interna do vaso em relação à pressão aplicada, e na figura 4.6 os valores da tensão principal $\sigma_{1}$ ao longo do eixo radial do vaso para uma pressão aplicada igual $14 \mathrm{dN} / \mathrm{mm}^{2}$. Os resultados obtidos foram comparados com aqueles apresentados pela bibliografia [OWEN et all, 1980].

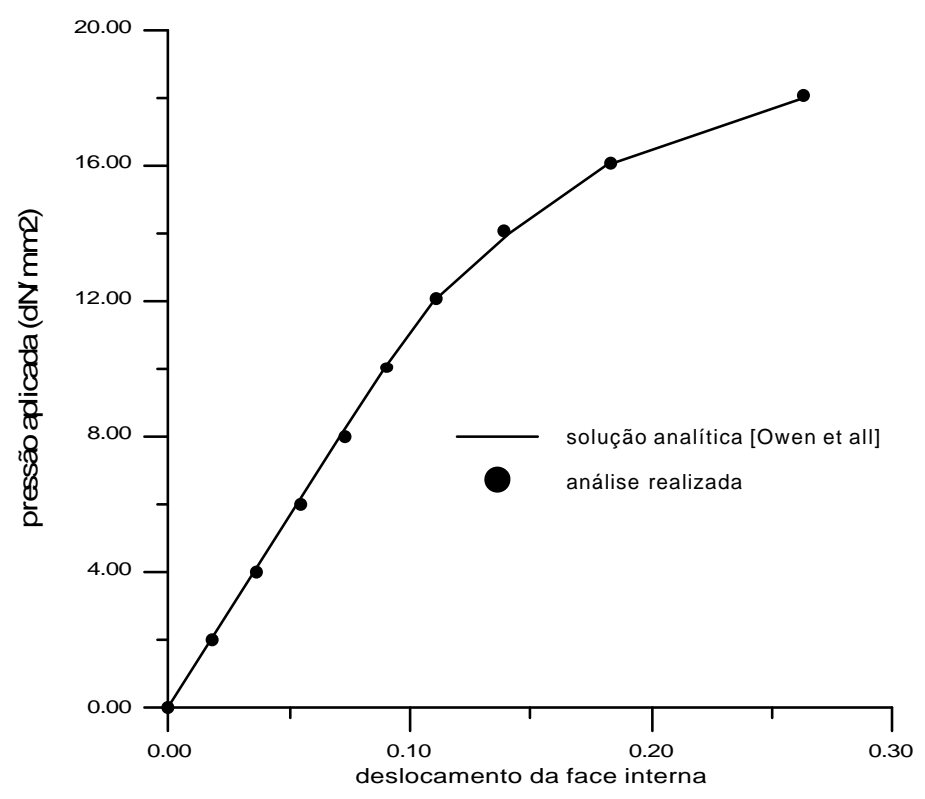

Figura 4.5: deslocamento da face interna com o aumento da pressão para o Exemplo 4.2.1 


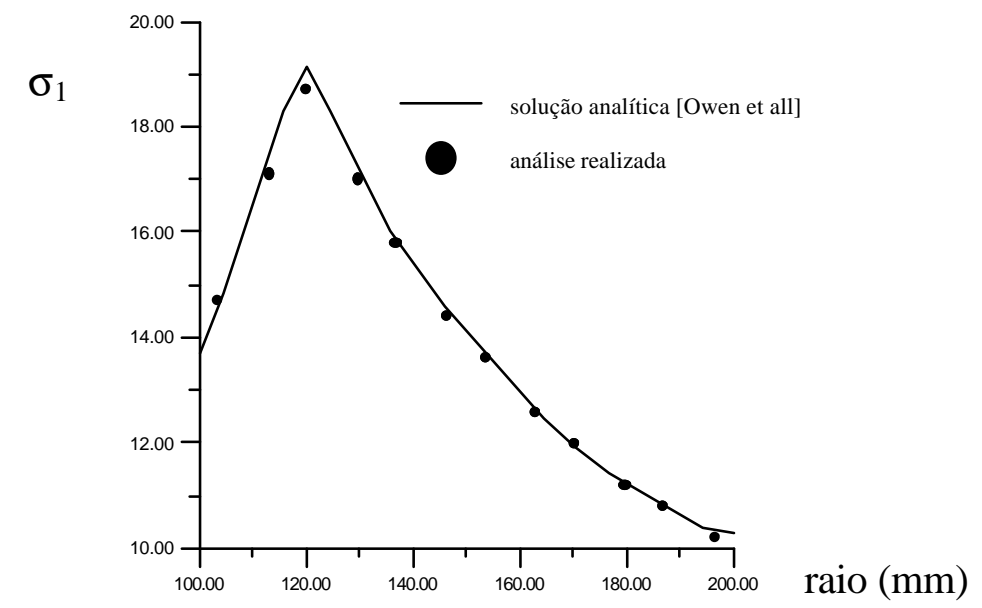

Figura 4.6: tensão $\sigma_{1}$ quando a pressão é igual a $14 \mathrm{dN} / \mathrm{mm}^{2}$ para o Exemplo 4.2.1

Exemplo 4.2.2: Neste exemplo tem-se o caso de uma placa de $20 \mathrm{~mm}$ x $18 \mathrm{~mm}$, chanfrada, submetida a tração na direção $y$. É considerado estado plano de tensões e plasticidade perfeita. As constantes do material são dadas por $E=7000 \mathrm{~kg} / \mathrm{mm}^{2}, v=0,2$ e $\sigma_{\mathrm{y}}=24,3 \mathrm{~kg} / \mathrm{mm}^{2}$. Na figura 4.7 abaixo é mostrada a malha utilizada (a), com 162 elementos T3, 101 nós e 182 graus de liberdade, bem como a região de escoamento para o passo de carga $\mathrm{F}=936 \mathrm{~kg}$ (b). Os nós da borda inferior têm restrição de deslocamento na direção y e os nós do eixo de simetria vertical têm restrição de deslocamento na direção $x$.
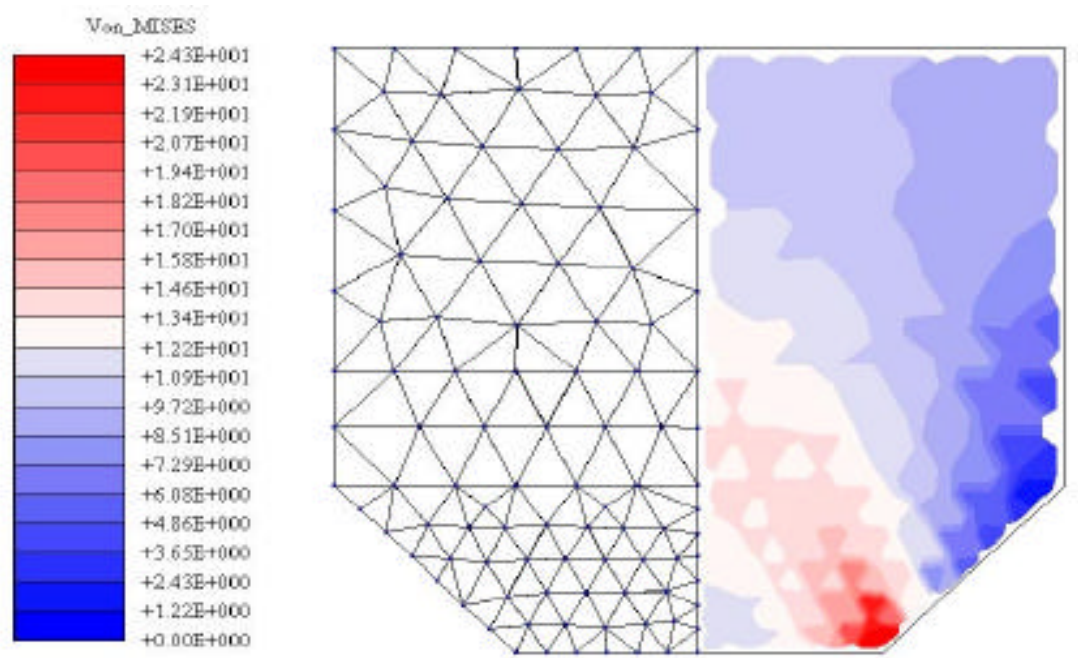

(a)

(b)

Figura 4.7: (a) malha utilizada e (b) tensões de von Mises do Exemplo 4.2.2 
Exemplo 4.2.3: Neste exemplo tem-se o caso de uma placa de $20 \mathrm{~mm}$ x $36 \mathrm{~mm}$, furada no centro, submetida a tração na direção $y$. É considerado estado plano de tensões e encruamento isotrópico com $\mathrm{H}=0,032$. As constantes do material são dadas por $E=7000 \mathrm{~kg} / \mathrm{mm}^{2}, v=0,2$ e $\sigma_{\mathrm{y}}=24,3 \mathrm{~kg} / \mathrm{mm}^{2}$. Na figura 4.8 abaixo é mostrada a malha de elementos finitos utilizada (a), com 116 elementos isoparamétricos Q8, 141 nós, 261 graus de liberdade e quatro pontos de Gauss por elemento, bem como região de escoamento para o passo de carga $F=936 \mathrm{~kg}$ (b). Os nós da borda inferior têm restrição de deslocamento na direção y e os nós do eixo de simetria vertical têm restrição de deslocamento na direção $x$.
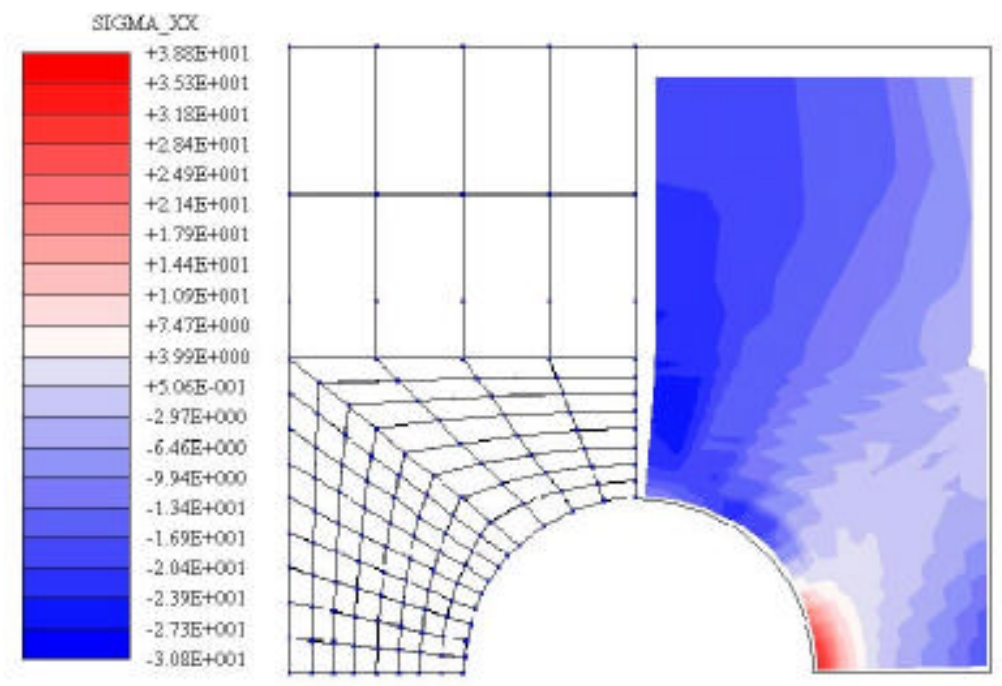

(a)

(b

Figura 4.8: (a) malha utilizada e (b) do Exemplo 4.2.3

\subsection{Análise termo-elástica}

Neste item são apresentados alguns exemplos de análise por elementos finitos do problema termo-elástico em peças de aço, com o objetivo de validar os resultados posteriores.

Nesses 3 exemplos os resultados obtidos são os mesmos da resolução analítica.

Exemplo 4.3.1: considera-se uma barra reta de dimensões $10 \times 2 \times 1 \mathrm{~cm}$, estaticamente indeterminada que é, portanto, impedida de se alongar quando submetida a um aumento uniforme de temperaturas, ficando sujeita a um estado uniforme de tensões normais de 
compressão. Os extremos da barra são fixos em um suporte, de tal modo que a dilatação na direção $x$ seja impedida e não haja dilatação térmica em $y$. A temperatura inicial da barra é de $30^{\circ} \mathrm{C}$ e foi aquecida a $130^{\circ} \mathrm{C}$. É considerado estado plano de tensões e o material da barra é caracterizado através dos parâmetros $E=3000 \mathrm{kN} / \mathrm{m}^{2}, v=0,25$ e $\alpha=10^{-5} \rho C$.

Utilizando-se o programa desenvolvido neste trabalho, os resultados obtidos foram $\sigma_{\mathrm{x}}=$ $-3,0 \mathrm{Kgf} / \mathrm{m}^{2}$ e o deslocamento nos nós superiores igual a $0.0025 \mathrm{~cm}$, coincidindo com os resultados analíticos.

Exemplo 4.3.2: Considera-se uma viga bi-engastada da altura $h=1,2 m$, largura $b=1,0 m$ e comprimento $l=10 \mathrm{~m}$, sujeita a variação de temperatura na superfície superior de $\Delta T_{s}=10^{\circ} \mathrm{C}$ e na superfície inferior $\Delta T_{i}=-10^{\circ} \mathrm{C}$. É considerado estado plano de tensões e o material da viga possui módulo de elasticidade $E=10^{6} \mathrm{kN} / \mathrm{m}^{2}$ e coeficiente de dilatação térmica $\alpha=10^{-5} \rho \mathrm{C}$.

O modelo adotado para representar o problema descrito acima é constituído de uma malha e elementos finitos de cinco elementos Q8 (figura 4.9), considerando a simetria e a anti-simetria do problema.

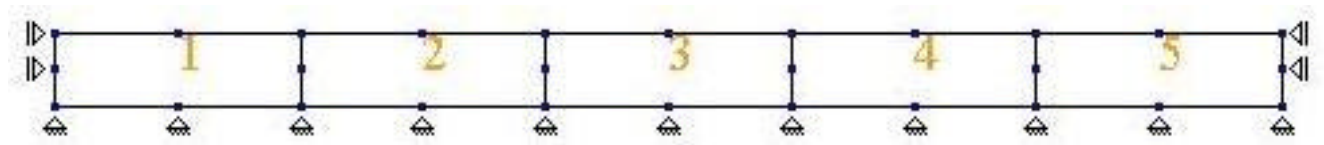

Figura 4.9: malha de elementos finitos do exemplo 4.3.2

A tensão nos pontos de ordenada $0,4732 \mathrm{~m}$ é dada por $\sigma_{\mathrm{x}} \mid=78,8675 \mathrm{Kgf} / \mathrm{m}^{2}$, o mesmo quando calculado analiticamente através de $\left|\sigma_{x}\right|=\frac{M y}{J}$, onde $M$ é o momento fletor, $y$ a distância do ponto ao eixo neutro e $J$ o momento de inércia.

Exemplo 4.3.3: Considera-se a mesma viga do exemplo anterior, porém com coeficiente de dilatação em $y$ nulo, $v=0,0$, a fronteira superior sendo resfriada de 50 a $10^{\circ} \mathrm{C}$ e a inferior sendo aquecida de 50 a $90^{\circ} \mathrm{C}$ e restrições como apresentadas na figura 4.10 abaixo. A 
discretização da viga para análise por elementos finitos foi feita por 20 elementos finitos quadráticos Q8, 85 nós, 166 graus de liberdade e quatro pontos de Gauss por elemento. Também é considerado estado plano de tensões.

A tensão obtida por esta análise nos pontos de Gauss de ordenada 0,2113249 foi de $\left|\sigma_{x}\right|=0,9464101 N / m^{2}$, o mesmo que calculado analiticamente. Na figura 4.9 vê-se a configuração deformada.

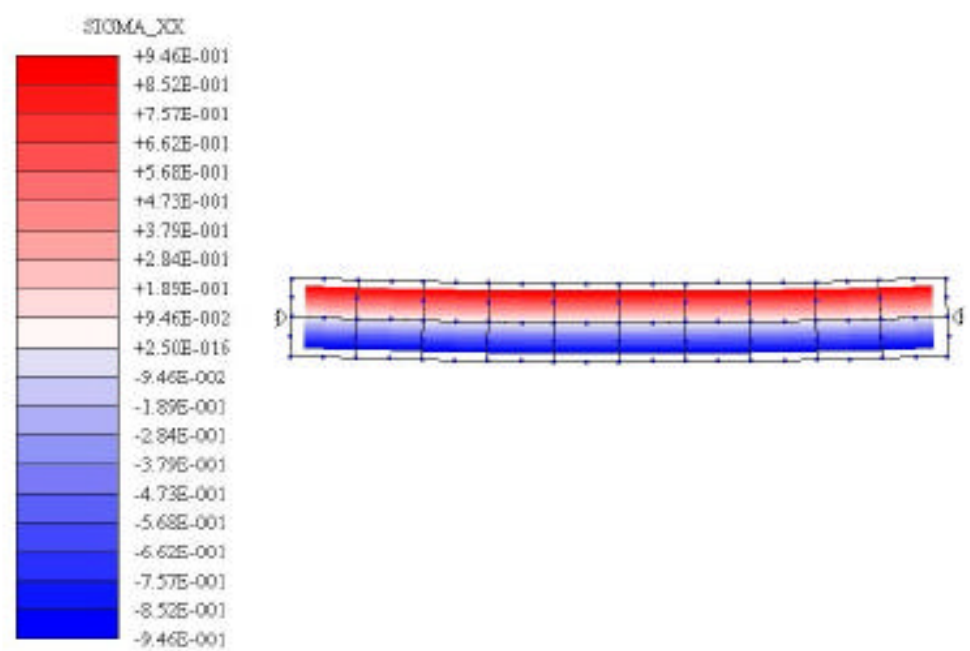

Figura 4.10: configuração deformada e tensões $\sigma_{\mathrm{x}}$ do Exemplo 4.3.3

\subsection{Análise termo-plástica}

Nesta seção é apresentado um exemplo de análise por elementos finitos do problema termo-plástico.

Considera-se um cilindro de aço com as mesmas dimensões do cilindro do exemplo 4.2.1, porém com constantes mecânicas do material dadas por $\mathrm{E}=7000 \mathrm{dN} / \mathrm{mm}^{2}, \mathrm{v}=0,2$, $\sigma_{\mathrm{y}}=425 \mathrm{dN} / \mathrm{mm}^{2}$ e $\mathrm{H}^{\prime}=0$. As constantes térmicas são dadas por condutividade térmica $\kappa=$ $0,035 \mathrm{~W} / \mathrm{mm}^{\circ} \mathrm{K}$, calor específico $c_{v}=460$ e densidade $\rho=0.000008618$. As temperaturas externa e interna ao cilindro são iguais a $23^{\circ} \mathrm{C}$ e o coeficiente de transferência de calor é dado por $h=0,025 \mathrm{~W} / \mathrm{mm}^{2} \mathrm{~K}$. A malha de elementos finitos utilizada é a mesma do exemplo 4.2.1. 
A figura 4.11 mostra as tensões de von Mises e a região de escoamento da peça após 1s de resfriamento.
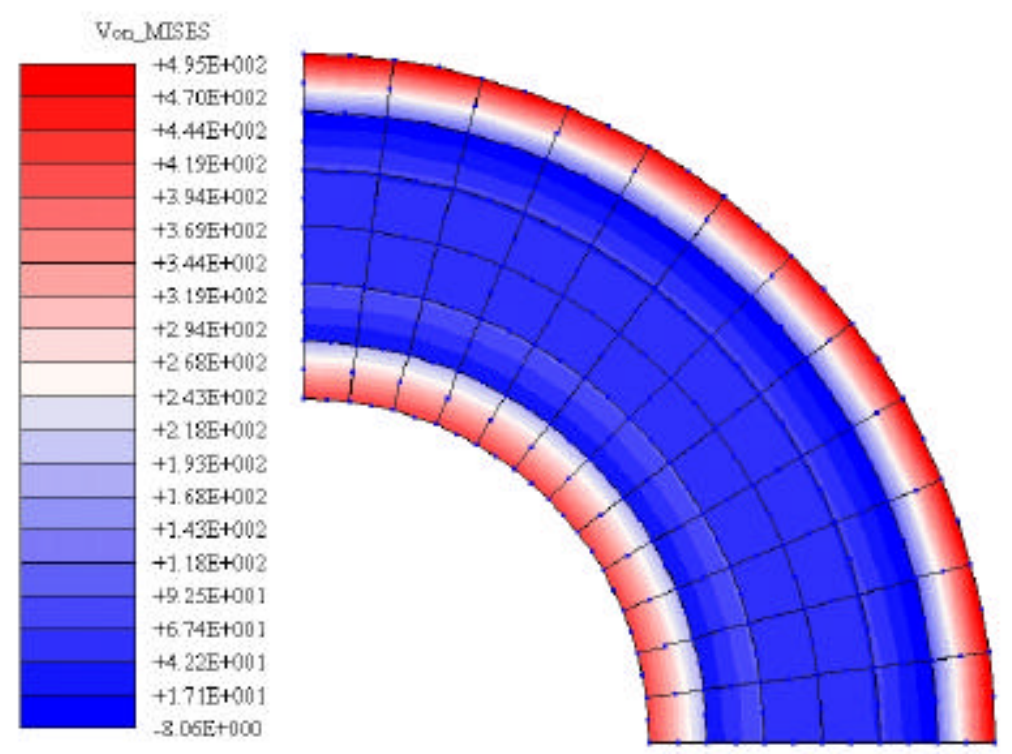

Figura 4.11: tensões de von Mises para o exemplo 4.4.1

\subsection{Análise térmica e de micro estrutura}

Nesta seção são apresentados alguns exemplos de análise por elementos finitos do problema térmico acoplado ao cálculo das frações parciais dos constituintes de uma liga ferroníquel, ou seja, considera-se a transformação austenita-martensita durante o processo de resfriamento.

Exemplo 4.5.1: este exemplo trata da têmpera de um cilindro de aço níquel $(17,6 \%)$ com 25mm de diâmetro, resfriado em água a $0{ }^{\circ} \mathrm{C}$ a partir de $900{ }^{\circ} \mathrm{C}$ [ARGYRIS et all, 1985]. Devido a forte não-linearidade das características termo-físicas do material, tanto a plasticidade induzida por transformação quanto a expansão volumétrica estão confinadas em um estreito intervalo de temperatura, próximo a temperatura M. Além disso, foi preciso utilizar um passo de tempo apropriado para garantir convergência. Neste caso, as características termo-físicas são iguais para martensita e austenita. Na figura 4.12 abaixo vê- 
se os gráficos da condutividade térmica e da capacidade térmica em relação a temperatura, obtidos interpolando-se os pontos provenientes de dados experimentais [ARGYRIS et all, 1985] por curvas Spline.
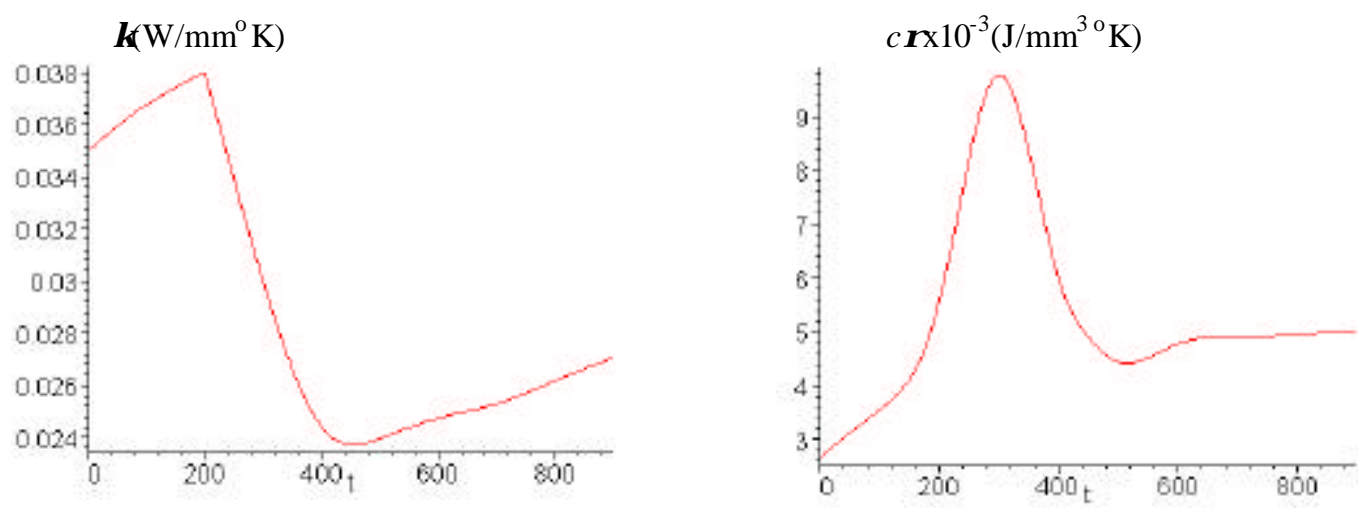

Figura 4.12: condutividade térmica e capacidade térmica do material do exemplo 4.5.1

A temperatura de início da transformação martensítica é dada por $\mathrm{M}_{\mathrm{S}}=350^{\circ} \mathrm{C}$ e a condição de transferência de calor na face externa é descrita pela função quadrática

$$
h_{c}(T)=-\frac{2,5}{63} 10^{-6} T^{2}+\frac{36,5}{63} 10^{-4} T+10^{-4}
$$

Devido a simetria axial e ao isolamento térmico das extremidades da peça, foi utilizada uma malha com 40 elementos quadráticos Q8, 203 nós e nove pontos de Gauss por elemento, como apresentada na figura 4.13. Optou-se pelo refinamento da malha próximo à superfície uma vez que nessa região encontram-se os maiores gradientes de temperatura. Neste figura apresenta-se também a distribuição de temperatura no instante $t=12 \mathrm{~s}$

Na figura 4.14 encontra-se a evolução da temperatura na superfície e no centro da peça. A diferença de temperatura nos instantes iniciais da análise não está bem compreendida, podendo ser justificada pela utilização de um passo de tempo ainda grande em relação ao gradiente de temperatura. 


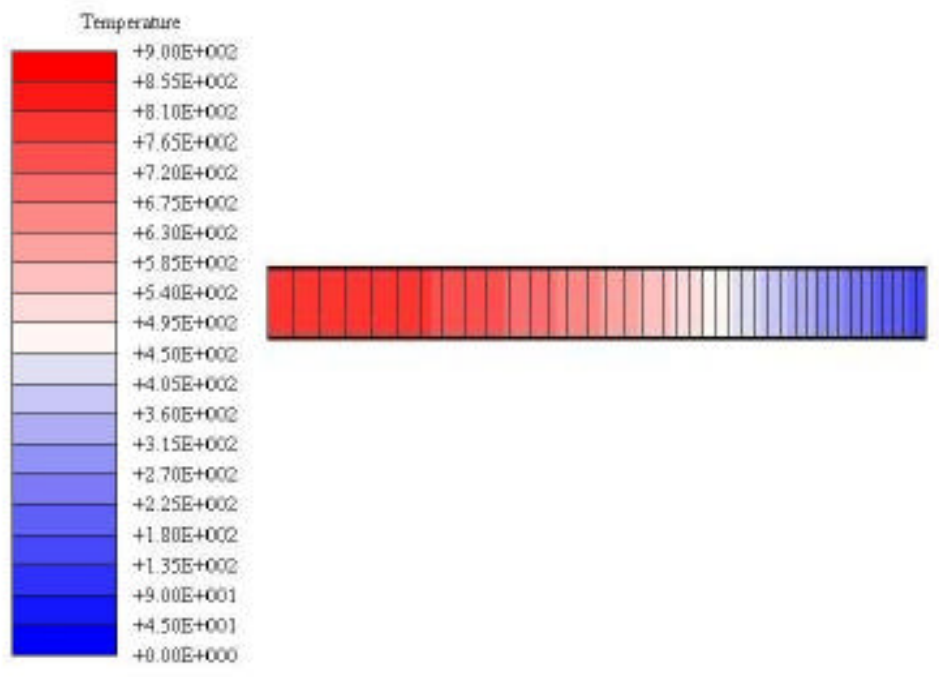

Figura 4.13: malha e distribuição de temperatura no instante $\mathrm{t}=12 \mathrm{~s}$ para o exemplo 4.5.1

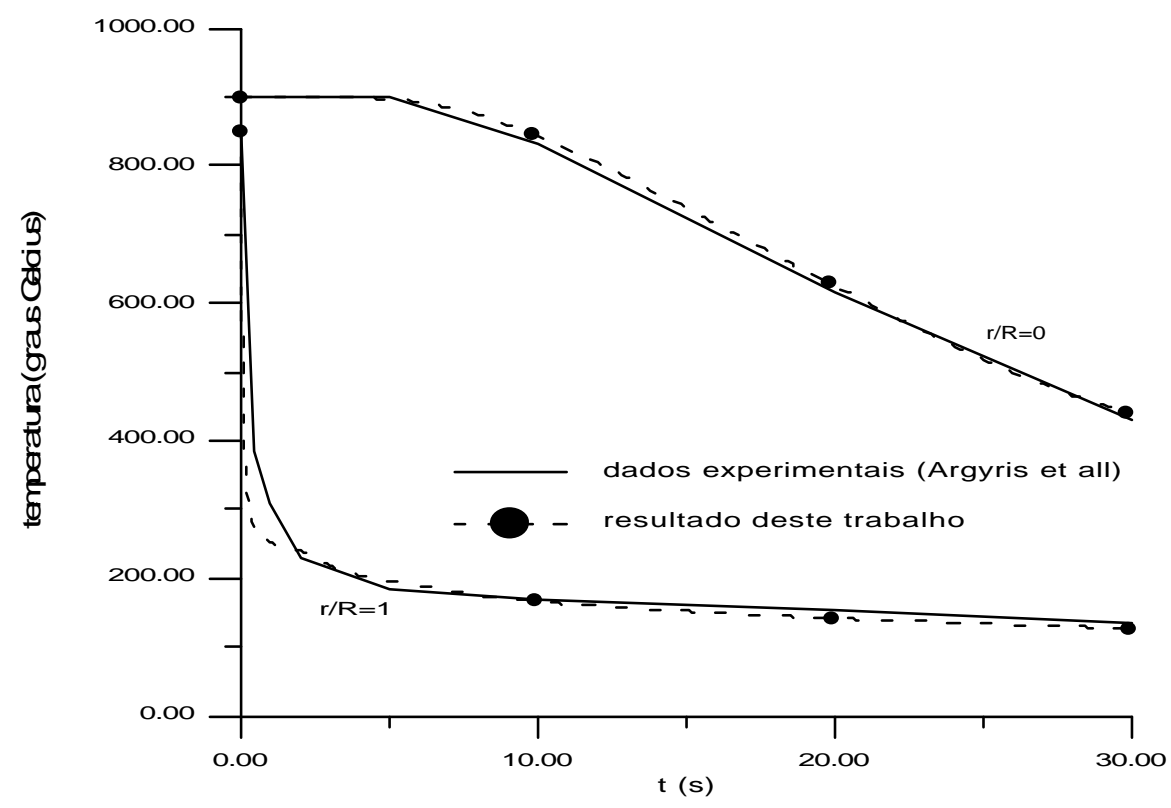

Figura 4.14: evolução da temperatura na superfície para o exemplo 4.5.1

Exemplo 4.5.2: têmpera de um cilindro de aço SCM-3, com 20mm de diâmetro, resfriado em água a partir de $850{ }^{\circ} \mathrm{C}$. Neste exemplo os dados do material [INOUE et all] são constantes, 
não dependendo da temperatura, porém diferentes para cada constituinte, e encontram-se na Tabela 1 abaixo.

\begin{tabular}{|l|c|c|}
\hline \multicolumn{1}{|c|}{ Aço SCM-3 } & Austenita & Martensita \\
\hline Densidade $\left(\mathrm{g} / \mathrm{mm}^{3}\right):$ & $8.15 \times 10^{-3}$ & $7.80 \times 10^{-3}$ \\
\hline Condutividade térmica $\left(\mathrm{cal} / \mathrm{mm} \cdot \mathrm{s} \cdot{ }^{\circ} \mathrm{C}\right)$ & $7.06 \times 10^{-3}$ & $12.5 \times 10^{-3}$ \\
\hline Capacidade térmica $\left(\mathrm{cal} / \mathrm{g} \cdot{ }^{\circ} \mathrm{C}\right)$ & 0.15 & 0.15 \\
\hline Coeficiente de expansão térmica $\left(1 /{ }^{\circ} \mathrm{C}\right)$ & $2.08 \times 10^{-5}$ & $1.25 \times 10^{-5}$ \\
\hline \multicolumn{2}{|c|}{ Transformação austenita $\rightarrow$ martensita } \\
\hline Calor latente(cal/g) & 26.0 \\
\hline Coeficiente de expansão por transformação & $1.0 \times 10^{-3}$ \\
\hline Temperatura de início de transformação $\left({ }^{\circ} \mathrm{C}\right)$ & 460 \\
\hline
\end{tabular}

Tabela 1: dados do material para o exemplo 4.5.2

Na figura 4.15 está representada a evolução da temperatura ao longo do tempo e na figura 4.16 a evolução das frações parciais dos constituintes em três pontos distintos do cilindro. A malha de elementos finitos utilizada é a mesma do exemplo anterior.

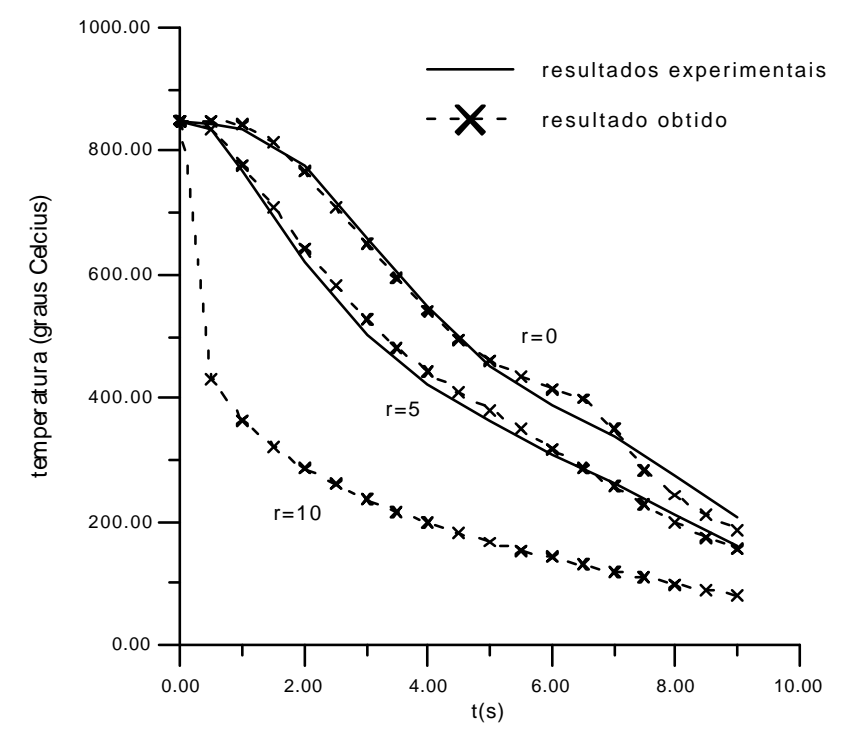

Figura 4.15: distribuição de temperatura em 3 pontos do cilindro do exemplo 4.5.2

Na figura 4.16 nota-se o perfil exponencial do crescimento da quantidade de martensita. Na figura 4.15 a diferença dos valores obtidos com aqueles apresentados na bibliografia entre os instantes 5 e 7s deve-se por ter sido considerada a geração de calor devido a transformação 
de austenita em martensita, o que torna os resultados obtidos mais coerentes com o problema físico proposto do que os apresentados pela referência citada.

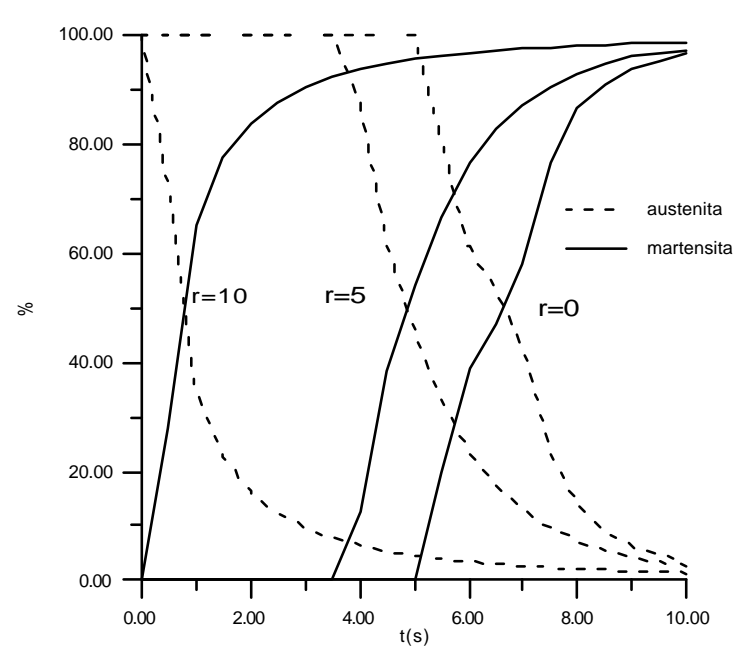

Figura 4.16: frações parciais de martensita e perlita do exemplo 4.5.2

\subsection{Análise termo-elasto-plástica com mudança de fase}

Quando uma peça de aço é temperada, a superfície se resfria mais rapidamente do que o núcleo, sofrendo primeiro a transformação martensítica e endurecendo em relação ao centro.

O surgimento de tensões de tração na superfície e de tensões compressivas no núcleo, ou vise versa, depende das velocidades relativas de resfriamento nessa regiões, o que é uma função da espessura da peça e da velocidade do meio de têmpera.

Em peças espessas e/ou submetidas a um rápido resfriamento, a superfície tempera quando o centro está ainda a uma temperatura muito alta, fazendo com que a contração térmica do núcleo, após a têmpera da superfície, exceda a expansão martensítica. Neste caso, obtêm-se tensões residuais de compressão na superfície e de tração no núcleo, efeito este muitas vezes desejado para aumentar a resistência da peça.

Por sua vez, tensões residuais de tração na superfície e de compressão no núcleo ocorrem em peças delgadas e/ou submetidas a resfriamento lento, onde a diferença entre as velocidades de resfriamento da superfície e do centro é moderada. Neste caso, a contração 
térmica das áreas centrais, após a têmpera da superfície, é menor que a expansão devida à formação de martensita.

Nesta seção serão apresentados dois exemplos de têmpera de peças espessas de aço 3.25Ni-1Cr [NAGASAKA,1993], de alta temperabilidade, resfriado por jato de água de alta pressão, cujo coeficiente de transferência de calor é considerado constante, uma vez que a temperatura na superfície da peça a ser temperada decresce para um valor próximo ao da temperatura da água em um período de tempo muito curto. Este processo por jato de água é utilizado visando diminuir a influência da camada gasosa que se forma na superfície da peça e que prejudica a troca de calor entre a peça e o meio.

O valor do coeficiente de transferência de calor é estimado da relação empírica para um jato perpendicular alinhado com respeito a uma placa plana

$$
N u_{B}=1,42 \operatorname{Pr}^{0.43} \operatorname{Re}_{B}^{0.58}\left(\frac{H}{B}\right)^{-0.62}
$$

onde $N u_{B}$ é o número local de Nusselt, $P r=v / \alpha$ é o número de Prandtl, $R e_{B}=U_{\infty} B N$ o número de Reynolds, $H$ a distância e $B$ o diâmetro da ducha de resfriamento, $v$ a viscosidade cinemática do fluido, $\alpha$ a difusividade térmica do fluido e $U_{\infty}$ a velocidade do fluido.

O número de Nusselt relaciona-se com o coeficiente de transferência da calor através de

$$
N u_{B}=\frac{h B}{\kappa}
$$

onde $\kappa$ é a condutividade térmica do fluido, considerada constante para este cálculo.

Sendo assim,

$$
h=\frac{\kappa 1,42 \operatorname{Pr}^{0.43} \operatorname{Re}_{B}^{0.58}\left(\frac{H}{B}\right)^{-0.62}}{B}
$$


Considerando a temperatura da água constante e igual a $25^{\circ} \mathrm{C}$, tem-se que $\kappa=0,6 \mathrm{~W} / \mathrm{mK}$, $v=0,00899 \times 10^{-4}, \alpha=0,00144 \mathrm{~cm}^{2} / \mathrm{s}$ e $P r=6,21$. Considerando também $U_{\infty}=10 \mathrm{~m} / \mathrm{s}, B=3 \mathrm{~mm}$ e $H=77,5 \mathrm{~mm}$, chega-se a $\operatorname{Re}_{B}=33557,04698$ e então o valor do coeficiente de transferência de calor é dado por

$$
h=3.4974 \times 10^{4} \frac{W}{m^{2} K}
$$

As características mecânicas do material são consideradas como funções da temperatura e das concentrações dos constituintes, com exceção dos coeficientes de dilatação térmica, considerados constantes.

Exemplo 4.6.1: este exemplo trata da têmpera de um cilindro de aço $3.25 \mathrm{Ni}-1 \mathrm{Cr}$ [NAGASAKA,1993], de alta temperabilidade, resfriado por jato de água de alta pressão.

O cilindro tem $75 \mathrm{~mm}$ de diâmetro e $180 \mathrm{~mm}$ de comprimento, e foi austenizado a $880^{\circ} \mathrm{C}$ e a temperatura de início da transformação martensítica é $400^{\circ} \mathrm{C}$. Devido a alta temperabilidade da liga utilizada, é considerado que o material transforma-se idealmente em martensita.

A malha de elementos finitos utilizada neste exemplo é composta por 200 elementos axissimétricos Q8 e 661 nós. Para a análise térmica e de micro-estrutura foram utilizados nove pontos de Gauss e para a análise de tensões quatro pontos de Gauss por elemento e, devido às restrições de deslocamento, 1150 graus de liberdade. Em ambos os casos foi considerada a simetria axial do modelo. A figura 4.17 abaixo representa a malha de elementos finitos e as restrições consideradas para o cálculo de tensões. 


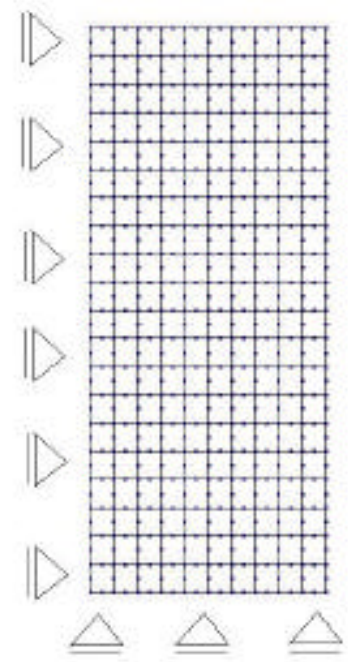

Figura 4.17: malha de elementos finitos para o exemplo 4.6.1

Na figura 4.18 abaixo mostra-se a distribuição de temperatura após 13s de têmpera e na figura 4.19 a concentração da fração de martensita transformada para este mesmo instante. Os resultados obtidos apresentam boa concordância com aqueles apresentados originalmente no trabalho citado.
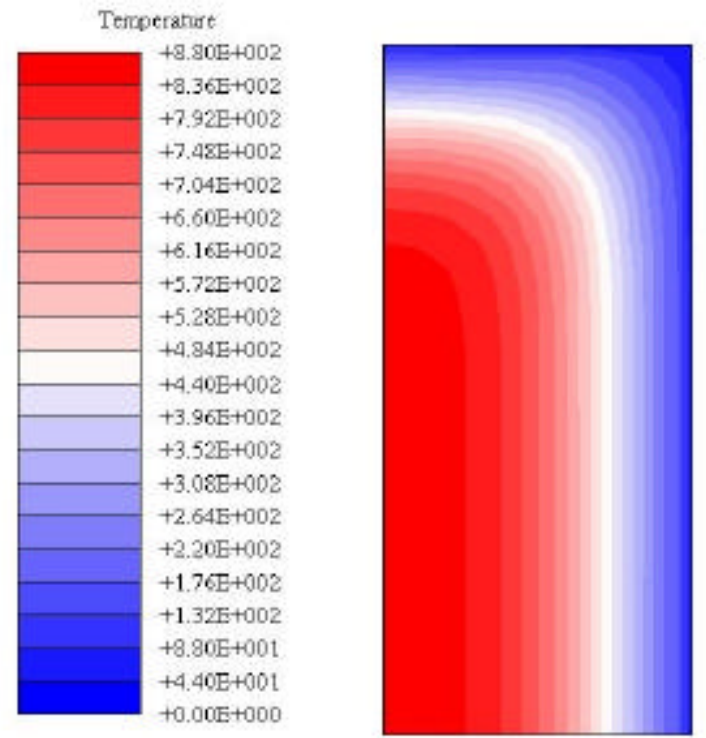

Figura 4.18: distribuição de temperaturas após 30s de têmpera do cilindro de aço $3.25 \mathrm{Ni}-1 \mathrm{Cr}$ 


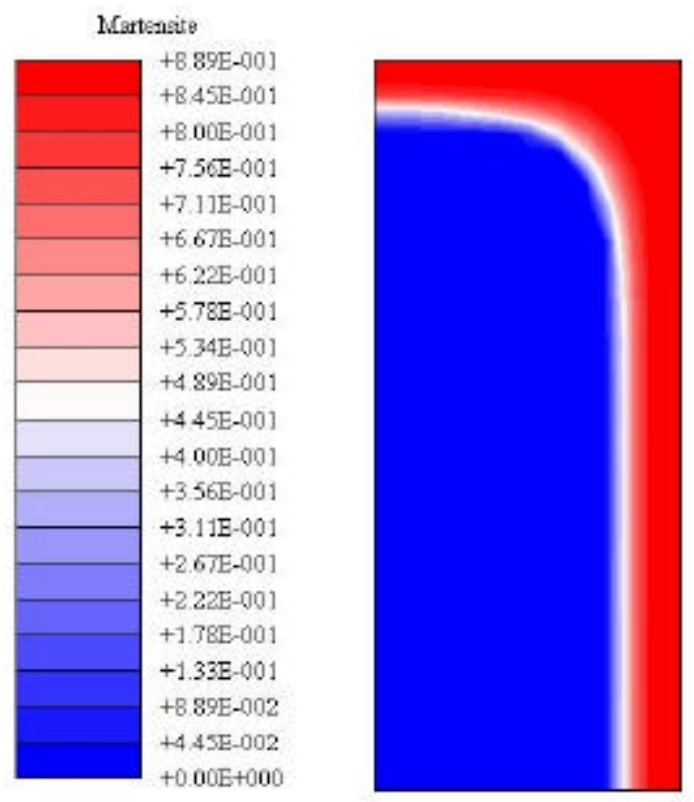

Figura 4.19: região transformada em martensita após 30s de têmpera do cilindro de aço $3.25 \mathrm{Ni}-1 \mathrm{Cr}$

Com as informações obtidas acima como dados de entrada, foi efetuada um análise mecânica visando prever as tensões resultantes do processo de têmpera. Foram consideradas tensões térmicas, de transformação e plásticas induzidas pela transformação (PIT). Na figura 4.20 está representada, para $t=13 \mathrm{~s}$, a tensão $\sigma_{z}$ no centro da peça, ao longo do raio, cujo resultado apresenta-se coerente com o esperado, segundo interpretação feita no início desta seção.

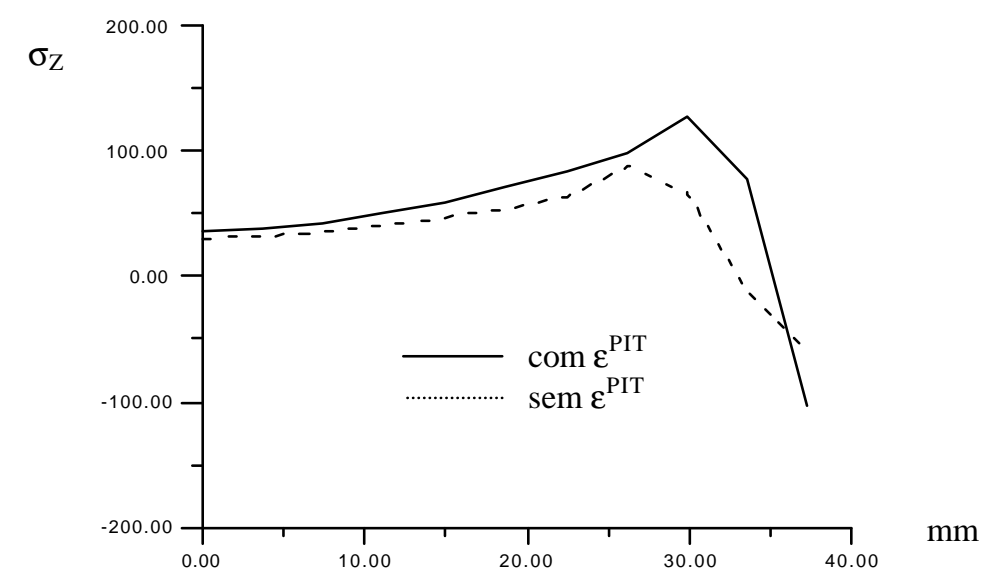

Figura 4.20: tensões $\sigma_{z}$ no centro da peça do cilindro de aço $3.25 \mathrm{Ni}-1 \mathrm{Cr}$, após $13 \mathrm{~s}$ 
O gráfico acima evidencia a diferença entre as tensões obtidas quando a deformação plástica induzida pela transformação martensítica é considerada. Nota-se que a maior diferença encontra-se na região da peça onde ocorreu a transformação, como era esperado.

$\mathrm{Na}$ figura 4.21 abaixo estão representadas as configurações não deformada e deformada, esta última relacionada com a concentração de martensita.

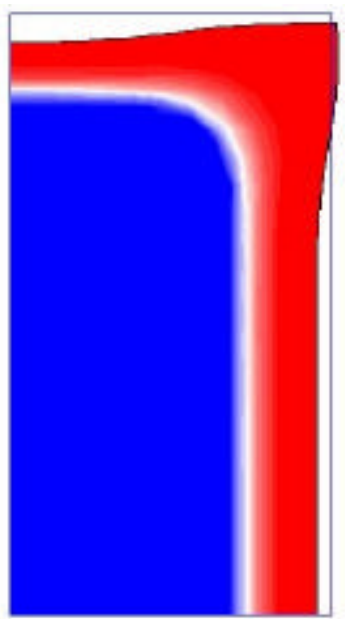

Figura 4.21: configuração deformada e não-deformada e fração martensítica transformada após $13 \mathrm{~s}$

Nota-se, além da contração sofrida pela peça, uma dilatação na região onde há uma maior concentração de martensita, dilatação esta devido a deformação causada pela transformação de fase.

O gráfico da figura 4.22 representa a deformação plástica induzida equivalente no instante $t=13 \mathrm{~s}$ e o gráfico da figura 4.23 as curvas de nível para a deformação plástica equivalente neste mesmo instante. 

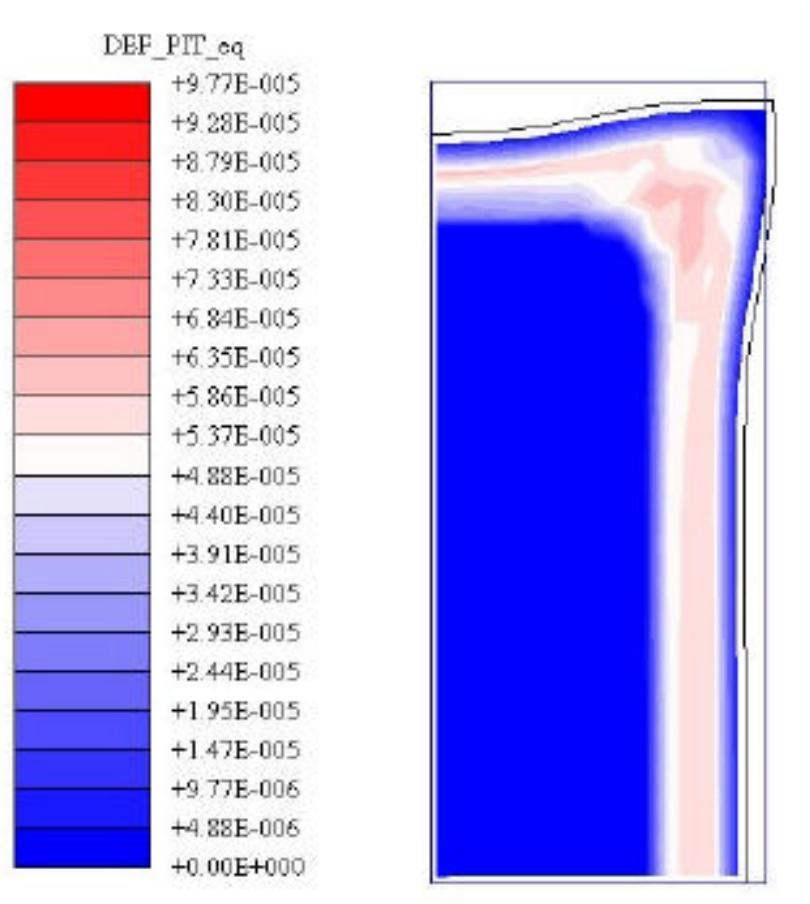

Figura 4.22: deformação plástica induzida equivalente em $t=13 \mathrm{~s}$
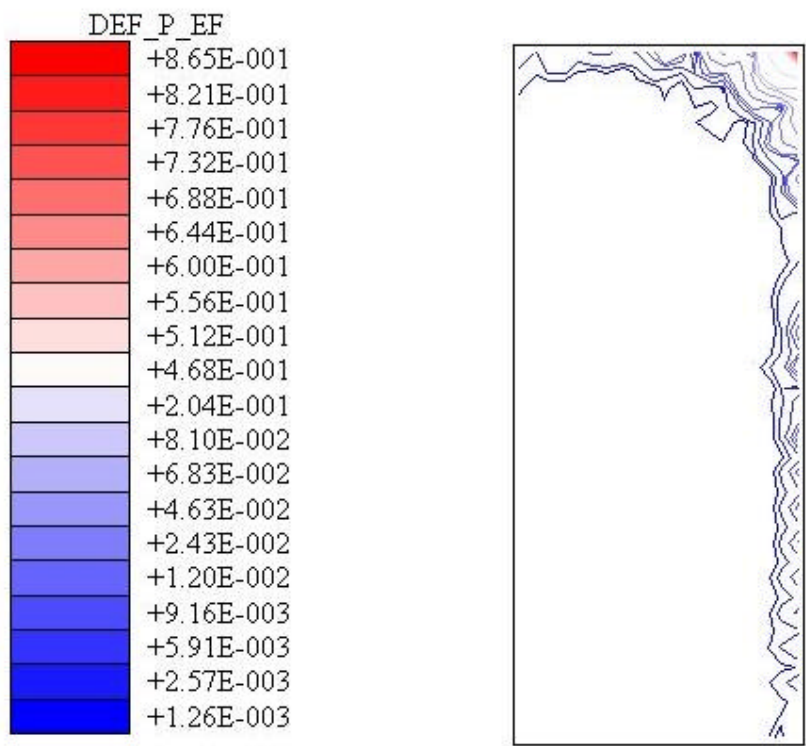

Figura 4.23: deformação plástica equivalente em $t=13 \mathrm{~s}$ 
Exemplo 4.6.2: este exemplo trata da têmpera progressiva por jato d'água de um chapa de aço $3.25 \mathrm{Ni}-1 \mathrm{Cr}$, com $6 \mathrm{~mm}$ de espessura. A figura 4.24 abaixo apresenta o esquema do tratamento térmico realizado

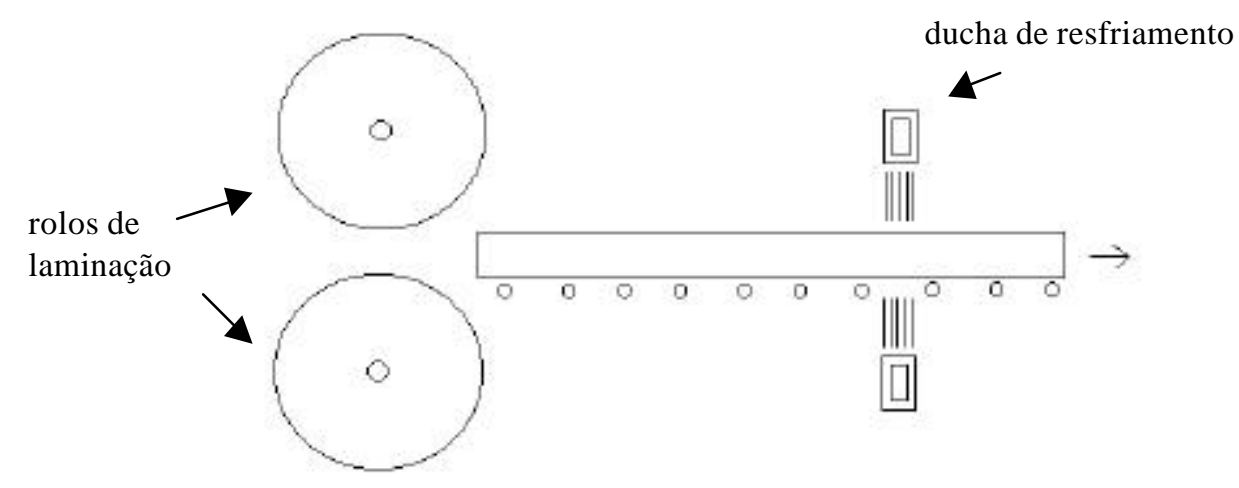

Figura 4.24: têmpera progressiva de uma chapa de aço

A malha de elementos finitos utilizada neste exemplo é composta por 20 elementos quadráticos Q8 e 165 nós. Para a análise térmica e de micro-estrutura foram utilizados nove pontos de Gauss e para a análise de tensões quatro pontos de Gauss por elemento e, devido às restrições de deslocamento, 308 graus de liberdade. Considerou-se também estado plano de tensões para a análise de tensões.

A figura 4.25 abaixo representa a malha de elementos finitos $\mathrm{e}$ as restrições consideradas para o cálculo de tensões.

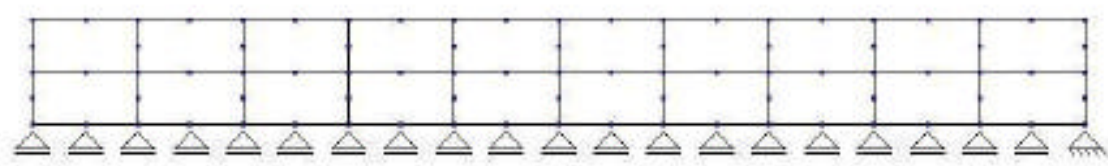

Figura 4.25: malha de elementos finitos e restrições ao deslocamento para o exemplo 4.6.2 
Na figura 4.26 está representada a distribuição de temperatura para os instantes $1 \mathrm{~s}, 2 \mathrm{~s}$ e 5s, e na figura 4.27 a fração de martensita formada para os mesmos instantes.
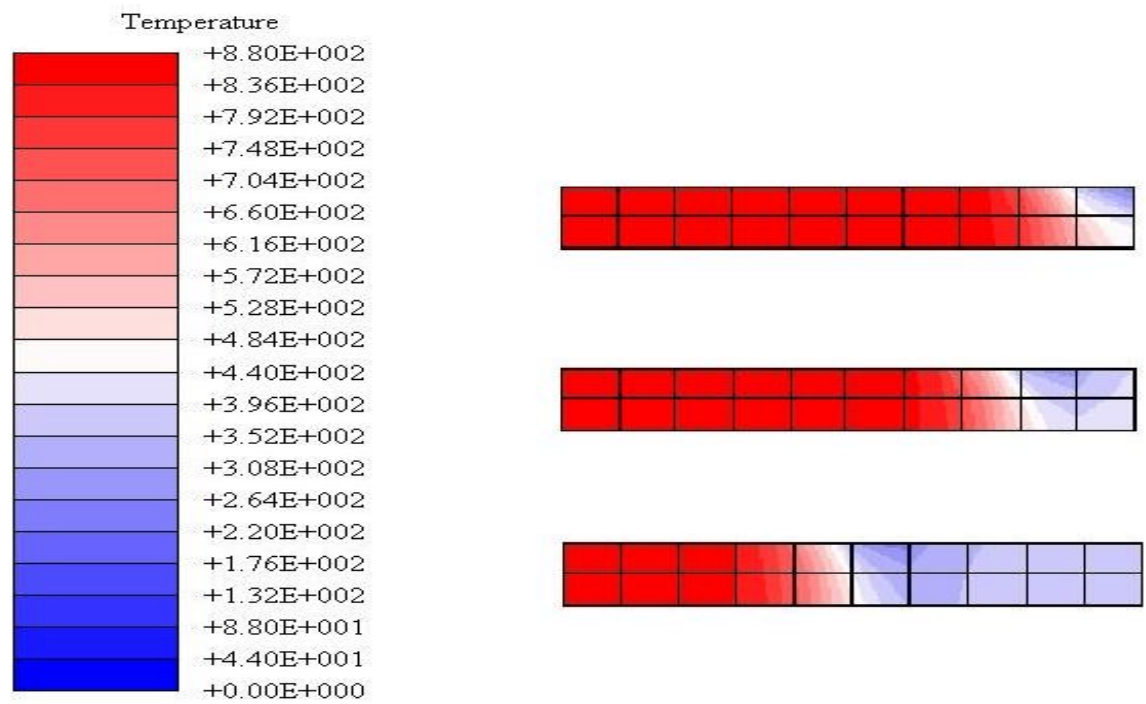

Figura 4.26: distribuição de temperatura nos instantes 1s, 2s e 5s para a têmpera progressiva
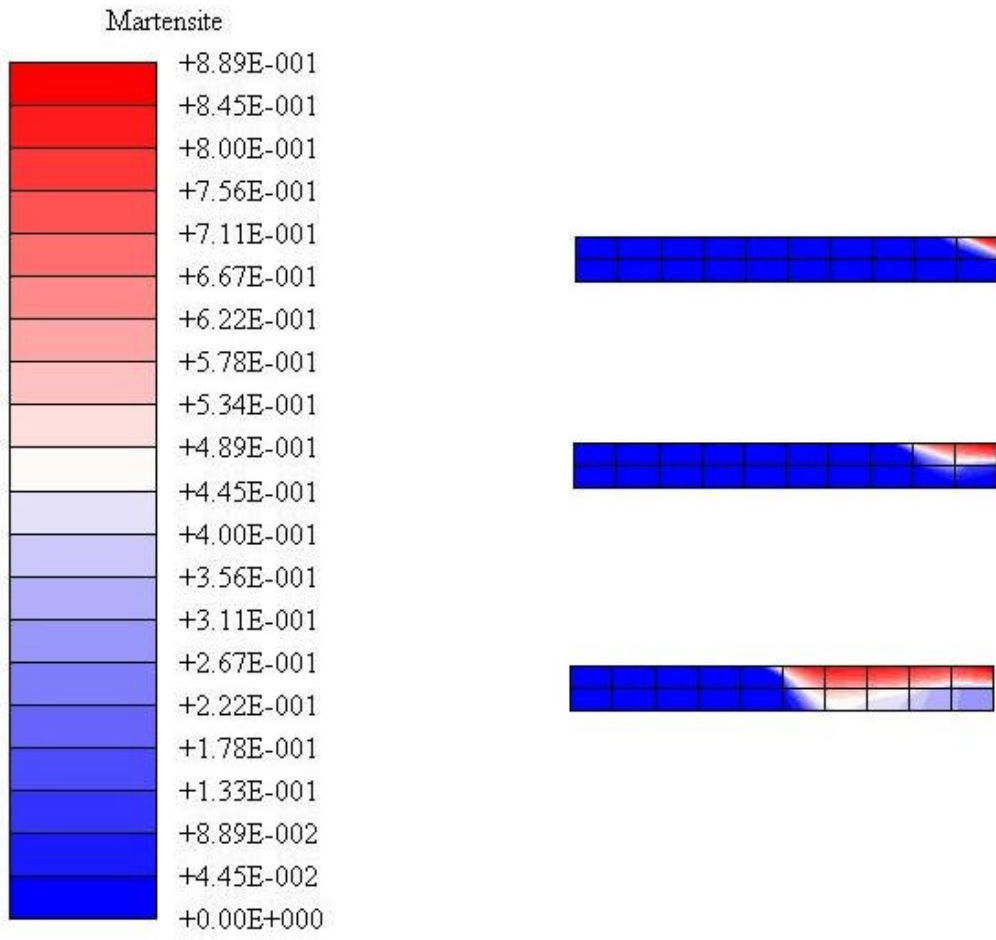

Figura 4.27: fração transformada de martensita nos instantes 1s, 2 s e 5 s para a têmpera progressiva 
Na figura 4.28 abaixo está representada a tensão $\sigma_{x}$ e a configuração deformada nos instantes $1 \mathrm{~s}, 2 \mathrm{~s}$ e $5 \mathrm{~s}$. Nota-se que a barra sofre uma contração na região próxima da incidência do jato d'água, devida ao resfriamento, e ao mesmo tempo uma dilatação na região de incidência, causada pela transformação de fase. Alguns instantes após a passagem do jato d'água a região volta a contrair, uma vez que não há mais transformação de fase mas a peça continua a resfriar.

Apesar de não haver resultados na literatura para que possa ser feita uma comparação com os resultados obtidos, o estado de tensão desta análise está coerente com o esperado, como discutido no início desta seção: tensões de tração no núcleo e de compressão na borda de contato com a água.
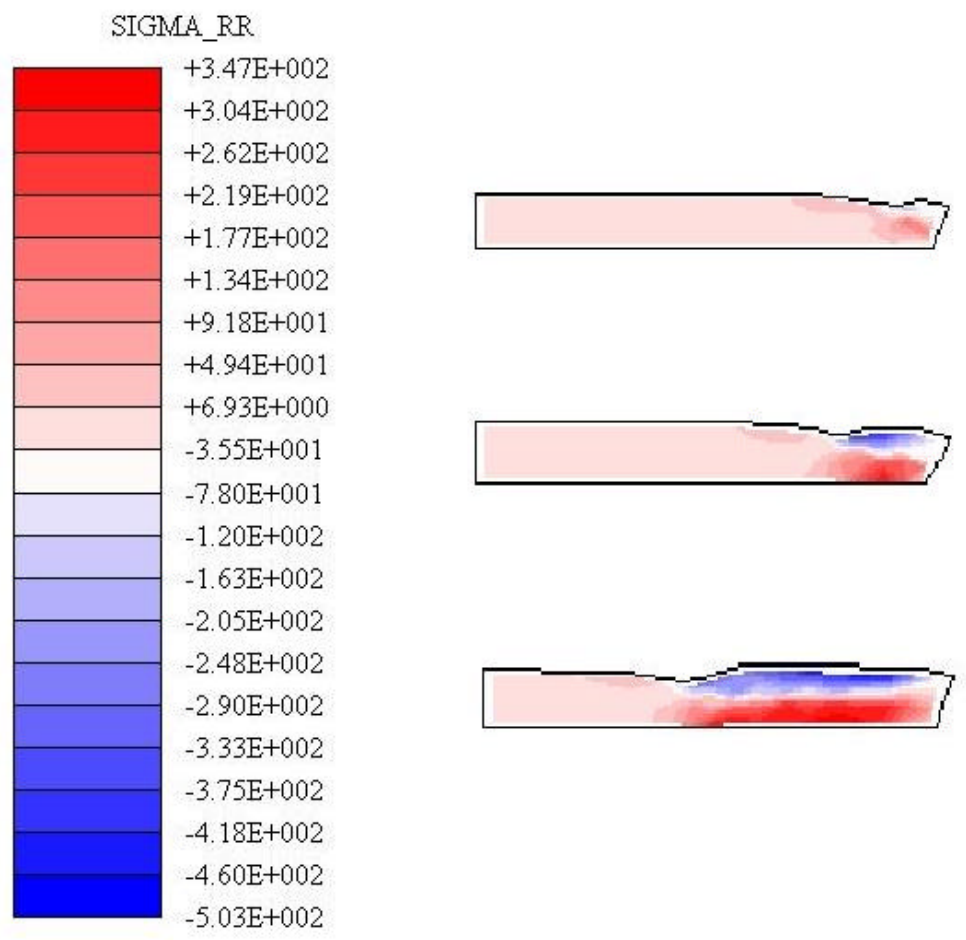

Figura 4.28: tensão $\sigma_{\mathrm{x}}$ e configuração deformada nos instantes $1 \mathrm{~s}, 2 \mathrm{~s}$ e 5 s para a têmpera progressiva 


\subsection{Análise dos resultados obtidos}

$\mathrm{Na}$ seção anterior foram apresentados vários exemplos numéricos visando a validação dos modelos e dos programas computacionais desenvolvidos.

Apesar da dificuldade em obter dados confiáveis dos materiais, pelos diversos exemplos apresentados nota-se que os resultados obtidos estão coerentes com resultados apresentados em outros trabalhos.

As seções 4.2.1 e 4.2.4 consideraram todos os casos de interesse da análise numérica por elementos finitos do problema térmico, em particular do processo de têmpera. No Capítulo 5, que trata de transformações difusionais, serão apresentados alguns resultados de simulações de aços ao carbono, onde ocorre transformação de austenita em ferrita, perlita e bainita.

Nas seções 4.2.2 e 4.2.3 o programa mecânico foi testado utilizando-se problemas clássicos da literatura, obtendo-se resultados satisfatórios.

$\mathrm{Na}$ seção 4.2.5, foi testado o acoplamento dos três problemas como apresentado na Introdução deste trabalho: tanto a distribuição de temperatura quanto as frações parciais transformadas influenciando as tensões geradas pelo processo de resfriamento brusco durante a têmpera. Os resultados obtidos, apesar de não comprovados por experimentos, estão coerentes com o esperado.

Desse modo, pode-se concluir que os resultados obtidos fornecem uma estimativa qualitativa confiável para as tensões geradas durante processos de têmpera de ligas de aço $3.25 \mathrm{Ni}-1 \mathrm{Cr}$.

$\mathrm{Na}$ continuidade deste trabalho de pesquisa serão efetuados ensaios em laboratório visando aperfeiçoar as resultados obtidos numericamente. 